\title{
Effect of Steam Corrosion on Core Post Strength Loss: \\ I. Low, Chronic Steam Ingress Rates
}

R. P. Wichner 


\section{DISCLAIMER}

This report was prepared as an account of work sponsored by an agency of the United States Government. Neither the United States Government nor any agency Thereof, nor any of their employees, makes any warranty, express or implied, or assumes any legal liability or responsibility for the accuracy, completeness, or usefulness of any information, apparatus, product, or process disclosed, or represents that its use would not infringe privately owned rights. Reference herein to any specific commercial product, process, or service by trade name, trademark, manufacturer, or otherwise does not necessarily constitute or imply its endorsement, recommendation, or favoring by the United States Government or any agency thereof. The views and opinions of authors expressed herein do not necessarily state or reflect those of the United States Government or any agency thereof. 


\section{DISCLAIMER}

Portions of this document may be illegible in electronic image products. Images are produced from the best available original document. 
Printed in the United States of America. Available from National Technical Information Service

U.S. Department of Commerce

5285 Port Royal Road, Springfield, Virginia 22161

Price: Printed Copy $\$ 4.50$, Microfiche $\$ 2.25$

$$
6.20
$$

This report was prepared as an account of work sponsored by the United States Government. Neither the United States nor the Energy Research and Development Administration/United States Nuclear Regulatory Commission, nor any of their employees, nor any of their contractors, subcontractors, or their employees, makes any warranty, express or implied, or assumes any legal liability or responsibility for the accuracy, completeness or usefulness of any information, apparatus, product or process disclosed, or represents that its use would not infringe privately owned rights. 
ORNL/TM-5534

Dist. Category UC -77

Contract No. W-7405-eng-26

CHEMICAI TECHNOLOGY DIVISION

EFFECT OF STEAM CORROSION ON CORE POST STRENGTH LOSS:

I. LOW, CHRONIC STEAM INGRESS RATES

R. P. Wichner

Date Published: October 1976

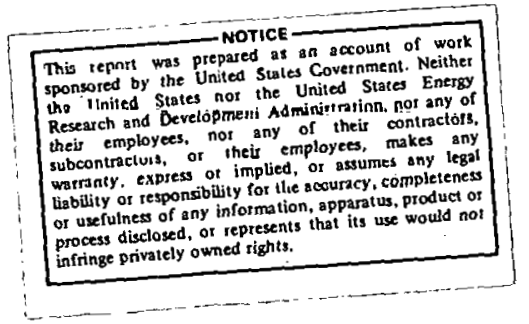

OAK RIDGE NATIONAL LABORATORY

Oak Ridge, Tennessee 37830 operated by

UNION CARBIDE CORPORATION

for the

ENERGY RESEARCH AND DEVELOPMENT ADMINISTRATION 
THIS PAGE

\section{WAS INTENTIONALLY LEFT BLANK}




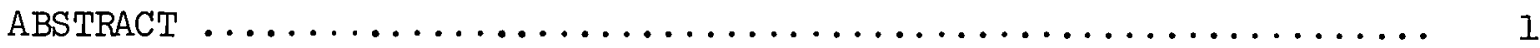

1. INTRODUCTION $\ldots \ldots \ldots \ldots \ldots \ldots \ldots \ldots \ldots \ldots \ldots \ldots \ldots \ldots \ldots \ldots \ldots \ldots$

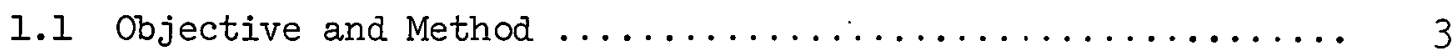

1.2 Interim Nature of This Study $\ldots \ldots \ldots \ldots \ldots \ldots \ldots \ldots \ldots \ldots \ldots$

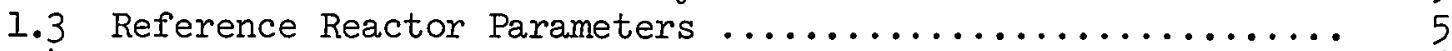

1.4 Flaw Sizes to Yield Assumed Inleakage Rates ............ 6

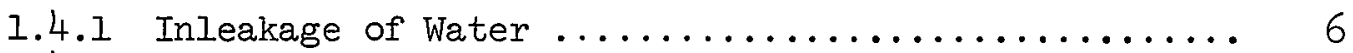

1.4.2 Flaw Sizes for Leakage in the Superheated-

Steam Region ....................... 11

1.5. References for section $1 \ldots \ldots \ldots \ldots \ldots \ldots \ldots \ldots \ldots \ldots \ldots \ldots$

2. CONCLUSIONS AND SUMmaRy $\ldots \ldots \ldots \ldots \ldots \ldots \ldots \ldots \ldots \ldots \ldots \ldots \ldots \ldots$

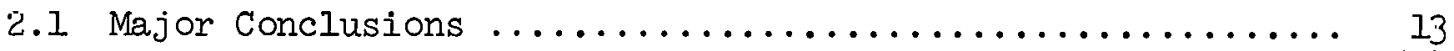

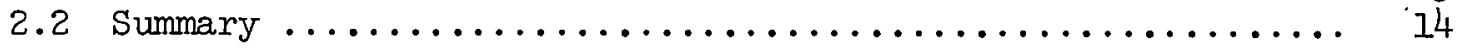

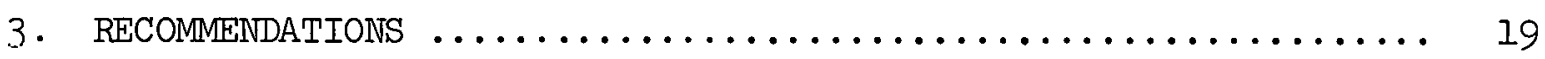

4. STEAM-GRAPHITE REACTION RATES $\ldots \ldots \ldots \ldots \ldots \ldots \ldots \ldots \ldots \ldots \ldots \ldots$

4.1 Corrosion of ATJ Graphite by Low Levels of Steam

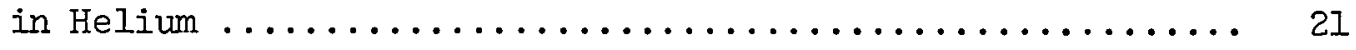

4.1.1 Properties of ATJ Graphite .......................... 21

4.1.2 General Features of ATJ Corrosion by Low Concentrations of $\mathrm{H}_{2} \mathrm{O}$ in Helium - Work of

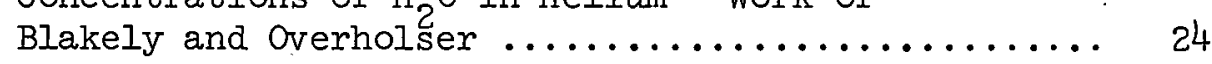

4.1.3 Currusiun Rate Expression for ATJ from the Data of Blakely and Overholser .................... 32

4.1.4 Conversion of ATJ Corrosion Rate Equation

[Eq. (4)] to Surface Units $\left(\mathrm{mol} / \mathrm{cm}^{2}-\mathrm{hr}\right) \ldots \ldots . \ldots 34$

4.2 Summary and Comparison of Steam-Graphite Corrosion

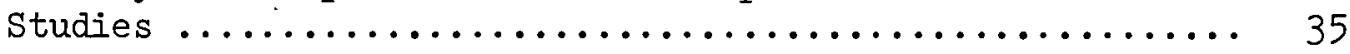

4.2.1 Work of Wicke et al. at the University of

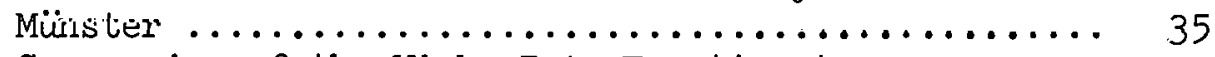

4.2.2 Conversion of the Wicke Rate Equation to

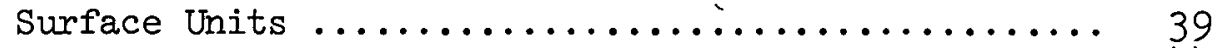

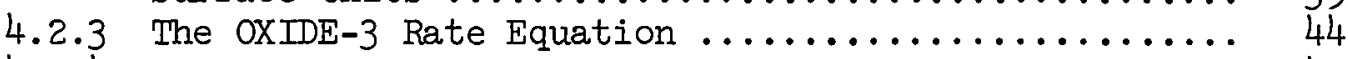

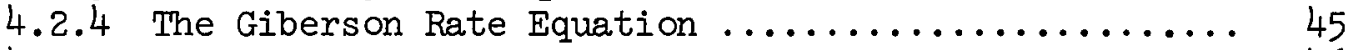

4.2.5 Comparison of Corrosion Rate Predictions ......... 46

4.3 References for section $4 \ldots \ldots \ldots \ldots \ldots \ldots \ldots \ldots \ldots \ldots \ldots \ldots \ldots \ldots \ldots$ 
Page

5. ESTTMATED IMPURITY LEVELS IN THE PRTMARY SYSTEM $\ldots \ldots \ldots \ldots \ldots \ldots$

5.I Variation of Impurity Level with Axial

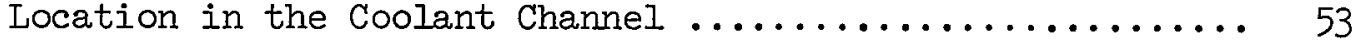

5.2 Impurity Concentrations Using Core Reactivity

to Steam Corrosion Derived from Dragon Steam

Ingress Data .............................. 56

5.2.1 Results of Dragon Steam Ingress Experiments....... 56

5.2.2 Interpretation of Dragon Steam Ingress Resul.t. .... 58

5.2.3 Estimated Dragon Core Reactivity ............. 63

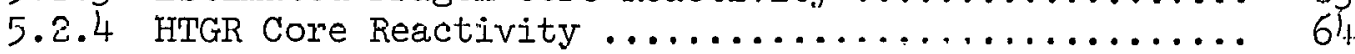

5.2.5 Estimated HTGR Impurity Lcvels Derived froul

Dragon Steam Ingress Data ................. 67

5.3 Impurity Concentrations Using TIMOX ............... 69

5.3.1. Primary System Parameters Used in TIMOX ......... 73

5.3.2 Impurity Levels in the Primary System for

Steady Steam Ingress Using TIMOX ............ 80

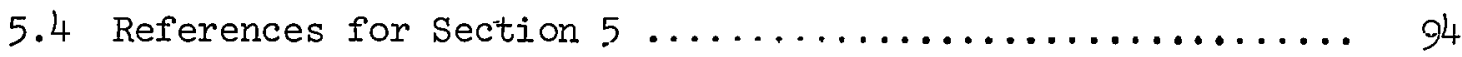

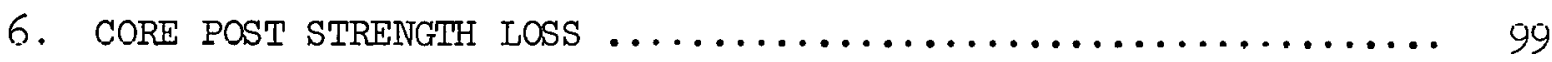

6.1 Empirical Strength Loss Correlation Based on Data

of Helsby and Everett ................................. 99

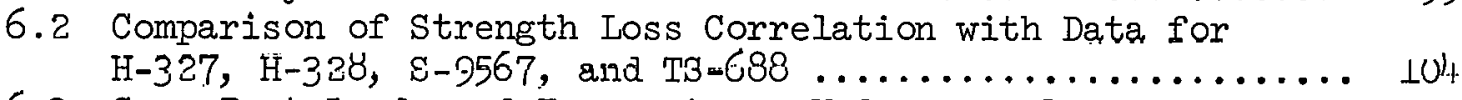

6.3 Cnre Pnst Loads and Tempcraturco Under Normal

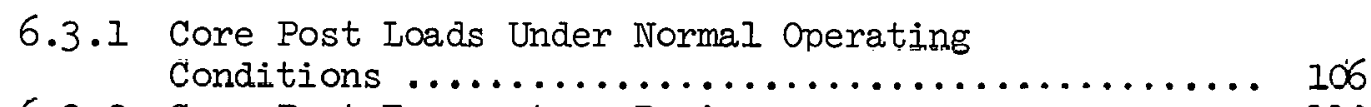

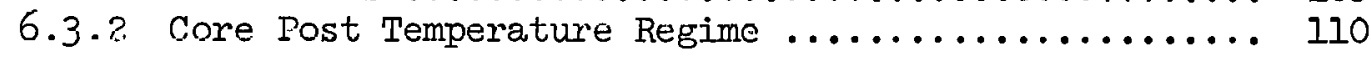

6.4 Predicted Core Post Burnoff's and Strength Loss at

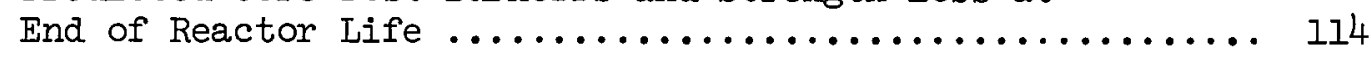

6.4.1. Trffent of 3tbam Ingrewn Ratc ............... 114

6.4.2 Effect of Purification Rate on Core Post

Burnoff and strength ........................ 19

6.4.3 Effect of Primary System Temperature Level

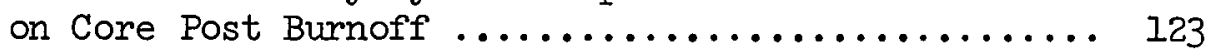

6.4.4 Meximum Permisstble Oxygen and Uxidant Levels ...... 127

6.5 References for section $6 \ldots \ldots \ldots \ldots \ldots \ldots \ldots \ldots \ldots$

7. ACKNOWLEDGMENTS $\ldots \ldots \ldots \ldots \ldots \ldots \ldots \ldots \ldots \ldots \ldots \ldots \ldots \ldots \ldots \ldots \ldots \ldots \ldots$ 
$\underline{\text { Page }}$

APPENDIX A: METHOD FOR ESTTMATING PROBABILITY OF 50\% CORE

POST STRENGTH LOSS FOR CASES WHERE THE ESTTMATED

BURNOFF RANGE AND THE RANGE FOR 50\% STRENGTH LOSS

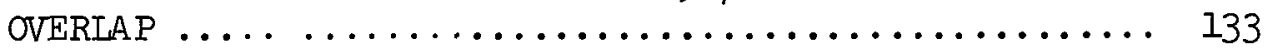

APPENDIX B: CORE POST STRENGTH LOSS VS STEAM INGRESS RATE AND

PURIFICATION FLOW. SUPPLEMENTARY INFORMATION TO

SECTION $6.4 \ldots \ldots \ldots \ldots \ldots \ldots \ldots \ldots \ldots \ldots \ldots \ldots \ldots \ldots \ldots \ldots \ldots$

NOMENCTATURE

145 
EFFECT OF STEAM CORROSION ON CORE POST STRENGTH LOSS:

I. LOW, CHRONIC STEAM INGGRESS RATES

R. P. Wichner

ABSTRACT

The purpose of this study was to assess the effect of chronic, low levels of steam ingress into the primary system of the HTGR on the corrosion, and consequent strength loss of the core support posts. The assessment necessarily proceeds through the following three steps: (1) The impurity composition in the primary system was estimated as a function of a range of steady ingress rates of from 0.001 to $1.0 \mathrm{~g} / \mathrm{sec}$, both by means of an analysis of the Dragon steam ingress experiment and a computer code, TIMOX, which treats the primary system as a well-mixed pot: (2) The core post burnoffs which result from 40-year exposures to these determined impurity atmospheres were then estimated using a corrosion rate expression derived from published ATJ-graphite corrosion rate data. Burnoffs were determined for both the core posts at the nominal and the maximum sustained temperature, estimated to be $90^{\circ} \mathrm{C}$ above nominal. (3) The final step involved assessment of the degree of strength loss resulting from the estimated burnoffs. An empirical equation was developed for this purpose which compares reasonably well with strength loss data for a number of different graphites and specimen geometries.

Steps (1) and (2) yield an error band of predicted burnoffs with varying ingress rate for both the nominal and hot core posts. Step (3) was used to estimate a burnoff range which may cause 50\% strength loss - the maximum allowable degree. of strength loss - for both the nominal and hot core posts. A method was developed for estimating the probability for $50 \%$ strength loss for the general case of overlapping error bands.

The results show that the nominal core posts have small probability (8\%) for $50 \%$ strength loss even at the maximum assumed 40-year ingress rate of $I \mathrm{~g} / \mathrm{sec}$ (corresponding to $850 \mathrm{vpm}^{*}$ total oxygen). The nominal core posts have o\% probability of $50 \%$ strength loss for ingress rates below $0.025 \mathrm{~g} / \mathrm{sec}$ (20 vpm total oxygen). The hot core posts show significantly greater probability for $50 \%$ strength loss: $50 \%$ at $0.004 \mathrm{~g} / \mathrm{sec}$ ingress (3.4 vpm total oxygen), $80 \%$ at $0.007 \mathrm{~g} / \mathrm{sec}$ ( $6 \mathrm{vpm}$ total oxygen), and $100 \%$ probability for ingress rates above $0.01 \mathrm{~g} / \mathrm{sec}$ (9 vpm total oxygen).

*

${ }^{*} \mathrm{vpm}=$ parts per million on a volumetric basis. 
Thus, a-major problem this study calls to attention is the potentially excessive loss of graphite strength in the hotter core post regions. It is recommended that a more accurate definition of the size, location, and temperature excess of the sustained core post hot zones (created by regional power peaking, hot streaking, and non-ideal coolant flow distributions) be obtained.

Modest changes in purification rate appear to have minor effect on the degree of strength loss. Significantly improved results begin to show only for purification flows above about five times the nominal rate. Similarly, modest changes in core temperature do not significantly affect core post strength loss. In some cases, small increases in temperature are shown to benefit the core posts because of improved.oxidant gettering by the core and the increased tendency for the corrosion to be contined to a narrower surface zone, which results in lower strength loss. 


\section{INTRODUCTION}

\subsection{Objective and Method}

The objective of this study was to assess the effect of slow, longterm steam leakages into the primary system of the HTGR on the corrosion, and consequent strength loss, of the core posts.*

As the first step in the approach to the problem, the impurity level and composition in the primary coolant for series of assumed steady-state ingress rate were estimated. No attempt was made to calculate ingress rates. Instead, the rate of steam inleakage was treated as a parameter ranging from $0.001 \mathrm{~g} / \mathrm{sec}$, which corresponds to a total oxygen level of $0.85 \mathrm{vpm}$ (parts per million on a volumetric basis) at the nominal purification rate in the reference plant, to $1.0 \mathrm{~g} / \mathrm{sec}$, which corresponds to $850 \mathrm{vpm}$ total oxygen. While the total impurity level depends solely on the steam inleakage and purification rates, the composition of the impurity atmosphere also depends on the reaction rate of steam with the core graphite.

Two basic methods were used to determine effective core reactivity to steam and the resulting impurity composition. Section 5.2 describes one method based on the analysis of steam ingress experiments performed at the Dragon Reactor. A second method, outlined in Sect. 5.3, utilizes a computer program that treats the primary coolant as a well-stirred pot. The core graphite is separater into four reactive zones, each characterized by an appropriately weighted mean temperature calculated from a more detailed temperature distribution. Impurity compositions are computed by the program as a function of time following the onset of a steady-steam ingress until steady state conditions are reached. The calculations are carried through employing three published corrosion rate equations as an eatimate of the core reactivity to steam corrosion. These three estimates, together with impurity compositions extracted using the Dragon ingress data, yield a band of equilibrium impurity compositions as a function of rate of steam ingress.

\footnotetext{
*In this report, the term "core post strength" refers solely to the compressive strength of the body of the post. Consideration of the contact stresses at each end of the post is excluded.
} 
The second step in the assessment was the estimation of the extent of long-term corrosion experienced by the core posts as a consequence of exposure to the above determined impurity compositions. A corrosion rate equation for ATJ graphite, ${ }^{*}$ the reference core-post material, was derived for this purpose from published rate data taken under reasonably representative conditions of temperature and impurity concentraions (see sect. 4.1). The uncertainties inherent in the use of the derived equations for predicting ATJ corrosion rates are significant; these are detailed in Sect. 4.1. Nevertheless, corrosion rates predicted for ATJ fall within a band of estimates using other rate equations and ganarally follow similar trends.

The final step in the assessment was to correlate the estimated 40year core post burnoffs with strength loss. An empirical strength loss model is developed in sect. 6.1 based on the concept that the fractional strength degradation of a graphite member is related to the ratio of an effective corrosion depth to member size. The effective corrosion depth is determined by computing the surface burnoff (the so-called onion skin burnoff) multiplied by a penetration fastinr, which varies invcrsely witl temperature. The penetration factor is estimated from published strength loss data in the temperature range of 950 to $1030^{\circ} \mathrm{C}$. Extrapolating the correlation down to core-post temperatures involves considerable uncertainty; consequently, a range of penetration factors are assumed for the core posts that yield a range of estimates for strength loss.

In Sect. 6.4, the estimated ranee of 40-year burnoffs is compared with the estimated range required to cause $50 \%$ core post strength Ioss (called the target burnoff) at both the nominal and upper sustained core pust temperatures.

Intersecting error bands of estimated and target burnoffs yield some nonzero probability for $50 \%$ strength loss. A method for computing this probability is described in Appendix $A$, based on the assumption that each error band represents a zone in which the estimated burnoff (or target burnoff) could lie with equal probability. Probabilities for reaching

*ATJ is the registered tradename for a type of graphite manufactured by Carbon Products Division of Union Carbide. 
$50 \%$ core post strength loss for a range of assumed steam ingress rates are calculated in sect. 6.4 by using this assumption of flat frequency function within each error band.

\subsection{Interim Nature of This Study}

A number of developments were known to be in progress during the course of this study that may have a significant impact on the calculated results. Most notable is the projected increase in the diameter of the core support posts from 6 in., specified in GASSAR- $6,{ }^{1}$ to a range of from 7-3/4 in. directly under the core to 9 in. around the periphery. A second design change being considered is the replacement of ATJ as a prime candidate for the core post material with an alternate graphite, possibly Stackpole 2020. The change of graphite type will probably have less of an impact on the conclusions than the projected change in diameter.

In addition, corrosion rate constants for the reference core graphite, H-45I, are still being developed and should be available soon. Use of these new values would tend to diminish some of the uncertainties of this assessment, since the reactivity to steam corrosion of the core graphite determines the oxidizing environment that the core posts experience for any given steam ingress rate. In the absence of rate constants specific to the reference-core graphite, several kinetics expressions for a number of graphites were selected from the literature, which yielded a range of calculated impurity compositions. It would therefore appear advisable to repeat these calculations at an opportune time using the newly established post dimensions and revised kinetics constants for the core graphite.

\subsection{Reference Reactor Parameters}

This study began at a time when the principal authoritative summary of HTGR reactor parameters was the Delmarva Power PSAR. ${ }^{2}$ For this reason, and because the first licensing actions for HTGRs would relate to reactors of this size, the $2000 \mathrm{MW}(t)$ HTGR was selected for this study. In the course of the analysis, a need arose for core temperature distribution data exceeding in detail those provided by the PSAR. This additional 
detail was provided by General Atomic Company (GAC) via informal transmission of a portion of a safety analysis report that was published later. ${ }^{3}$ The temperature levels however differed, the exit coolant temperatures from the core being about $30^{\circ} \mathrm{C}$ higher in the later safety study as compared with the Delmarva PSAR.

Hence basically, the reference reactor selected for this study is a $2000 \mathrm{MW}(t)$, Summit-type reactor employing the higher temperature levels indicated by ref. 3. The anticipated effect of this modest temperature difference on the results is shown in sect. 6.4 to be minor.

H'inally, GASSAR-6 became avallable rather late so that no CASSAR-6 parameters were adopted which would have required major calculational revisions. However, wherever otherwise possible, GASSAR-6 was used as the most recent authoritative source for design dimensions, material properties or other descriptive information. Table 1.1 lists the pertinent parameters of the reference reactor used in this study.

\subsection{Flaw Sizes to Yield Assumed. Inleakage Rates}

It is well to have in mind some approximate scale of the tlaws in the steam generator tubing that would result in the range of inleakage flows assumed in this study. Two cases will be examined, each of which was selected to avoid two-phase flow: (1) a tubing flaw located near the feedwater inlet of the steam generator where the water temperature is sufficiently low so that decompression to the helium side pressure does not cause vaporization; (2) a tubing flaw sufficiently far into the superheater region so that isenthalpic expansion within the flaw does not bring the steam into the two-phase region.

\subsubsection{Inleakage of water}

For the first case, the water side pressure near the feedwater inlet is about $2980 \mathrm{psi}(20.5 \mathrm{MPa})$, and is opposed by $705 \mathrm{psi}(4.86 \mathrm{MPa}$ ) on the helium side. Since a vapor pressure of $705 \mathrm{psi}(4.86 \mathrm{MPa}$ ) corresponds to a temperature of $500^{\circ} \mathrm{F}\left(260^{\circ} \mathrm{C}\right)$, it may be presumed that water leaks below $500^{\circ} \mathrm{F}\left(260^{\circ} \mathrm{C}\right)$ will pass through the flaw as liquid water. A test calculation shows that pinhole water leaks will not be limited by sonic velocity. 
Table 1.1. Reference reactor characteristics

\begin{tabular}{|c|c|c|}
\hline & $\begin{array}{l}\text { Common } \\
\text { units }\end{array}$ & $\begin{array}{l}\text { Metric } \\
\text { units }\end{array}$ \\
\hline Thermal power & $2000 \mathrm{MW}$ & \\
\hline \multicolumn{3}{|l|}{ Coolant } \\
\hline Inlet pressure & $49.3 \mathrm{~atm}$ & $5.00 \mathrm{MPa}$ \\
\hline Core pressure drop & $11.3 \mathrm{psi}$ & $0.0779 \mathrm{MPa}$ \\
\hline Flow rate & $7.3 \mathrm{E} 6 \mathrm{lb} / \mathrm{hr}^{\mathrm{a}}$ & $3.3 \mathrm{E} 6 \mathrm{~kg} / \mathrm{hr}$ \\
\hline Inlet temperature & $641^{\circ} \mathrm{F} \quad \mathrm{m}^{\prime}$ & $338^{\circ} \mathrm{C}$ \\
\hline Exit temperature & $1446^{\circ} \mathrm{F}$ & $786^{\circ} \mathrm{C}$ \\
\hline Core temperature distribution & $\mathrm{b}$ & - \\
\hline Average velocity & $130 \mathrm{ft} / \mathrm{sec}$ & $39.6 \mathrm{~m} / \mathrm{sec}$ \\
\hline Helium inventory & $15,000 \quad 1 b_{m}$ & $6700 \mathrm{~kg}$ \\
\hline Volume & $81,000 \mathrm{ft}^{3^{\mathrm{II}}}$ & $2300 \mathrm{~m}^{3}$ \\
\hline \multicolumn{3}{|l|}{ Coolant channels } \\
\hline Diameter & 0.827 in. 2 & $2.10 \mathrm{~cm}_{2}$ \\
\hline Total surface area & $103,000 \mathrm{ft}^{2}$ & $9,570 \mathrm{~m}^{2}$ \\
\hline Length of active core & $20.8 \mathrm{ft}$ & $6.34 \mathrm{~m}$ \\
\hline Number per element & 72 & 72 \\
\hline Purification rate & $-2070 \mathrm{Ib} / \mathrm{m} / \mathrm{hr}$ & $939 \mathrm{~kg} / \mathrm{hr}$ \\
\hline \multicolumn{3}{|l|}{ Core posts } \\
\hline Diameter & 6 in. & $15.2 \mathrm{~cm}$ \\
\hline Length & $7.1 \mathrm{ft}$ & $2.16 \mathrm{~m}$ \\
\hline Number & 255 & 255 \\
\hline Initial compressive strength & 10,000 psi & $68.9 \mathrm{MPa}$ \\
\hline Nominal temperature & $1446^{\circ} \mathrm{F}$ & $786^{\circ} \mathrm{C}$ \\
\hline Estimated maximum sustained temperature & $1608^{\circ} \mathrm{F}$ & $876^{\circ} \mathrm{C}$ \\
\hline Irittal safety ractur & 10 & 10 \\
\hline
\end{tabular}

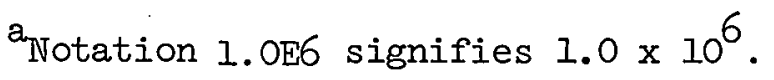

$\mathrm{b}_{\text {See Table }} 5.8$. 
We may approximate the flow through an assumed cylindrical pinhole of the diameter, $d_{j}$, by equating the driving pressure to the sum of the expansioncontraction pressure loss of approximately two velocity heads and the flow resistance with the flaw; that is,

$$
\Delta p=\left(2+\frac{L}{40 d_{j}}\right) \frac{1}{2} \rho u_{j}^{2},
$$

where $u_{j}$ is the velocity in the flaw, and $L$ is the tubing wall thickness of about $0.13 \mathrm{in}$. $(0.33 \mathrm{~cm})$. The term $\mathrm{L} / 40 \mathrm{~d}_{j}$ approximately equals the frictional resistance in the flaw in terms of velocity head-pressure loss. The leakage mass flow rate is given by:

$$
w_{s}=\rho u_{j} \frac{\pi}{4} d_{j}^{2}
$$

Equation (2) may be substituted into Eq. (I) to yield the flaw size, $d_{j}$, which corresponds to an assumed value for the leakage rate.

The results for cases of interest are shown in Table 1.2. Rather small tubing flaws cause the range of inleakage flow rates assumed in this study. The inleakage flow of $0.01 \mathrm{~g} / \mathrm{sec}$, which corresponds approximately to a total oxygen level of $10 \mathrm{vpm}$ at the nominal purification flow, is seen to result from pinhole flaw of about $0.6 \mathrm{mil}$ in the water leakage regime.

Table 1.2. Flaw sizes for a range of inleakage flows in the

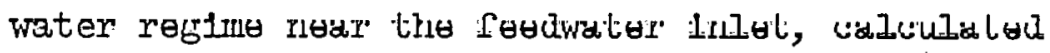

\begin{tabular}{|c|c|c|c|c|}
\hline \multirow{2}{*}{$\begin{array}{l}\text { Leak rate } \\
(\mathrm{g} / \mathrm{sec})\end{array}$} & \multicolumn{2}{|c|}{ Flaw size, $a_{-j}$} & \multicolumn{2}{|c|}{ Leakage velocity in flaw } \\
\hline & $(\operatorname{mil})$ & $(\mu \mathrm{m})$ & & \\
\hline 0.001 & 0.22 & 5.6 & 160 & 49 \\
\hline 0.01 & 0.59 & 15.0 & 240 & 73 \\
\hline 0.1 & 1.6 & 41.0 & 330 & 100 \\
\hline 1.0 & 4.5 & 110.0 & 400 & 120 \\
\hline
\end{tabular}
by uoing Eqo. (1) and (2) 
The interesting experiments of C. Harper et al. ${ }^{4}$ on the behavior of small water leaks in high-pressure mild-steel boiler tubing are worth noting here. The results of several runs at various initial manufactured flaw sizes are shown in Table 1.3. The wall thickness used was about onehalf of the $0.13 \mathrm{in.}(0.33 \mathrm{~cm})$ assumed above, and the water temperature was sufficiently high (about $660^{\circ} \mathrm{F}$ or $349^{\circ} \mathrm{C}$ ) so that the leakage probably flashed into the two-phase region; therefore, the results are not directly comparable.

Two important conclusions may be drawn from the test data summarized in Table 1.3:

(1) There appears to be a critical flaw size in these tests below which corrosion debris seals the leak and above which the leak increases with time. This critical size is bracketed between $2 \mathrm{mil}(5 \mathrm{l} \mu \mathrm{m})$, which yielded leakage rates that increased from about 0.4 to about $3 \mathrm{~g} / \mathrm{sec}$, and $0.6 \mathrm{mil}(15 \mu \mathrm{m})$ below which leaks quickly plugged.

(2) The second conclusion drawn from these experiments is that the mechanics of slow leaks driven by a highpressure driving force is a rather complex phenomenon. In no case was it found possible to generate a timesteady, slow leak. Leakage flows which d1d not plug varied greatly with time, reflecting accumulation of corrosion debris or erosion due to high velocitica. Occasionally, thermal cycling would break loose a plugged flaw.

It should be emphasized that the results of Harper et al. 4 pertain to the particular condition of this experiment, with respect to tubing material, wall thickness, water pressure, and temperature. Since the mechanics are not well understood, it is not possible to generalize these observations to other conditions, particularly to cases involving superheated steam instead of saturated water as the leaking material. Neither is it possible to assess vibration effects in sustaining small leakages. 
Table 1.3. Behavior of small leaks in mild-steel boiler tubes subjected tc water at $2500 \mathrm{psi}(17.2 \mathrm{MPa})$ and $350^{\circ} \mathrm{C}^{\mathrm{a}}$

\begin{tabular}{|c|c|c|c|c|c|}
\hline Test & $\frac{\text { Flaw }}{\text { (nil) }}$ & $\frac{\text { neter }}{(\mu \mathrm{m})}$ & $\begin{array}{l}\text { Water l } \\
\text { Initial } \\
\text { (g/sec) }\end{array}$ & $\frac{\text { age rate }}{\text { Final }}$ & Commentis \\
\hline 9 & $\therefore . C$ & 102 & - & 70.8 & Spark eroded hole \\
\hline 111 & $\div$. & 102 & 0.4 & 2.0 & Spark eroded $h: l \approx$ \\
\hline 12 & 0.6 & 15 & 0.003 & 0 & $\begin{array}{l}\text { Tapered, } b \text { laser-drilled hole; } \\
\text { leak sealed }\end{array}$ \\
\hline-3 & 0.5 & 13 & 0 & 0 & $\begin{array}{l}\text { Tapered, }{ }^{b} \text { las } ə r \text {-drilled hole; } \\
\text { sealed rapidly in water tests }\end{array}$ \\
\hline 14 & 2.0 & 51 & 0.53 & 2.3 & Tapered, ${ }^{b}$ laser-driled hole \\
\hline 15 & 3.0 & 5.1 & 0.37 & 3.6 & Ta’ered, ${ }^{b}$ laser-drilled hole \\
\hline
\end{tabular}

Eata taken Z̈rom ref. 4.

The minimu dianeter is given for the tapered holes. 
1.4.2 Flaw sizes for leakage in the superheated-steam region

Preliminary calculations indicated that the leakage rate of superheated steam through a small flaw in a steam generator tube would be sonic velocity limited. The leakage flow rate through a presumed pinhole size can be approximated by assuming that the steam expands isenthalpically to the helium side pressure and exits at the sonic velocity corresponding to steam properties in the expanded state.

The Mollier diagram for steam indicates that isenthalpic expansion from about $2980 \mathrm{psi}(20.5 \mathrm{MPa})$ down to about $705 \mathrm{psi}(4.86 \mathrm{MPa})$ avoids the two-phase region for temperatures above $770^{\circ} \mathrm{F}\left(376^{\circ} \mathrm{C}\right)$. Expansion would drop the steam temperatures to about $540^{\circ} \mathrm{F}\left(282^{\circ} \mathrm{C}\right)$ at $705 \mathrm{psi}(4.86$ $\mathrm{MPa}$ ); at these conditions the sonic velocity is estimated to be about $1900 \mathrm{ft} / \mathrm{sec}(580 \mathrm{~m} / \mathrm{sec})$. Assuming a pinhole location near the exit from the steam generator, where the steam conditions of $2500 \mathrm{psi}$ (17.2 $\mathrm{MPa}$ ) and $950^{\circ} \mathrm{F}\left(510^{\circ} \mathrm{C}\right)$ exist, would yield a temperature of $820^{\circ} \mathrm{F}\left(438^{\circ} \mathrm{C}\right)$ on isenthalpic expansion to $705 \mathrm{psi}(4.86 \mathrm{MPa})$, and somewhat higher sonic velocity of $2100 \mathrm{ft} / \mathrm{sec}(640 \mathrm{~m} / \mathrm{sec})$. Since these values are fairly close, there should be little difference in the nature of a small superheated steam leak anywhere in the superheated zone above $780^{\circ} \mathrm{F}\left(416^{\circ} \mathrm{C}\right)$.

An assumed steam exit velocity of $1900 \mathrm{ft} / \mathrm{sec}(580 \mathrm{~m} / \mathrm{sec})$ yields the flaw sizes for the given leakage rates shown in Table 1.4. Note that the flaw size corresponding to $0.01 \mathrm{~g} / \mathrm{sec}$ in the primary circuit, which yields about $10 \mathrm{vpm}$ tinta.1. sxygen, is about $1.2 \mathrm{mil}(30 \mu \mathrm{m})$.

Table 1.4. Tubing flaw sizes in the superheated regime

\begin{tabular}{lcc}
\hline $\begin{array}{c}\text { Leakage rate } \\
(\mathrm{g} / \mathrm{sec})\end{array}$ & $(\mathrm{mil})$ & Flaw size \\
\hline 0.001 & 0.39 & $(\mu \mathrm{m})$ \\
0.01 & 1.2 & 10 \\
0.1 & 3.9 & 30 \\
1.0 & 12.0 & 99 \\
\hline
\end{tabular}


Flaw sizes calculated by the indicated method should yield lower results than those calculated with more rigorous methods outlined in texts on compressible flow. However, calculations performed using the more rigorous method for the $0.01 \mathrm{~g} / \mathrm{sec}$ case yielded approximately the same result as shown.

No experimental data have been found on the nature of small superheated steam leaks from high pressure corresponding to the data of Harper 4 for saturated water.

\subsection{References for Section 1}

1. General Atomic Standard Safety Analysis Report (GASSAR-6), GA-A-13200.

2. Delmarva Power and Light Co., Summit Power Station, Preliminary Safety Analysis Report, Amendment 4 (November 1973).

3. A. W. Barsell and M. B. Peroomian, Consequences of Water Ingrese into the HTGR Primary Coolant, GA-A-13171 (April 1975).

4. C. Harper et al., Behavior of Small Leaks in Mild Steel Bo1ler Tubes when Subjected to Water at 2500 psi and $350^{\circ} \mathrm{C}$, D.P. Report 789 (July 1972). 


\section{CONCLUSIONS AND SUMMARY}

\section{I Major Conclusions}

(1) The core posts initially possess a safety factor of about 10 under normal operating conditions. Since a minimum safety factor of 5 has been set for the end of reactor life in GASSAR-6, a maximum allowable core-post strength loss of $50 \%$ has been assumed for this study.

(2) The burnoff causing 50\% strength loss is estimated to be between 260 and $620 \mathrm{mg} / \mathrm{cm}^{2}$ for the nominal core post.

(3) The range of burnoffs and strength reductions at the end of reactor life for the nominal core posts, assuming nominal purification flow, is estimated to be:

\begin{tabular}{|c|c|c|c|c|}
\hline $\begin{array}{c}\text { Ingress } \\
\text { rate } \\
\left(\frac{g}{\sec }\right)\end{array}$ & $\begin{array}{l}\text { Total } \\
\text { oxygen } \\
\text { level } \\
\text { (vpm) }\end{array}$ & $\begin{array}{c}\text { Burnoff } \\
\text { rainge } \\
\left(\frac{\mathrm{mg}}{\mathrm{cm}^{2}}\right)\end{array}$ & $\begin{array}{l}\text { Strength } \\
\text { loss } \\
\text { range } \\
(\%)\end{array}$ & $\begin{array}{l}\text { Probability for } \\
50 \% \\
\text { strength loss } \\
(\%)\end{array}$ \\
\hline 0.001 & 0.85 & $12-60$ & $1-20$ & 0 \\
\hline 0.01 & 8.5 & $170-240$ & $12-42$ & 0 \\
\hline 0.1 & 85.0 & $230-300$ & $19-56$ & 2 \\
\hline 1.0 & 850.0 & $250-340$ & $20-61$ & 8 \\
\hline
\end{tabular}

Continuous ingress rates of $0.025 \mathrm{~g} / \mathrm{sec}$ and below, corresponding to total oxygen levels below 21 vpm at nominal purification flow, cause 40-year burnoffs which show a zero probability of $50 \%$ strength loss.

(4) A semiquantitative examination indicates that the maximum sustained. core post temperature is approximately $90^{\circ} \mathrm{C}$ above nominal. The burnoff causing $50 \%$ strength loss is estimated to be between 520 and $760 \mathrm{~g} / \mathrm{cm}^{2}$ for the hot core post material. The higher burnoffs for $50 \%$ strength loss are due to the tendency of corrosion to be more concentrated at the surface with increasing temperature. 
(5) The following end-of-life burnofts and probabilities for $50 \%$ strength loss are predicted for the core post material at the estimated maximum sustained temperature:

\begin{tabular}{|c|c|c|c|c|}
\hline $\begin{array}{l}\text { Ingress } \\
\text { rate } \\
\left(\frac{g}{\mathrm{sec}}\right)\end{array}$ & $\begin{array}{l}\text { Total } \\
\text { oxygen } \\
\text { level } \\
\text { (vpm) }\end{array}$ & $\begin{array}{l}\text { Burnoff } \\
\text { range } \\
\left(\frac{\mathrm{mg}}{\mathrm{cm}}\right)\end{array}$ & $\begin{array}{l}\text { Strength } \\
\text { loss } \\
\text { range } \\
(\%)\end{array}$ & $\begin{array}{l}\text { Probability } \\
\text { for } 50 \% \\
\text { strength Ioss } \\
(\%)\end{array}$ \\
\hline 0.001 & 0.85 & $75-350$ & $6-36$ & 0 \\
\hline 0.004 & 3.4 & 300.980 & $30-76$ & 50 \\
\hline 0.01 & 8.5 & $670-1300$ & $49-94$ & 97 \\
\hline 0.1 & 85.0 & $1300-1900$ & $76-100$ & 100 \\
\hline
\end{tabular}

These results indicate the need for a more exact definition of the location and size of. the sustained hot zone in the bottom support structure.

(6) Increasing purification flows were tested as a means for mitigating strength loss of the hot post material. Modest changes in purification rate (about a factor of 2) were found to have little effect. Significant beneficial effect begins to appear for purification rates above about five times the nominal values.

\subsection{Summary}

(1) The following steam corrosion rate expression fur ATJ graphitc, tho present leading candidate for the core post material, was determined from published data on l-in. spherical specimens of $5 \%$ burnoff,

$R\left(\frac{m o l}{c m^{2}-h r}\right)=\frac{85.1 \times 10^{6} \exp \left(-\frac{50,000}{R T}\right) P_{\mathrm{H}_{2} \mathrm{O}}}{I+3560\left(\mathrm{P}_{\mathrm{H}_{2}}+\mathrm{P}_{\mathrm{CO}}\right)+6.950 \mathrm{P}_{\mathrm{H}_{2} \mathrm{O}}}$,

where partial pressures are expressed in atmospheres. A major uncertainty in use of the above rate equation is that the data on which the correlation is based exhibited a variation of observed corrosion 
rate with test flowrate of an imperfectly understood character. Hence, extrapolation to core post flow conditions is uncertain. However, the rates predicted for ATJ by the above correlation generally fall within the band for other ratè equations.

(2) Corrosion rate predictions from five published studies were compared for a number of representative conditions. Most frequently, the predictions lie within a factor of 10, but differences of a factor of 30 appear for some conditions. Some of the variation is due to the fact that some comparisons are necessarily made beyond the experimental conditions. A reasonable value for the range of intrinsic graphite corrosion rates is about 10. A range of a factor of 2 to 3 may be expected for different samples from one graphite type; this is believed to be caused primarily by a variation in microstructure at different locations.

(3) Analysis of the variation of impurity levels with axial location within one coolant channel indicates that the impurity concentrations are effectively constant from the top to the bottom of the core. This allows a simplified treatment of the primary system as a well-mixed pot, thereby ignoring spatial dependence of concentrations.

(4) One method of predicting primary system impurity compositions employed in this study was based on analysis of the steam ingless experiments pertormed at the Dragon Reactor. The data were interpreted in terms of a simple, first-order reaction model and extrapolated to HTGR conditions. These results indicate that about $65 \%$ of the steam ingress to the primary system exists as oxidant for long term, steady ingress at the nominal purification rate.

(5) A second method of predicting impurity compositions for a given steam ingress rate is based on a mixed-pot model of the primary system termed TIMOX. TIMOX employs three published rate equations for predicting the core reactivity to steam corrosion, the three calculations being carried along in parallel. These yield 
a range of estimates which reflect the uncertainty in predicting the core reactivity under the various conditions. The impurity compositions predicted from TIMOX compare reasonably well with predictions using the Dragon steam ingress experiment for total oxygen levels up to about $80 \mathrm{vpm}$; predictions diverge at higher impurity levels because of the simple model employed for interpreting the Dragon data.

(6) The corrosion rate expressions used $1 \mathrm{n}$ TIMOX are based on data acquired at $1 \mathrm{~atm}$. For extrapolation to $49 \mathrm{~atm}^{*}$, the representative pressure of the HTGR primary system, the corrosion rate was assumed to vary with $1 / \sqrt{\mathrm{P}_{\mathrm{T}}}$, when $\mathrm{P}_{\mathrm{T}}$ is the system pressure. While this assumption is surprisingly good, considering the simplified view on which it is based, it may be a source of significant error for so large an extrapolation in pressure. Comparison with one data set shows that the inverse square root assumption would lead to a $60 \%$ overestimate of the corrusion rate at $49 \mathrm{~atm}$. However, since this pressure correction was applied to both core und cure support-post graphite, erroro produced by the extrapolation tend to cancel each other. That is, an overestimate of the core corrosion rate leads to a less oxidative atmosphere which tends to compensate for the corresponding overestimate for the core support-post corrosion rate.

(7) A necessary prerequisite for using TIMOX was a detailed examination of the core tomperature distribution. The problem addressed was how to determine the appropriate average temperature of a relatively large region for a strongly temperature-dependent process 7 ike steam corrosion. The simple space-average temperature would tend to yield too low a rate, since the higher temperature zones are not given enough weight. The result of this examination shows that simple space averages are sufficiently accurate for regions as small as an OXIDE-3 region, but significant errors could result from use of the space average for larger regions, such as TIMOX regions, which are composed of about 100 smaller OXIDE-3 zones. 
(8) An empirical fit of strength loss data for 4-mm-thick specimens was found in the form,

$F S L=P(T) \cdot \frac{B O}{\rho_{b o} \cdot W}$,

where FSI is the fractional strength loss, BO is the burnoff in $\mathrm{g} / \mathrm{cm}^{2}, \rho_{\text {bo }}$ is about $90 \%$ of the graphite density, and $W$ is the specimen width. The multiplier, $P(T)$, depends inversely on temperature with values ranging from 1.8 at $1140^{\circ} \mathrm{C}$ to 4.4 at $950^{\circ} \mathrm{C}$. Extrapolating to core post conditions involves considerable uncertainty. The estimate for the parameter $P(T)$ at the nominal core post temperature ranges from 6.0 to 14.0 , and from 4.8 to 7.1 at the estimated maximum core post temperature.

(9) Strength loss predictions based on the above correlation compare reasonably well with data obtained on 1/2-in.-diam H-327 graphite specimens at $900^{\circ} \mathrm{C}$ and up to $15 \%$ burnoff, at which point $80 \%$ strength loss had occurred. The correlation was also tested against published data on 1/2-in. specimens of $\mathrm{H}-328$ and TS-688 graphite at $1000^{\circ} \mathrm{C}$. Again the comparison is reasonably good considering the scatter in the data. One graphite, S-9567, was found to lose strength with burnoff more slowly than predicted by the correlation.

(10) Comparison of results with core post loads under normal operating conditions generally agrees with GASSAR-6 results which state that an inftial safety factor of about 10 exists. However, the reasoning which leads to this result differs somewhat. In each case (GASSAR-6 and this study) an additional load factor of about 2 is assumed somewhat arbitrarily for some core posts to account for nonideal load distribution due to varying post lengths.

(II) The degree of sustained temperature excess over and above the nominal post temperature is shown to be a critical parameter in the study. Judgments outlined in Sect. 6.3.2, which involve stated operating characteristics of coolant flow-distribution valves, hot-streaking results reported for the steam generator 
inlet, and intraregional power tilts indicated by OXDE-3 results, lead to the conclusion that $90^{\circ} \mathrm{C}$ is a reasonable estimate for the sustained temperature excess in the core post region.

(12) Since the reference reactor chosen for this study has somewhat different temperature levels from that reported in GASSAR- 6 , which appeared late in this study, the effect of modest changes in primary system temperature levels was investigated. These comparisons show that in some circumstances a general primary system temperature rise may benefit the core posts because the oxidant gettering abllity of the core is enhanced; in addition, the corrosion tends to be more closely confined to the post surface zone, thereby causing less strength reduction for a given amount of burnoff. A more confident prediction of the effect of primary system temperature on core post strength loss would require more accurate graphite reactivities for both post and core material.

(13) A useful method has been developed, outlined in Appendix A, for predicting the probability that an estimated range of burnoffs would cause 50\% strength loss. This problem needs formal treatment because the burnoffs that may cause $50 \%$ strength loss exist a.3 cotimateo with a given range. Hence, we are comparing a predicted burnoff range which could overlap a target burnoff range for $50 \%$ strength loss in varying degrees. The formal procedure provides an estimate for the probabllity of $50 \%$ strength reduction based on the assumption of flat probability density distribution within each estimated burnoff range. 


\section{RECOMMENDATIONS}

(1) It is essential to more accurately define the location and extent of the persistent hot zones in the bottom core support structure, including the core posts. These hot zones are caused by a combination of intraregional power tilting, nonideal coolant flow distribution at the core inlet plenum, and hot streaking at the core exit.

(2) Additional data are needed to develop an understanding of the problems that exist in the area of graphite strength loss due to corrosion by low levels of oxidants. Experiments are recommended on the selected reference structural graphites to determine the change in pertinent mechanical properties caused by corrosion. The effects of specimen size, temperature of burnoff, stress, and oxidant concentration need to be investigated. Preferably, data should be acquired at $50 \mathrm{~atm}$, or alternatively, at a number of lower pressures to allow extrapolation to $50 \mathrm{~atm}$. Although a pragmatic and direct type of experiment is recommended, it is important to accompany these tests with sufficient before-and-after graphite characterization work to gain some understanding of the strength loss process. The burnoff experiments should be performed in a manner allowing verification or correction of the corrosion rate predictive equations for these structural graphites.

(3) A special effort should be made to obtain additional corrosion rate data for ATJ, the reference core post graphite, in view of its nontypical behavior in laboratory tests (i.e., the unexpected dependency of the observed rate on He flow, and the unusually large amount of $\mathrm{CO}_{2}$ observed in the effluent).

(4) This study should be repeated, with special attention given to: (a) the projected revised core post diameters; (b) the revised estimate for maximum allowable core post strength loss dictated by upset conditions; (c) improved corrosion rate data for reference core graphite; (d) improved knowledge of the maximum sustained post temperature; and (e) improved strength loss data, if available. 
(5) This study deals exclusively with projected consequences of a given range of steam ingress rates; thus, the total impurity level was treated as a parameter. A next logical step would be to devote some effort to predicting what these total impurity levels could be on a realistic basis. Consideration should be given to a study program directed to devising measures for reducing steam generator leakage based on understanding of the root causes.

(6) Additional basic work on the nature of graphite corrosion is recommended. Despite much existing. work in this area, and the recognized difficulty in extrapolating baslc data to engineering systems because of the complexity and variability of graphite, further basic work is recommended to fill the following specific safety-related needs.

(a) Present computer programs used to predict the composition of impurities in the primary system employ an unreasonably simple model for the distribution of oxidant in the core graphite. Hence, the predicted oxidant level for a given inleakage rate (a fundamental quantity fur assesslly effecl in lie graplite structure) is uncertain, thereby contributing to the error band on predicted burnoffs.

(b) Little information is available on the distribution of burnoffs within a graphite member under a variety of corrosion conditions. This type of data is fundamertal to detormining the degres of strength lnss for a given amount of corrosion.

4.1.1 Properties of ATJ graphite

"Grade ATJ is an extremely fine-grain, essentially flaw free, high strength, premium quality graphite. It can be machined to very close limits and sharp detail with fine surface finish. " 5 ATJ is not impregnated. Some properties of ATJ are listed in Table 4.1. 5

The pore size distribution, as determined by mercury porosimeter measurements, is shown in Fig. 4.1. ATJ shows a characteristic bimodal 
4. STEAM-GRAPHITE REACTION RATES

The first half of this section is devoted to a description of ATJ graphite (which is the presently selected core post material) and a derivation of a reaction rate expression for ATJ corrosion by low levels of steam from published data. The second half of the section summarizes three major graphite kinetics studies which have culminated in complete reaction rate expressions, and could therefore be incorporated in a systems study of the HTGR primary circuit. These three studies are thus used as stand-ins for the reactivity of reference core graphite for which a comparable rate expression is not now available. In each case, the rate equation is presented in its original form, and is then converted to a consistent set of units based on exposed graphite surface area for expendient comparison of predicted reaction rates.

4.1 Corrosion of ATJ Graphite by Low Levels of Steam in Helium

The oxidation of ATJ graphite by low concentrations of water vapor and carbon dioxide in helium has been studied by Blakely and Overholser. ${ }^{1}$ A prior paper ${ }^{2}$ by these authors on Speer Moderator-2 graphite contains the description of the experimental method as well as some interesting comparisons of ATJ Vs Speer Moderator-2 corrosion. Additional data on ATJ corrosion appear in refs. 3 and 4; however, since pure steam at about 1 atm was used for these studies they will not be included in this description, though they may contain some potentially useful data - particularly regarding the change in BET area with burnoff for ATJ.

\subsubsection{Properties of ATJ graphite}

"Grade ATJ is an extremely fine-grain, essentially flaw free, high strength, premium quality graphite. It can be machined to very close limits and sharp detail with fine surface finish. "5 ATJ is not impregnated. Some properties of ATJ are listed in Table 4.1.5

The pore size distribution, as determined by mercury porosimeter measurements, is shown in Fig. 4.1. ATJ shows a characteristic bimodal 
Table 4.1. Room temperature ATJ properties ${ }^{2}$

Forming method

Bulk density, $\mathrm{g} / \mathrm{cm}^{3}$

Maximum grain size, $\mu \mathrm{m}$

Flexure strength, with grain, psi across grain, psi

Tensile strength, with grain, psi across grain, psi

Compressive strength, with grain, psi across grain, psi

Young's modulus, with grain, psi across grain, psi

Coefficient of thermal expansion, with grain, ${ }^{\circ} \mathrm{C}^{-1}$ across grain, ${ }^{\circ} \mathrm{C}^{-1}$

Thermal conductivity, with grain, cal/cm-sec- ${ }^{\circ} \mathrm{C}$ across grain, cal $/ \mathrm{cm}-\mathrm{sec}-{ }^{\circ} \mathrm{C}$

Permeability, with grain, darcys acruss gralil, lapey's

Ash content, percent

Impurity levels, percent of graphite
$\mathrm{Fe}$
$\mathrm{V}$
$S$
$\mathrm{Ca}$
Ti
Al
B
$\mathrm{Li}$
Cd

Molded

1.73

150

4010

3580

1790

1420

8270

8540

$1.45 \times 10_{6}^{6}$

$1.15 \times 10^{6}$

$2.19 \times 10^{-6}$

$3.42 \times 10^{-6}$

0.281

0.241

0.015

0.012

$0.16 \pm 0.038$

0.042

$\sim 0.004$

$\sim 0.04$

$\sim 0.0 .7$

$\sim 0.004$

$\sim 0.01$

$\sim 0.00011$

$<0.0010$

$<0.0010$

From the Industrial Graphite Engineering Handbook, Carbon Products Division, Union Carbide Corp. 


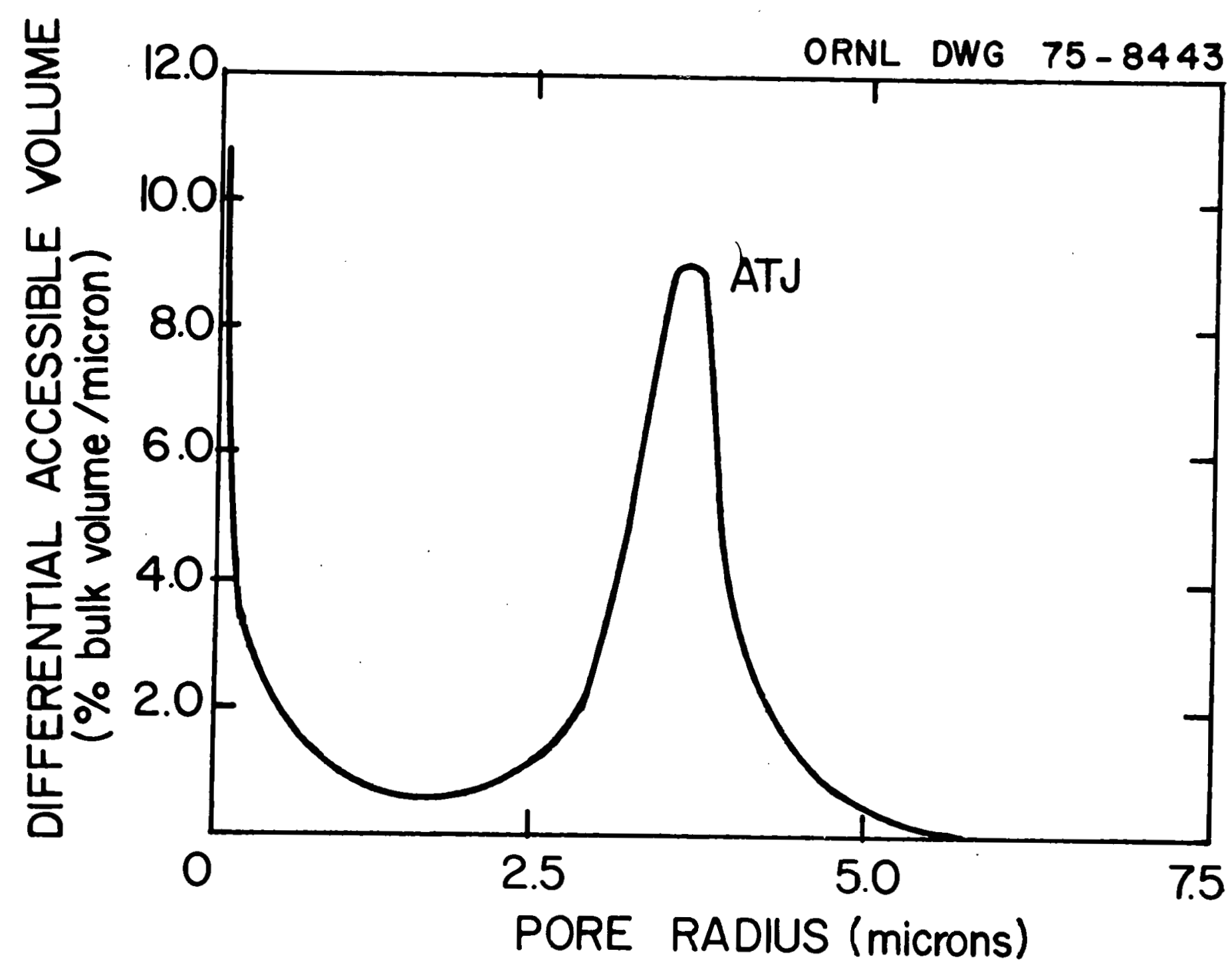

Iig. 4.1. Pore size distribution of ATJ graphite by mercury porosimetry. 
pore size distribution with the larger pores in the 3 to $4 \mu \mathrm{m}$ range, and micropores centering about $\sim 0.1 \mu \mathrm{m}$.

Some selected ATJ thermomechanical properties measured by $\mathrm{GAC}^{6}$ are listed in Table 4.2. Measurements were performed on specimens drawn from 8-in.-diam molded round bar stock, both parallel and perpendicular to the axis of the cylinder, and $8 \times 18 \times 50$ in. molded rectangular bar stock. The designations 8,18 , and 50-in. direction shown in Table 4.2 denote measurements on samples of stock in the three coordinate directions of rectangular bar stock.

\subsubsection{General teatures of A'l'J corrosion by low concentrations of $\mathrm{H}_{2} \mathrm{O}$ in helium - work of Blakely and Overholser}

In these experiments, ${ }^{1}$ a single l-in.-diam sphere of machined ATJ graphite, degassed under vacuum at $1025^{\circ} \mathrm{C}$ for 4 days, was suspended from the arm of a recording balance in a 2-in.-diam quartz tube. The flowing gas stream entered near the bottom of the quartz tube, passed upward, and departed through an opening near the top of the tubs. Helium, which was used as a carrier at 1 atm, was purified by passage through a refrigerated charcoal trap. The desired concentrations of carbon dioxide were obtained by passing the helium through a bed of calcium carbonate held at various carefully controlled temperatures. The helium-water vapor mixtures were prepared by dividing the helium stream, saturating prescribed fractions of the gas over saturated calcium chloride $\left(0^{\circ} \mathrm{C}\right)$, and combining the two streams. Additions of hydrogen or carbon monoxide to the helium-water vapor or helium-carbon dioxide mixtures were made by metering helium containing $\sim 1.5 \%$ of hydrogen or carbon monoxide. The influent and effluent gas streams were analyzed by a gas chromatograph for all consitituents of interest except water vapor, which was determined by a CEC Moisture Monitor.

These experiments show a puzzling feature which render it difficult to make quantitative use of the results. The reaction rate was observed to markedly increase with increasing helium flowrate, as indicated in Fig. 4.2. A cross plot of the data shows an approximately linear increase 
Table 4.2. ATJ graphite properties from GAC measurements ${ }^{a}$

Coefficient of thermal expansion, Ave. $22-1000^{\circ} \mathrm{C},{ }^{\circ} \mathrm{C}^{-1} \times 10^{6}$

50-in. direction

18-in. direction

$3.57 \pm 0.19$

8-in. direction

$3.63 \pm 0.15$

$4.88 \mp 0.05$

Thermal conductivity at $800^{\circ} \mathrm{C}$, cal $/ \mathrm{cm}-\mathrm{sec}-{ }^{\circ} \mathrm{C}$

| |-direction

$0.123+0.004$

1 -direction

$0.162 \pm 0.009$

Density at $25^{\circ} \mathrm{C}, \mathrm{gm} / \mathrm{cm}^{3}$

Molded round stock

Molded rectangular bar stock

$1.784 \pm 0.024$

$1.765 \mp 0.114$

Ultimate compressive strength at $25^{\circ} \mathrm{C}$, psi

$$
\begin{aligned}
& \text { 11-direction } \\
& \text { L-direction } \\
& \text { 8-in. direction } \\
& \text { 18-in. direction } \\
& \text { 50-in. direction }
\end{aligned}
$$

$$
\begin{aligned}
& 10,420 \pm 220 \\
& 10,560 \pm 600 \\
& 10,060 \pm 230 \\
& 9,420 \pm 1,170 \\
& 10,820 \pm 550
\end{aligned}
$$

Ultimate tensile strength at $25^{\circ} \mathrm{C}$, psi

$$
\begin{aligned}
& \text { 1 1-direction } \\
& \text { 1-direction } \\
& \text { 8-in. direction } \\
& \text { 18-in. direction } \\
& \text { 50-in. direction }
\end{aligned}
$$

$$
\begin{aligned}
& 1,818 \pm 573 \\
& 2,963 \pm 217 \\
& 2,383 \pm 247 \\
& 2,385 \pm 443 \\
& 3,318 \pm 358
\end{aligned}
$$

$a_{\text {From C. Meyers and K. Koyama, Evaluation of Candidate Graphites for }}$ PSC Core Support Applications, GAMD-837I (February 1968). 
ORNL-DWG 64-10960

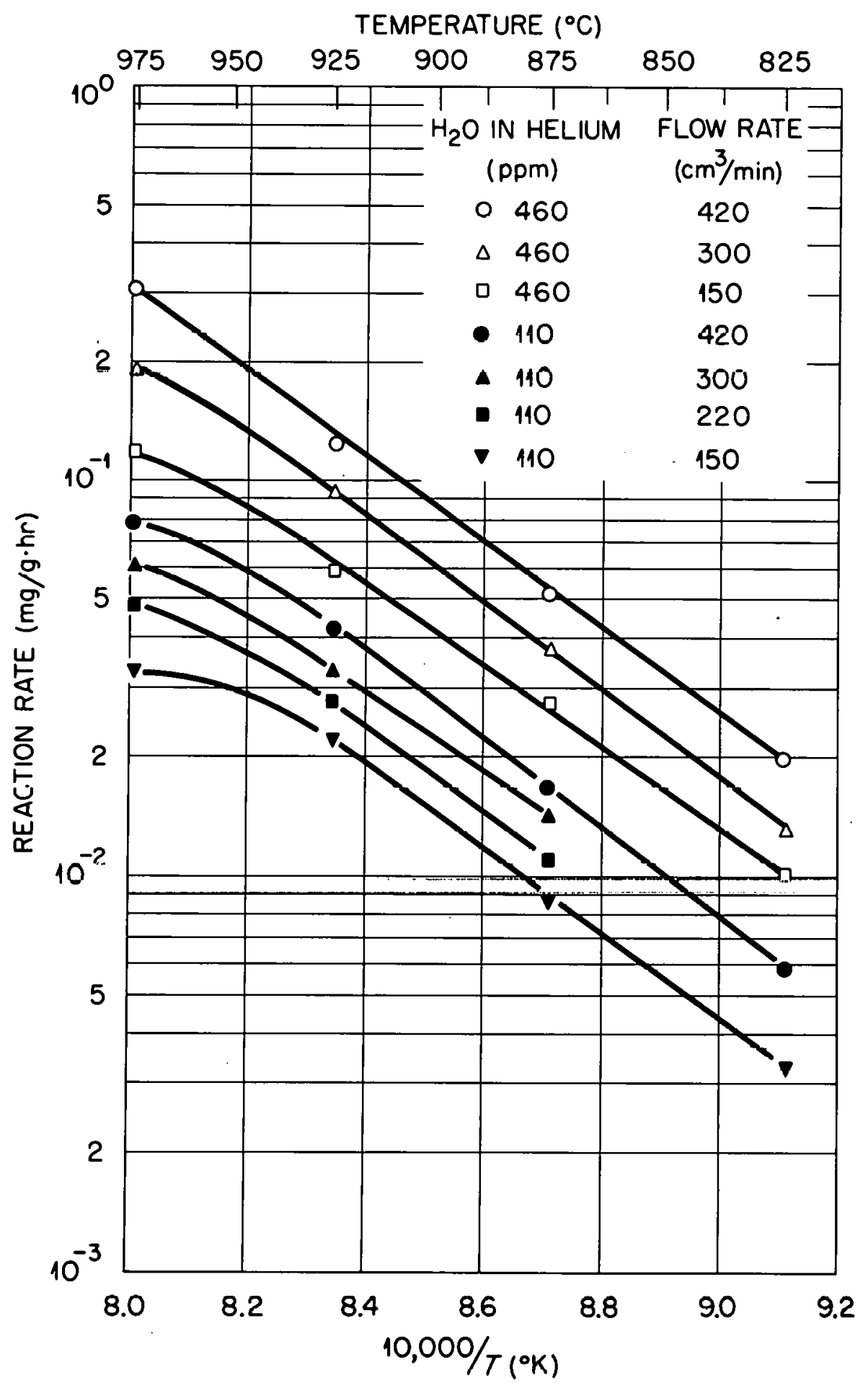

Fig. 4.2. Effect of temperature and flow rate on the $\mathrm{H}_{2} \mathrm{O}$-graphite reaction at inlet $\mathrm{H}_{2} \mathrm{O}$ concentrations of 110 and $460 \mathrm{vpm}$ ( $\sim 5$ wt \% burnoff) for ATJ graphite. ${ }^{1}$ 
with flowrate, which implies a mass-transfer control mechanism through the surface film. However, the variation with temperature is such that the activation energy equals $\sim 50 \mathrm{kcal} / \mathrm{mol}$, which is not consistent with surface film control. Surface film control should show far less temperature dependence, whereas $50 \mathrm{kcal} / \mathrm{mol}$ is typical of in-pore diffusion control; however, it should not be so flow sensitive.

Surface drag effects due to the upward flow of helium, which could alter the specimen mass determination if sufficiently large, appear to be ruled out because this phenomenon was seen only slightly with speer Moderator-2 graphite employing the same apparatus. Blakely and Overholser do not offer an explanation for this effect, but the most likely cause is some not well-understood manifestation of the diffusion process applicable to ATJ graphite. Extrapolating these data to core post conditions, where the velocities are much higher than in these experiments, introduces a large uncertainty, principally because the reason for this behavior is not known.

The variation of reaction rate with burnoff at $975^{\circ} \mathrm{C}$ is shown in Fig. 4.3. The reaction rate increases rapidly at the outset of corrosion and up to approximately $0.05 \%$ burnoff, reflecting the corrosion of the more reactive portions of the ATJ specimen. The rate of increase following this initial rapid rate and up to about $1 \%$ burnoff appears to be fairly typical behavior. For example, the burnoff factor used in the OXIIE-3 code ${ }^{7}$ increases about $70 \%$ between 0.1 and $1 \%$ burnot ${ }^{7}$, compared with a rise of about $115 \%$ for $A T J$ in the same range.

The rate of increase in the reaction rate beyond $1 \%$ burnoff is of vital interest. No specific data are given by Blakely and Overholser either in ref. I or the GCRP progress reports covering the work during this period; however, it is implied that at least for $875^{\circ} \mathrm{C}$ the reaction rate continued to increase with burnoff up to $8 \%$ burnoff, but more slowly than the linear rise shown between 0.1 and $1 \%$. It should be emphasized that this is surmised from the text, but is not stated specifically. However, this behavior appears to be at least qualitatively consistent with other graphites. For example, the OXIDE-3 burnoff factor shows a 


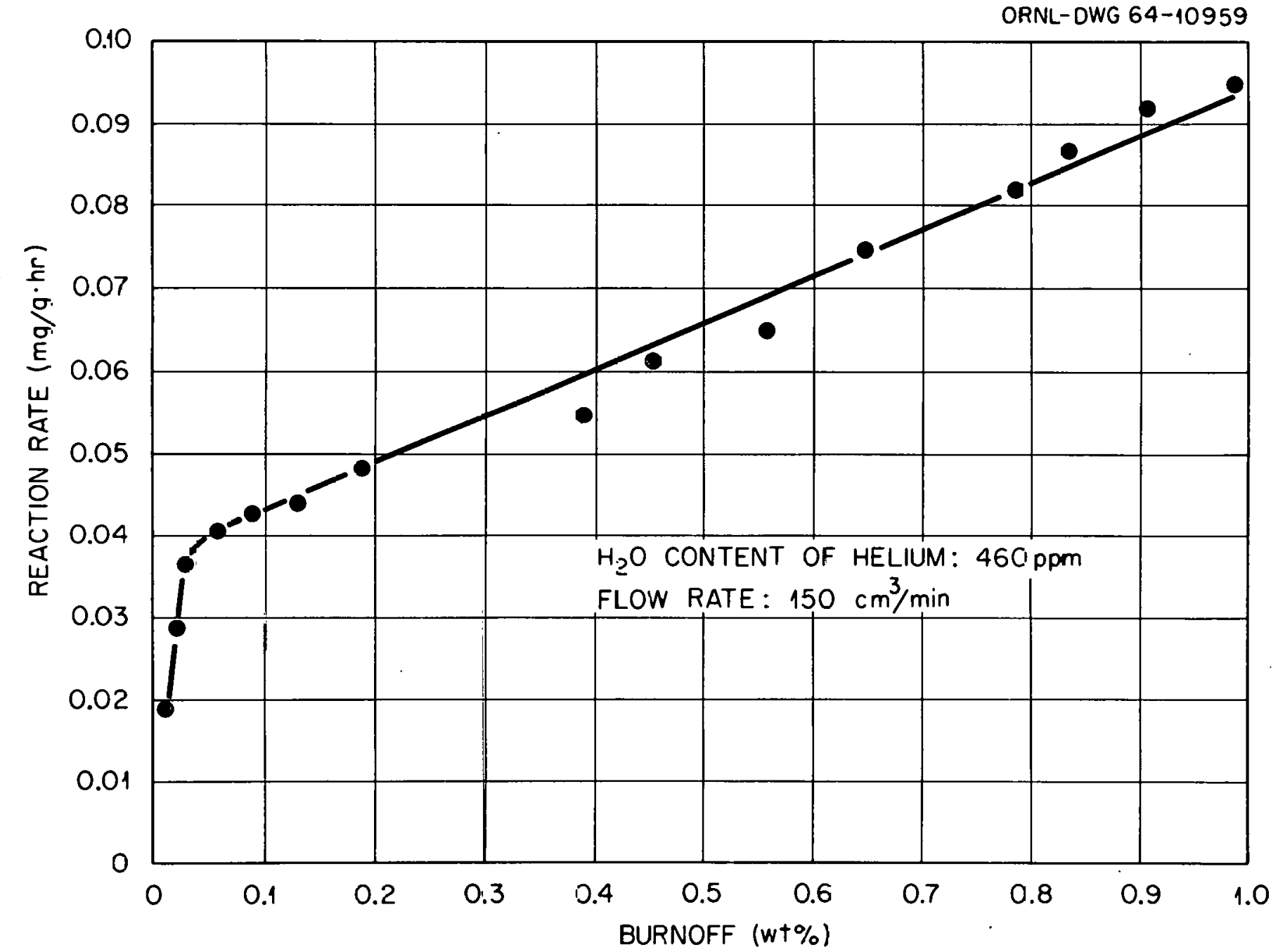

Fig. 4.3. Effect of jurnoff on the $\mathrm{H}_{2} \mathrm{O}-\mathrm{ATJ}$ graphite reaction at $975^{\circ} \mathrm{C}$ (flow rate of $150 \mathrm{~cm} /$ min STP, inlet concentration of $460 \mathrm{rpm}$ of $\left.\mathrm{H}_{2} \mathrm{O}\right)$. $^{3}$ 
gradual rise of about $65 \%$ between $I$ and $10 \%$ burnoff. No data are given by Blakely and Overholser on the distribution of burnoff within the I-in.diam specimen.

Another unique feature of the data is the large amount of $\mathrm{CO}_{2}$ produced (see Table 4.3). Identical runs using Speer Moderator-2 graphite showed little or no $\mathrm{CO}_{2}$ in the effluent gas. In-pile steam oxidation of graphite usually does form $\mathrm{CO}_{2}$ via the photon-catalyzed shift reaction

$$
\mathrm{H}_{2} \mathrm{O}+\mathrm{CO} \stackrel{\gamma}{\longrightarrow} \mathrm{CO}_{2}+\mathrm{H}_{2} \text {, }
$$

but $\mathrm{CO}_{2}$ is normally not present to any significant extent in thermally activated corrosion studies. It is hypothesized by Blakely and Overholser that the large amounts of $\mathrm{CO}_{2}$ observed in the ATJ steam corrosion experiments also result from the shift reaction, catalyzed by impurities in ATJ. (Production of some $\mathrm{CO}_{2}$ is thermodynamically favored with excess steam at temperatures below about $1000^{\circ} \mathrm{K}$.)

Figure 4.4 illustrates the dependence of reaction rate on the concentration of $\mathrm{H}_{2} \mathrm{O}$ in the inlet gas, and also the relative rates of ATJ corrosion with $\mathrm{H}_{2} \mathrm{O}$ and $\mathrm{CO}_{2}$ at $875^{\circ} \mathrm{C}$ under identical conditions. The apparent reaction order of 0.67 for $\mathrm{H}_{2} \mathrm{O}$ corrosion is consistent with a rate expression in the commonly accepted Hinshelwood form,

$$
\text { Rate }=\frac{\mathrm{k}_{1} \mathrm{P}_{\mathrm{H}_{2} \mathrm{O}}}{1+\mathrm{k}_{2}\left(\mathrm{P}_{\mathrm{H}_{2}}+\mathrm{P}_{\mathrm{CO}}\right)+\mathrm{k}_{3} \mathrm{P}_{\mathrm{H}_{2} \mathrm{O}}} \text {, }
$$

at least over modest ranges of $\mathrm{H}_{2} \mathrm{O}$ concentration. Equation (2) presumes a retardation effect for $\mathrm{H}_{2}$ and $\mathrm{CO}$ of about equal magnitude, as observed by Wicke et al. " for type "G-5" graphite. Blakely and Overholser show that $\mathrm{CO}$ does indeed have an intrinsic retardation effect in the steam oxidation of ATJ, other than the secondary effect of depleting $\mathrm{H}_{2} \mathrm{O}$ via the shift reaction, but they do not specifically determine a relative value for $\mathrm{H}_{2}$ and $\mathrm{CO}$ retardation.

Figure 4.4 also illustrates that for similar inlet concentrations, the thermally activated $\mathrm{H}_{2} \mathrm{O}$ oxidation rate of ATJ is only about twice that 
Table 4.3. Inlet and efflient gas compositions and reaction rates for $\mathrm{H}_{2} \mathrm{O}$ conrosion of $\mathrm{ATJ}$ at $875^{\circ} \mathrm{C} .{ }^{1}$ Flowrate $=\sim 300$ cc $\mathrm{STP} / \mathrm{min}$, burroff $=\sim 5 \%$

\begin{tabular}{|c|c|c|c|c|c|c|c|c|c|}
\hline \multicolumn{2}{|c|}{$\begin{array}{c}\text { Inlet } \\
\text { concentrat‡ons } \\
\text { (vpm) }\end{array}$} & \multicolumn{3}{|c|}{$\begin{array}{c}\text { Observed effluent } \\
\text { ccncentrations } \\
\text { (vpm) }\end{array}$} & \multicolumn{3}{|c|}{$\begin{array}{c}\text { Modified }{ }^{a} \text { efiluent } \\
\text { concentrations } \\
\text { (vpm) }\end{array}$} & \multicolumn{2}{|c|}{$\begin{array}{c}\text { Reaction rate } \\
(\mu \mathrm{g} / \mathrm{gm} \cdot \mathrm{hr})\end{array}$} \\
\hline (1) & (2) & (3) & (4) & (5) & $(6)$ & $(7)$ & $(8)$ & (9) & (10) \\
\hline $\mathrm{H}_{2} \mathrm{O}$ & $\mathrm{K}_{2}$ & $\mathrm{CO}_{2}$ & $\mathrm{CO}$ & $\mathrm{H}_{2}$ & $\mathrm{H}_{2} \mathrm{O}$ & $\mathrm{CO}$ & $\mathrm{H}_{2}$ & Observed & $\begin{array}{c}\text { Calculated } \\
\mathrm{Eq} \cdot(3)^{\mathrm{b}}\end{array}$ \\
\hline 30 & 0 & 7 & 6 & 21 & 16.5 & 13 & 14 & 8 & 7.84 \\
\hline 60 & 0 & 12 & 9 & 35 & 38 & 21 & 23 & 13 & 14.1 \\
\hline 110 & 0 & 25 & 13 & 60 & 73.5 & 38 & 35 & $\Xi 2$ & 21.2 \\
\hline 250 & 0 & 50 & 15 & $100^{\circ}$ & ¿9ङ & 65 & 50 & 37 & 32.9 \\
\hline 110 & 0 & 21 & 15 & 65 & 70.5 & 36 & 44 & $\varepsilon 2$ & 20.8 \\
\hline 110 & 120 & 14 & 14 & 170 & 77.5 & 28 & 156 & 16.5 & $17 \cdot 3$ \\
\hline 110 & 280 & 11 & 14 & 325 & 85.5 & 25 & 314 & 14.5 & 14.3 \\
\hline 110 & 530 & 6 & 11 & 570 & 84.5 & 17 & 564 & 10.5 & 10.9 \\
\hline 110 & 1050 & 3 & 8 & 1080 & 89 & 11 & 1077 & 7.5 & 7.38 \\
\hline
\end{tabular}

$a_{\text {See sect. }}$.1.1.

bee p. 33 . 


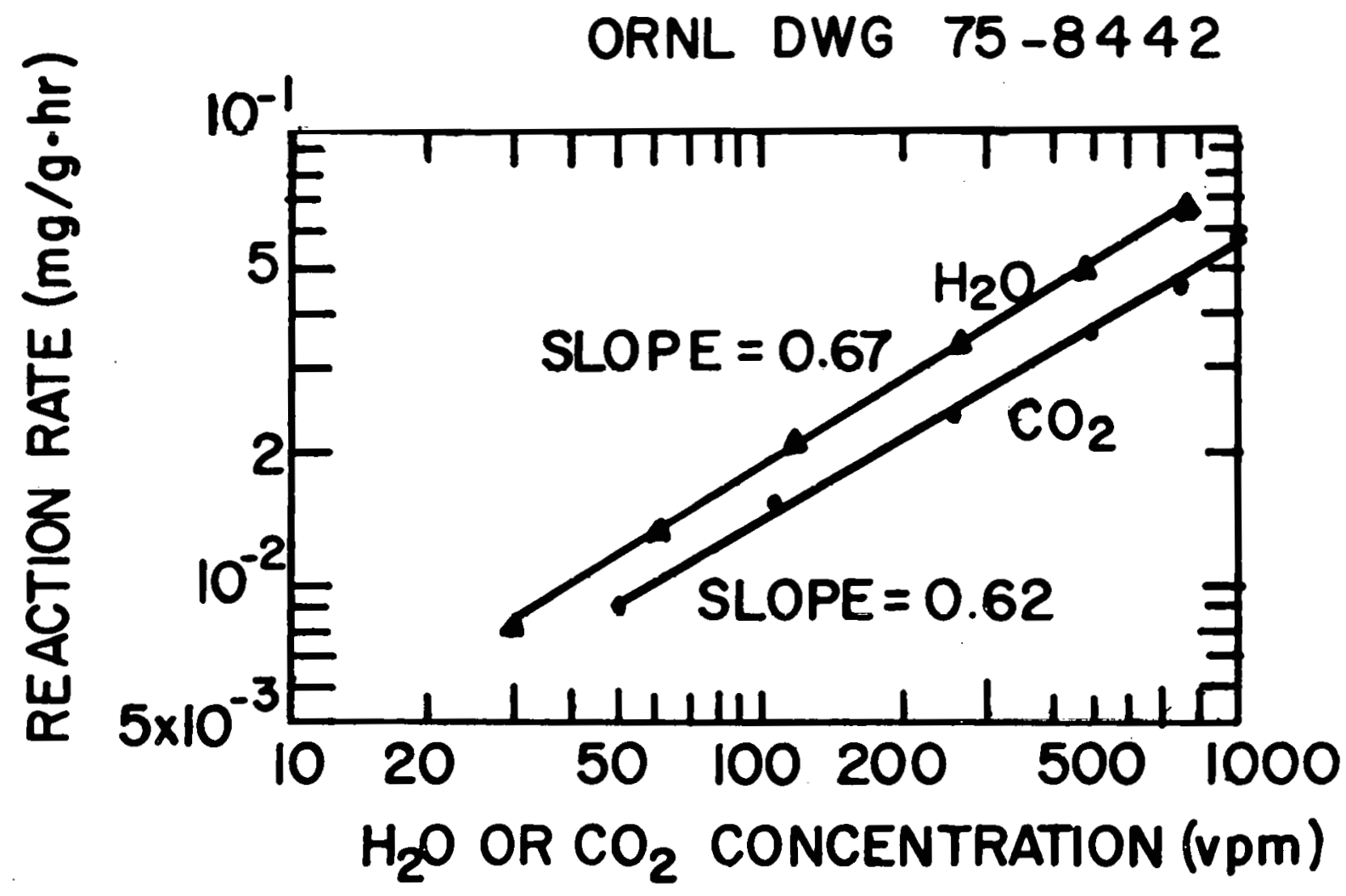

Fig. 4.4. Apparent order of the $\mathrm{H}_{2} \mathrm{O}$ and $\mathrm{CO}_{2}$ reactions with ATJ graplitite at $875^{\circ} \mathrm{C}$ (rluw rule of $300 \mathrm{~cm}^{3} / \mathrm{mln} \mathrm{STP}, \sim 5$ wt $\%$ burnofit, inlet concentrations given). ${ }^{1}$ 
of $\mathrm{CO}_{2}$. Identical runs using Speer Moderator-2 graphite ${ }^{2}$ indicated about a factor of 8 higher corrosion rate with $\mathrm{H}_{2} \mathrm{O}$ relative to $\mathrm{CO}_{2}$. Again, it is hypothesized that the difference may be attributed to the different impurity contents of the two materials.

\subsubsection{Corrosion rate expression for ATJ from the data of Blakely and Overholser}

In this section, an empirical corrosion rate expression for ATJ will be developed in the form given in Eq. (2), based on tabular data presented by Blakely and Overholser. ${ }^{\perp}$ Table 4.3 lists the observed inlet and effluent compositions in columns 1 through 5 for a series of runs at $875^{\circ} \mathrm{C}$. The observed reaction rates, given in column 9, are the average of that measured directly by the beam balance and the computed value using the total carbon in the effluent stream. These two rates were always within $10 \%$ of each other; hence, the reaction rate is known with some confidence.

Though not explicitly stated in ref. I, the presented data apparently pertain to a. specimen of about $5 \%$ burnoff. The observed rates at this degree of burnoff are surmised to be about a factor of 3 higher than the rates observed at $0.1 \%$ burnoff, assuming that ATJ behaves as a typical graphite above $1 \%$ burnoff.

In Table 4.3, a comparison of columns 3 to 5 with columns 1 and 2 , taken directly from ref. I, shows less total hydrogen and oxygen in the ef'luent than in the inlet flow. Although not stated in the reference, this is evidently due to $\mathrm{H}_{2} \mathrm{O}$ in the effluent which was not measured. The concentrations of $\mathrm{H}_{2} \mathrm{O}$ shown in column 6 are computed from the average of a hydrogen and oxygen mass balance, and bring the inlet and outlet hydrogen and oxygen flows in agreement to within an average of about $10 \%$.

An additional problem in the data analysis is the treatment of the $\mathrm{CO}_{2}$ observed in the effluent within the framework of the proposed form of rate expression, $\mathrm{Eq}$. (2), in which $\mathrm{CO}_{2}$ concentration does not appear. We will handle this as follows: Since the appearance of $\mathrm{CO}_{2}$ is evidently not due to corrosion, but rather to a reaction between $\mathrm{H}_{2} \mathrm{O}$ and $\mathrm{CO}$, and since the products of this reaction, $\mathrm{CO}_{2}$ and $\mathrm{H}_{2}$, each have approximately 
the same effect on ATJ as the reactants, we will modify the observed effluent concentrations to what they would have been had this shift reaction not occurred.

Thus, the modified effluent concentrations shown in columns 6-8 of Table 4.3 were obtained - by reversing the shift reaction by which $\mathrm{CO}_{2}$ is produced and by adding $\mathrm{H}_{2} \mathrm{O}$ to the effluent to balance the hydrogen and oxygen.

A least squares fit of the data in Table 4.3 yields the following corrosion rate expression:

$$
\mathrm{R}\left(\frac{\mu \mathrm{m}}{\mathrm{g}-\mathrm{hr}}\right)=\frac{0.408 \mu_{\mathrm{H}_{2} \mathrm{O}}}{1+0.00356\left(\mu_{\mathrm{H}_{2}}+\mu_{\mathrm{CO}}\right)+0.00695 \mu_{\mathrm{H}_{2} \mathrm{O}}} .
$$

The constants in E'q. (3) are based on the assumption that the graphite specimen in the tests experienced an effective impurity composition given by the average of the measured inlet composition and the effluent compositions modified in the manner indicated above. The comparison between the rates observed and those calculated by using Eq. (3) are listed in columns 9 and 10 of Table 4.3. The average deviation between observed and calculated values is $\pm 10.3 \%$.

A temperature dependence is introduced into Eq. (3) by noting that the reaction was observed to vary linearly on an Arrhenius plot with an effectlve actlvation energy of $50 \mathrm{kcal} /$ mol (see Fig. 4.2). Applying this variability solely to the coefficient in the numerator, and noting that the data presented in Table 4.3 refer to $875^{\circ} \mathrm{C}$, yields,

$$
\mathrm{R}\left(\frac{\mathrm{g}}{\mathrm{g}-\mathrm{hr}}\right)=\frac{1.34 \times 10^{9} \exp \left(-\frac{50,000}{\mathrm{RT}}\right) \mathrm{P}_{\mathrm{H}_{2} \mathrm{O}}}{1+3560\left(\mathrm{P}_{\mathrm{H}_{2}}+\mathrm{P}_{\mathrm{CO}}\right)+6950 \mathrm{P}_{\mathrm{H}_{2} \mathrm{O}}},
$$

with compositions now expressed in atmospheres partial pressures, and the rate given in terms of grams reacted per hour per gram of specimen. 
4.1.4. Conversion of ATJ corrosion rate equation [Eq. (4)] to surface

In most graphite corrosion studies and literature publications on the subject of graphite corrosion including the work of Blakely and Overholser, ${ }^{1}$ but with the notable exception of recent Dragon Project work, the reaction rate is expressed in units of $[g / g-h r]$, or some equivalent thereof. This is inappropriate for large graphite members at high temperature where the active corrosion zone of perhaps 1 to $3-\mathrm{mm}$ depth (see sect. 4.2.2) represents a small fraction of the total mass. In these cases, the reaction rate is proportional to the exposed surface area rather than the total mass of graphite; hence, an expression of the reaction rate in terms of $\left(\mathrm{g} / \mathrm{cm}^{2} \cdot \mathrm{hr}\right)$, or some equivalent, is more appropriate. It is therefore necessary to obtain a relationship between these two means for expressing the reaction rate in order to convert to the surface based units.

It will be shown in sect. 4.2.2 that the depth of the active corrosion zone is approximately $2 \mathrm{~mm}$ at $874^{\circ} \mathrm{C}$, the temperature representative of the data in Table 4.3. Since the tests were made with 1-in. diam spheres, we will term the reported reaction rates, $R_{\text {app }}$ (g/g-hr), where the subscript refers to "apparent"; this signifies that the active zone of the reaction is much less than the total specimen mass, $\mathrm{m}_{\mathrm{T}}$.

The rate in terms of the actual amount of mass involved in the reaction, $\mathrm{m}$, is related to $\mathrm{R}_{\text {app }}$ by:

$$
\mathrm{R}_{\text {act }}\left(\frac{g}{g-h r}\right)=R_{a p p}\left(\frac{g}{g-h r}\right) \frac{m_{T}}{m} \text {. }
$$

The ratio $\mathrm{m}_{\mathrm{T}} / \mathrm{m}$ is given by $\mathrm{R} / 3 \cdot \Delta \mathrm{h}$, for a large spherical sproimen in which $R \gg \Delta h$, where $\Delta h$ is the active reaction depth. Hence, Eq. (5) may be written

$$
R_{a c t}\left(\frac{g}{g-h r}\right)=R_{a p p}\left(\frac{g}{g-h r}\right) \frac{R}{3 \Delta h} \text {. }
$$


The rate based on exposed surface area, $R_{s}$, is related to $R_{\text {act }}$ by

$$
R_{S}\left(\frac{m o l}{c^{2}-h r}\right)=R_{a c t}\left(\frac{g}{g-h r}\right) \frac{\Delta h p}{M_{w}}
$$

where $\mathrm{M}_{\mathrm{W}}$ is the molecular weight. Combining Eqs. (6) and (7) yields the desired conversion,

$$
R_{S}\left(\frac{m o l}{\mathrm{~cm}^{2}-h r}\right)=R_{a p p}\left(\frac{g}{g-h r}\right) \frac{R p}{3 M_{w}} .
$$

A similar discussion for a cylindrical specimen with radius $\mathrm{R}$ yields

$$
R_{S}\left(\frac{m o l}{c^{2}-h r}\right)=R_{a p p}\left(\frac{g}{g-h r}\right) \frac{R p}{2 M_{w}} .
$$

Applying the conversion indicated by Eq. (8) to Eq. (4) using a graphite density of $1.8 \mathrm{~g} / \mathrm{cm}^{3}$ yields

$$
\mathrm{R}_{\mathrm{s}}\left(\frac{\mathrm{mol}}{\mathrm{cm}^{2}-\mathrm{hr}}\right)=\frac{85.1 \times 10^{6} \exp \left(-\frac{50,000}{\mathrm{RT}}\right) \mathrm{P}_{\mathrm{H}_{2} \mathrm{O}}}{1+3560\left(\mathrm{P}_{\mathrm{H}_{2}}+\mathrm{P}_{\mathrm{CO}}\right)+6950 \mathrm{P}_{\mathrm{H}_{2} \mathrm{O}}}
$$

for the corrosion rate of ATJ based on exposed surface area.

Equation (10) is compared with other published kinetics equations in Sect. 4.2.5. In general, the rates predicted by Eq. (10) for ATJ are within the band of predictions of the other kinetics equation which refer to a number of other types of graphite.

\subsection{Summary and Comparison of Steam-Graphite Corrosion Studies}

\subsubsection{Work of Wicke et a.1. 8 at the University of Münster}

Perhaps the most extensive study of graphite corrosion at high temperatures by low concentrations of oxidant was conducted at the Institute for Physical Chemistry of the University of Minster under contract by the Dragon Project. The work extended over a 4 year period beginning in 1961, and is summarized in a final report. 8 Much additional information is 
given in a major review article by Everett, Kinsey, and Romberg ${ }^{9}$ which incorporated much of the work of the Münster group. The major objectives and findings of this study are given below.

Graphite characterization and classification results from the Muinster study. The first objective of the study was the classification of a variety of graphites from different origins and preparation processes with respect to their susceptibility to corrosion. Two standarized tests employing pure $\mathrm{CO}_{2}$ as the oxidant were used to screen and grade graphites according to corrosion rate.

All data and descriptive material for this phase of the work appear in internal progress reports, and hence are unavailable. The following conclusions, appearing in the summary report, 8 are based on a total of about 100 reactivity tests involving 11 graphite types.

(1) All nonimpregnated graphites behaved in a qualitatively similar fashion. Corrosion susceptibility was found to increase continuously with burnoff from 0 to $15 \%$ burnoff. Also, the degree of reactivity increase was quite similar for the nonimpregnated graphites under similar oxidizing conditions. In all cases the reactivity increase wilh burnoff was greatest when the oxidation rate was slowest.

(2) Intrinsic reactivities of a.17 nonimpregnated graphites varied through a range of about one order of magnitude at the selected reference condition of $1100^{\circ} \mathrm{C}$ and $10 \%$ burnoff. Differences in impurity level are given as the major cause of reactivity differences at this reference condition.

(3) The range in observed reactivity of samples drawn from different locations on the same bar were about a factor of 2 to 3 . These were attributed to microstructural differences.

(4) Impregnated graphites behaved quite differently from the nonimpregnated graphites. * The initial reactivity was

* There is some question as to whether these comments pertain only to furfural alcohol-impregnated graphite but exclude pitch impregnations. 
high, and dropped to a minimum at 5\% burnoff, reflecting the burnoff of the impregnant which is the most reactive component.

(5) Impregnated specimens were also more reactive than nonimpregnated specimens at higher burnoffs for not wellunderstood reasons. It is speculated that impregnation adds impurities which increase graphite reactivity.

(6) Impregnation caused nonuniform reactivity throughout the bars.

Detailed investigation of $\mathrm{H}_{2} \mathrm{O}$ and $\mathrm{CO}_{2}$ induced graphite corrosion by the Miinster group. The least reactive graphite from phase 1 of the Münster study was selected for detailed examination of its reaction kinetics with $\mathrm{H}_{2} \mathrm{O}$ and $\mathrm{CO}_{2}$. The graphite chosen was designated as Péchiney G5 with properties given in Table 4.4. The graphite was preburned to $20 \%$ burnoff, at which point its reactivity remained fairly constant over a wide range of burnoffs. The graphite was crushed to a size range of 0.4 to $1.0 \mathrm{~mm}$ to assure uniform corrosion throughout each particle.

Table 4.4. Properties of Péchiney G5 graphite used in the Miinster study

\begin{tabular}{lc}
\hline Density, $\mathrm{g}^{\mathrm{c}} \mathrm{cm}^{3}$ & 1.82 \\
Total porosity, \% & 19.1 \\
Characteristic pore radius, $\mu \mathrm{m}$ & 1.5 \\
Initial BET surface area, $\mathrm{m}^{2} / \mathrm{g}$ & $\sim 0.5$ \\
Permeability, $\mathrm{cm}^{2} / \mathrm{sec}$ & $\sim 10^{-2}$ \\
Impurities, ppm & \\
Total ash & $50-750$ \\
Fe & $2-20$ \\
Al & $1-10$ \\
Ca & $15-200$ \\
Ni & $<3$ \\
Si & $50-150$ \\
Ti & $4-75$ \\
V & $4-60$ \\
\hline
\end{tabular}


The kinetics experiments were conducted at 1-atm total pressure and through a temperature range of $940^{\circ}$ to $1030^{\circ} \mathrm{C}$. The $\mathrm{H}_{2} \mathrm{O}$ level ranged from 350 to $1040 \mathrm{vpm}$, with helium as the carrier gas. $\mathrm{CO}$ and $\mathrm{H}_{2}$ levels were varied from 130 to $1050 \mathrm{vpm}$.

The major result of this portion of the study is embodied in the derived kinetics equation, given in final form in ref. 9, as

$$
R\left(\frac{m o l}{g-s \theta c}\right)=\frac{k_{7 .} C_{H_{2}} \mathrm{O}}{1+k_{2} C_{H_{2}}+k_{3} C_{C O}},
$$

where

$$
\begin{aligned}
& \mathrm{c}=\text { concentration, } \mathrm{mol} / \mathrm{cm}^{3}, \\
& \mathrm{k}_{1}=5.0 \times 10^{1 \%} \exp \left(-\frac{68,()(0)}{R T}\right), \mathrm{cm}^{3} / \mathrm{g}-\mathrm{sec}, \\
& \mathrm{k}_{2}=3.7 \times 10^{5} \exp \left(\frac{14,500}{R T}\right), \mathrm{cm}^{3} / \mathrm{mol}, \\
& \mathrm{k}_{3}=3.0 \times 10^{5} \exp \left(\frac{14,500}{\mathrm{RT}}\right), \mathrm{cm}^{3} / \mathrm{mol} .
\end{aligned}
$$

Equation (11) shows the following features compared with the ATJ corrosion discussed in sect. 4.1 and other graphite corrosion work to be described below.

(1) The dependence of reactivity with temperature was the highest of all the studies which were reviewed. Activation energies in the range of 30 to $50 \mathrm{kcal} / \mathrm{mol}$ are more typical than the value of 68 derived in this study. The probable reason for this behavior was that this was the only work employing crushed particles. The gaseous diffusion process linternal to the graphite is known to decrease observed temperature dependence of chemical reactions. Thus, the value of $68 \mathrm{kcal} / \mathrm{mol}$ may be close to the inherent graphite activation energy, while the commonly observed range of from 30 to $50 \mathrm{kcal} / \mathrm{mol}$ represents the effect of in-pore diffusion.

(2) A second significant observation is that the reaction products, $\mathrm{H}_{2}$ and $\mathrm{CO}$, were found to inhibit the reaction 
to approximately the same degree, as reflected by the approximately equal values of the constants $k_{2}$ and $k_{3}$. There is by no means agreement on this feature; but these results were obtained from an extensive series of tests in which the $\mathrm{H}_{2}$ and $\mathrm{CO}$ levels were independently varied in the feed gas, and hence are rather convincing.

(3) Another point of departure between Eq. (11) and other studies is the absence of a $\mathrm{H}_{2} \mathrm{O}$-dependent inhibition factor in the denominator. As a result, Eq. (11) invariably yields high predicted reactivities at high assumed $\mathrm{H}_{2} \mathrm{O}$ concentrations.

(4) In contrast with the ATJ corrosion studies, but consistent with all other thermally activated graphite corrosion work, only small amounts of $\mathrm{CO}_{2}$ were observed in the effluent gas.

\subsubsection{Conversion of the Wicke rate equation to surface units}

Equation (1I) was based on data using small particles of graphite in the range of 0.4 to $1 \mathrm{~mm}$, so chosen to assure uniform corrosion throughout the particle. Therefore, conversion of the rate, given in units of $(\mathrm{g} / \mathrm{g}-$ $\mathrm{sec}$ ), to a per unit area of exposed surface basis requires knowledge of the mass of graphite contained in the actively reacting corrosion zone.

Variation of corrosion depth with temperature - work of Helsby and Everett. $^{10}$ Figure 4.5 illustrates the variation in degree of corrosion observed with depth from the original graphite surface for two burnoffs and three temperatures. ${ }^{10}$ The graphite type was identified by the designation "No. 1," and described as a triply pitch-impregnated, Gilsonite-based, isotropic graphite. The specimen thickness was initially $4 \mathrm{~mm}$, and the

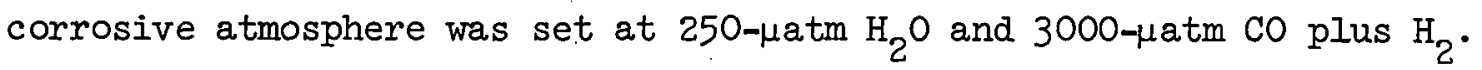

The curves show graphite in different stages of corrosion. At $1740^{\circ} \mathrm{C}$ and $186 \mathrm{mg} / \mathrm{cm}^{2}$ burnoff, the density profile may be termed as fully established. The active reaction zone extends from a depth of approximately $0.5 \mathrm{~mm}$ to $1.5 \mathrm{~mm}$, while a slowly reacting residue of density 0.17 to 0.2 


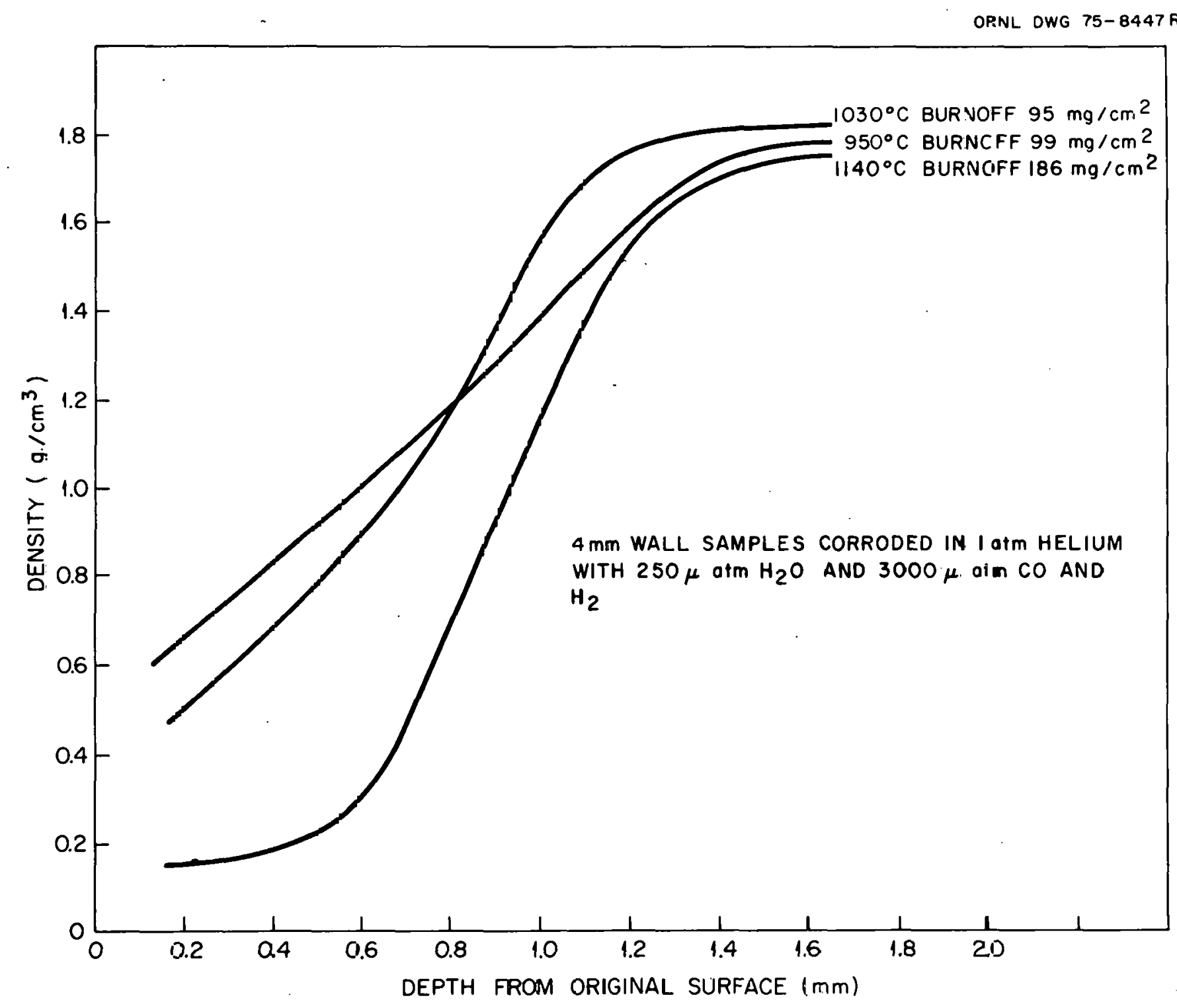

Fij.j 4.5. Densit; profiles for graphite corrosion at various 
$\mathrm{g} / \mathrm{cm}^{3}$ remains on the outer $0.5 \mathrm{~mm}$. The other two corrosion profiles, at 95 and $99 \mathrm{mg} / \mathrm{cm}^{2}$ burnoff, have not yet achieved full establishment; however, the curve at the higher temperature appears to be closer to it.

While the evidence is rather skimpy, the burnoff profiles shown in Fig. 4.5 are consistent with the following picture of graphite corrosion under these conditions:

(1) When graphite first comes in contact with low concentrations of $\mathrm{H}_{2} \mathrm{O}$ at high temperatures, the active reaction zone gradually moves inward from the exposed face to some equilibrium depth.

(2) The depth of the reaction zone at equilibrium, or full establishment, diminishes with increasing temperature.

(3) Following establishment of the fully developed corrosion profiles, corrosion proceeds by an inward movement of the reaction zone, leaving behind a slowly reacting residue of density 0.17 to $0.20 \mathrm{~g} / \mathrm{cm}^{3}$.

Depths of the fully established reaction zone as a function of temperature, estimated from the density profiles shown in Fig. 4.5, are listed in Table 4.5. The values given for the temperatures 1030 and $950^{\circ} \mathrm{C}$ were obtained by extending the curves shown to the left to the density range of approximately $0.2 \mathrm{~g} / \mathrm{cm}^{3}$. The values listed for 1200 , and 900 to $700^{\circ} \mathrm{C}$ were obtained by linear extrapolation. The data on which this view of graphite corrosion is based are small, and should be extended to more relevant types of graphites (i.e., the HTGR reference core and structural graphites) and a broader range of corrosive atmospheres. However, no additional burnoff profile data, other than that cited from Helsby and Everett, ${ }^{10}$ were found.

A comparison of the corrosion reaction depths given in Table 4.5 with the core-post temperature range of $786^{\circ} \mathrm{C}$ to $876^{\circ} \mathrm{C}$ in the reference design selected for this study (see sect. 6.3), indicates the anticipated range of active corrosion depths for the core posts to be about 2 to $3 \mathrm{~mm}$. Since the core porte are 6-in. in diameter, we therefore conclude that it i.s 
Table 4.5. Estimated depth of fully established reaction zone in graphite corroded by low concentrations of steam ${ }^{2}$

\begin{tabular}{cc}
$\begin{array}{c}\text { Temperature } \\
\left({ }^{\circ} \mathrm{C}\right)\end{array}$ & $\begin{array}{c}\text { Reaction zone } \\
(\mathrm{mm})\end{array}$ \\
\hline 1200 & $0.6^{\mathrm{b}}$ \\
1140 & 0.9 \\
1030 & $1.4^{2}$ \\
950 & $1.9^{\mathrm{b}}$ \\
900 & $2.1^{\mathrm{b}}$ \\
800 & $2.6^{\mathrm{b}}$ \\
700 & $3.1^{\mathrm{b}}$ \\
\hline
\end{tabular}

$a_{\text {See ref. } 10 .}$

botained by linear extrapolation.

appropriate to view the corrosion process as a surface corrosion process. In such cases, the reaction rate is proportional to the exposed superficial area of the graphite. This also appears to be true for the portion of the core graphite with surface temperatures above approximately $750^{\circ} \mathrm{C}$. This includes most of the core below the midplane where calculations outlined in Sect. 5.3 show that about $90 \%$ of the reaction of core graphite with steam oceurs.

The Wicke equation [Eq. (11)] in surface units. The amount of actively corroding graphite per unit area of exposed surface of a specimen or graphite member which is large compared with the active corrosion depth, is equal to $p$ Ah. Therefore, the approprlate corversion of urits for this case is

$$
R_{1}\left(\frac{g}{g-s e c}\right) \cdot \rho \Delta h\left(\frac{g}{c^{2}}\right)=R_{2}\left(\frac{g}{c^{2}-s e c}\right) \text {, }
$$

where $R_{1}$ is based on specimen sizes which are smaller than the reaction depth, $\Delta h$. Thus, the conversion to surface units is temperature dependent, since $\Delta \mathrm{h}$ varies with temperature, as shown in Table 4.5. We will avoid this additional complication by selecting a value of $\Delta \mathrm{h}$ appropriate for 
graphite at the average surface temperature in the lower half of the core. In sect. 5.3, it is shown that this temperature is about $820^{\circ} \mathrm{C}$ for the reference design selected for this study; by interpolation in Table 4.5, this yields a value for $\Delta h$ of about $0.25 \mathrm{~cm}$. Hence, the desired conversion factor is

$$
R_{1}\left(\frac{g}{g-s e c}\right) \times 0.45=R_{2}\left(\frac{g}{\mathrm{~cm}^{2}-\mathrm{sec}}\right) \text {. }
$$

It is also desirable for consistancy to convert Eq. (1I) to the use of partial pressures as an expression of concentration rather than mol $/ \mathrm{cm}^{3}$. The conversion is given by

$$
\text { Matm }=\mathrm{C}\left(\frac{\mathrm{mol}}{\mathrm{cm}^{3}}\right) \times 82.06 \times 10^{6} \times \mathrm{T}\left({ }^{\circ} \mathrm{K}\right),
$$

using the ideal gas law; once again, the conversion is temperature dependent. However, it can be shown that only a small error is introduced if a representative, average temperature is selected. The exponential temperature dependency of the multiplicative rate constant. is much higher and tends to mask the linear variation in Eq. (14). Thus, selecting $\mathrm{T}=1100^{\circ} \mathrm{K}$ yields

$$
R_{S}\left(\frac{m o l}{c^{2}-s e c}\right)=\frac{k_{1} \mu_{H_{2} O}}{I=k_{2} \mu_{H_{2}}+k_{3} \mu_{C O}}
$$

for the modified Wicke equation, Eq. (II), where

$$
\begin{aligned}
& k_{1}=21.4 \exp \left(-\frac{68,000}{R T}\right), \\
& k_{2}=3.5 \times 10^{-6} \exp \left(\frac{14,500}{R T}\right), \\
& k_{3}=2.9 \times 10^{-6} \exp \left(\frac{14,500}{R T}\right), \\
& \mu=\mu \text { atm. }
\end{aligned}
$$




\subsubsection{The OXIDE-3 rate equation}

The steam-graphite kinetics equation used on the OXIDE-3 program ${ }^{11}$ is given as

$$
\mathrm{R}_{\mathrm{v}}\left(\frac{\%}{\mathrm{hr}}\right)=\frac{\mathrm{k}_{1} \mathrm{P}_{\mathrm{H}_{2} \mathrm{O}} \mathrm{F}_{\mathrm{b}} \mathrm{F}_{\mathrm{c}}}{1+\mathrm{k}_{2} \mathrm{P}_{\mathrm{H}_{2}}^{\mathrm{n}}+\mathrm{k}_{3} \mathrm{P}_{\mathrm{H}_{2} \mathrm{O}}},
$$

whlere

$$
\begin{aligned}
k_{1} & =1.067 \times 10^{10} \exp \left(-\frac{40,900}{R T}\right), \% / h r-a t m, \\
k_{2} & =0.0166 \exp \left(\frac{28,600}{R T}\right), a t m^{-0.75}, \\
k_{3} & =0.0531 \exp \left(\frac{27,500}{R T}\right), a t m^{-1}, \\
n & =0.75 \\
P & =\text { atm, } \\
F_{b}, F_{c} & =\text { burnoff and catalyst factors. }
\end{aligned}
$$

The burnoff factor is expressed as a polynominal function of the percent burnoff which varies from 0.5 at 0 burnoff to 1.7 at $10 \%$ burnoff. $\mathrm{F}_{\mathrm{b}}$ is set to unity at $1 \%$ burnoff. The catalyst factor, $\mathrm{F}_{4}$, is given as a temperature dependent function of the sum of the barium and strontium concentrations in the graphite, normalized to a value of unity for noncatalyzed graphite. The concentrations of barium and strontium, which are the major fission product catalysts for the steam graphite reaction, are computed by OXIDE-3 from the fission yields and diffusion from the fuel. The initial concentration of these catalytic materials is assumed to be zero. No indication of the maximum anticipated value for $F_{c}$ is given in ref. 11 . In the present study, the factors $F_{b}$ and $F_{c}$ are assumed to be unity.

Since Eq. (16) was developed from a compilation of data from a variety of sources, there is no completely rational way to convert it to units based on exposed surface area. As seen above, such conversion depends on the particular geometry of each experiment. However, an approximation can be made by noting that most of the studies on which Eq. (16) was based employed specimen sizes of about 1 to $2 \mathrm{~cm}$. Hence, we will use a rough conversion 
of the OXIDE-3 equation to surface units by assuming that it is based on data taken on 1-cm-diam cylinders. Thus, using Eq. (9) yields the following modified OXIDE-3 equation,

$$
R_{s}\left(\frac{m o l}{c m^{2}-h r}\right)=\frac{k_{1} P_{H_{2} O}}{1+k_{2} P_{N_{2}}^{n}+k_{3} P_{H_{2} O}},
$$

where

$$
\begin{aligned}
k_{1} & =4.00 \times 10^{6} \exp \left(-\frac{40,900}{R T}\right), \\
k_{2}, k_{3}, n & =\text { unchanged. }
\end{aligned}
$$

4.2.4 The Giberson rate equation ${ }^{12}$

This study was performed in support of the operation of the Hanford reactors which often have measurable $\mathrm{CO}_{2}$ and $\mathrm{H}_{2} \mathrm{O}$. levels in the helium coolant. Therefore, a so-called KC-graphite was selected as being the typical core graphite of one of the Hanford reactors.

Type KC graphite is made from Kendall coke and Chicago Pitch by the National Carbon Company. It is a purified, anisotropic graphite with an initial density of $1.70 \mathrm{~g} / \mathrm{cm}^{3}$ and an initial $\mathrm{BET}$ area of $0.55 \mathrm{~m}^{2} / \mathrm{g}$. The test samples were cylinders of $1.1 \mathrm{~cm}$ diam and $5 \mathrm{~cm}$ length. Each was preoxidized in air to $5 \%$ burnoff.

The experiments were conducted at 1 atm pressure through a temperature range of 800 to $1000^{\circ} \mathrm{C}$. Steam concentrations in helium ranged from 500 to 10,000 ppm. Hydrogen levels ranged from 0 to $5000 \mathrm{ppm}$, and $\mathrm{CO}$ was not introduced independently. The reported data were correlated by

$$
R_{v}\left(\frac{g}{g-h r}\right) \frac{k_{1} \mathrm{P}_{H_{2}} \mathrm{O}}{1+k_{2} \sqrt{\mathrm{P}_{\mathrm{H}_{2}}}+\mathrm{k}_{3} \mathrm{P}_{\mathrm{H}_{2} \mathrm{O}}},
$$

where 


$$
\begin{aligned}
& \mathrm{k}_{1}=127 \exp \left(-\frac{32,700}{\mathrm{RT}}\right), \mathrm{g} / \mathrm{g}-\mathrm{hr}-\mathrm{mm}, \\
& \mathrm{k}_{2}=1.24 \times 10^{-11} \exp \left(\frac{60,800}{\mathrm{RT}}\right), \mathrm{mm}^{-1 / 2}, \\
& \mathrm{k}_{3}=6.51 \times 10^{-19} \exp \left(\frac{79,300}{\mathrm{RT}}\right), \mathrm{mm}^{-1}, \\
& \mathrm{P}=\mathrm{mm} \mathrm{Hg} .
\end{aligned}
$$

Converting the rate to a surface area basio as specified by use of Eq. (9), and converting the partial pressure values from mm-Hg to atmospheres, yields the following values for the constants,

$$
\begin{aligned}
\mathrm{P} & =\text { atm } \\
\mathrm{k}_{1} & =3990 \exp \left(-\frac{32,700}{\mathrm{RT}}\right), \mathrm{mol} / \mathrm{cm}^{2}-\mathrm{hr}-\mathrm{atm}, \\
\mathrm{k}_{2} & =3.10 \times 10^{-10} \exp \left(\frac{60,800}{\mathrm{RT}}\right), \mathrm{atm}^{-1 / 2}, \\
\mathrm{k}_{3} & =4.95 \times 10^{-16} \exp \left(\frac{79,300}{\mathrm{RT}}\right), \mathrm{atm}^{-1} .
\end{aligned}
$$

Use of the above values in Eq. (18) yields the rate expressed as $\mathrm{mol} / \mathrm{cm}^{2}-\mathrm{hr}$.

\subsubsection{Comparison of corrosion rate predictions}

The ATJ corrosion equation derived in sect. 4.1 and the Wicke, OXIDE-3, and Giberson equations given in this section have been put on a common basis, expressing the predicted rates in terms of mole/ $/ \mathrm{cm}^{2}-\mathrm{hr}$, and are compared here with each other for a number of representative conditions.

In adition to these four kinetics equations, two others will be included in the comparisons which are the result of less complete studies. The first of these is reported by Giberson and Walker, ${ }^{13}$ whose data are limited to the case of no $\mathrm{H}_{2}$ or $\mathrm{CO}$ in the oxidizing gas. The TSX graphite used in these studies was manufactured by the National Carbon Co. from Continental Lake Charles No. I coke and Allied Chemical Co. No. 30 medium coal tar pitch. The graphite was baked as bars and pitch-impregnated once. Test samples were cut from the bars to $5-\mathrm{cm}$ length and $1.1 \mathrm{~cm}$ diameter. 
The test variables ranged from 130 to $33,000 \mu \mathrm{atm} \mathrm{P}_{\mathrm{H}_{2}} \mathrm{O}$ and from $750^{\circ}$ to $900^{\circ} \mathrm{C}$. The results were correlated by

$$
\mathrm{R}_{\mathrm{v}}\left(\frac{\mathrm{g}}{\mathrm{g}-\mathrm{hr}}\right)=4.78 \times 10^{9} \exp \left(-\frac{70,200}{\mathrm{RT}}\right) \sqrt{\mathrm{P}_{\mathrm{H}_{2} \mathrm{O}}},
$$

with $P$ given in millimeters of mercury.

The second additional set of data included in this comparison are given by Helsby and Everett 10 for three graphites designated as "reference graphite," "graphite No. I," and "graphite No. 96." The latter two are molded, isotropic Gilsocarbon graphites, while the first is not otherwise identified. These tests were limited to $\mathrm{P}_{\mathrm{H}_{2} \mathrm{O}}=250 \mu \mathrm{atm}, \mathrm{P}_{\mathrm{H}_{2}}+\mathrm{P}_{\mathrm{CO}}=$ $3000 \mu \mathrm{tm}$, while the temperature was varied from 950 to $1150^{\circ} \mathrm{C}$.

Figure 4.6 compares predicted reaction rates at $\mathrm{P}_{\mathrm{H}_{\mathrm{g}}}=1000 \mu \mathrm{atm}$ and $\mathrm{P}_{\mathrm{H}_{2}}+\mathrm{P}_{\mathrm{CO}}=3000 \mu \mathrm{atm}$ as a function of temperature. The actually observed temperature range inclusive for each study is indicated in the figure by the heavy band. Note that at $800^{\circ} \mathrm{C}$ about a factor of 10 range exists from the ATJ to the lowest value predicted by Giberson. At $900^{\circ} \mathrm{C}$ the span between ATJ, OXIDE-3, Wicke, and Giberson predictions narrows to about a factor of 3 . At $1000^{\circ} \mathrm{C}$, the range predicted by these four rate equations widens to about a factor of 4 .

Figure 4.7 illustrates the comparison for no $\mathrm{H}_{2}$ or $\mathrm{CO}$ added to the oxidizing gas. In this case, the predictions range through a factor of $6,2,5$, and 20 at $700,800,900$, and $1000^{\circ} \mathrm{C}$, respectively.

The variation of predicted corrosion rates as a function of $\mathrm{P}_{\mathrm{H}_{2} \mathrm{O}}$ at $\mathrm{T}=900^{\circ} \mathrm{C}$ and $3000 \mu \mathrm{atm}$ of $\mathrm{CO}+\mathrm{H}_{2}$ is shown in Fig. 4.8. The span of predictions ranges through a factor of 5 for $\mathrm{P}_{\mathrm{H}_{2} \mathrm{O}}$ values less than about $500 \mu \mathrm{atm}$, excluding the high values of Helsby and Everett. From $500 \mu \mathrm{atm}$ and up to about $3000 \mu \mathrm{atm} \mathrm{H}_{2} \mathrm{O}$, the predictions converge to within a factor of about 2 .

Figure 4.9 shows the same comparison with no $\mathrm{H}_{2}$ or $\mathrm{CO}$ added to the oxidizing gas, a condition which permits comparison with data of Giberson and Walker. ${ }^{13}$ The predictions diverge much more than is shown in Fig. 4.8. The range is a factor of about 30 at $10 \mu a t m \mathrm{H}_{2} \mathrm{O}$ and converges to a factor of 5 at $1000 \mu \mathrm{atm} \mathrm{H}_{2}$. 


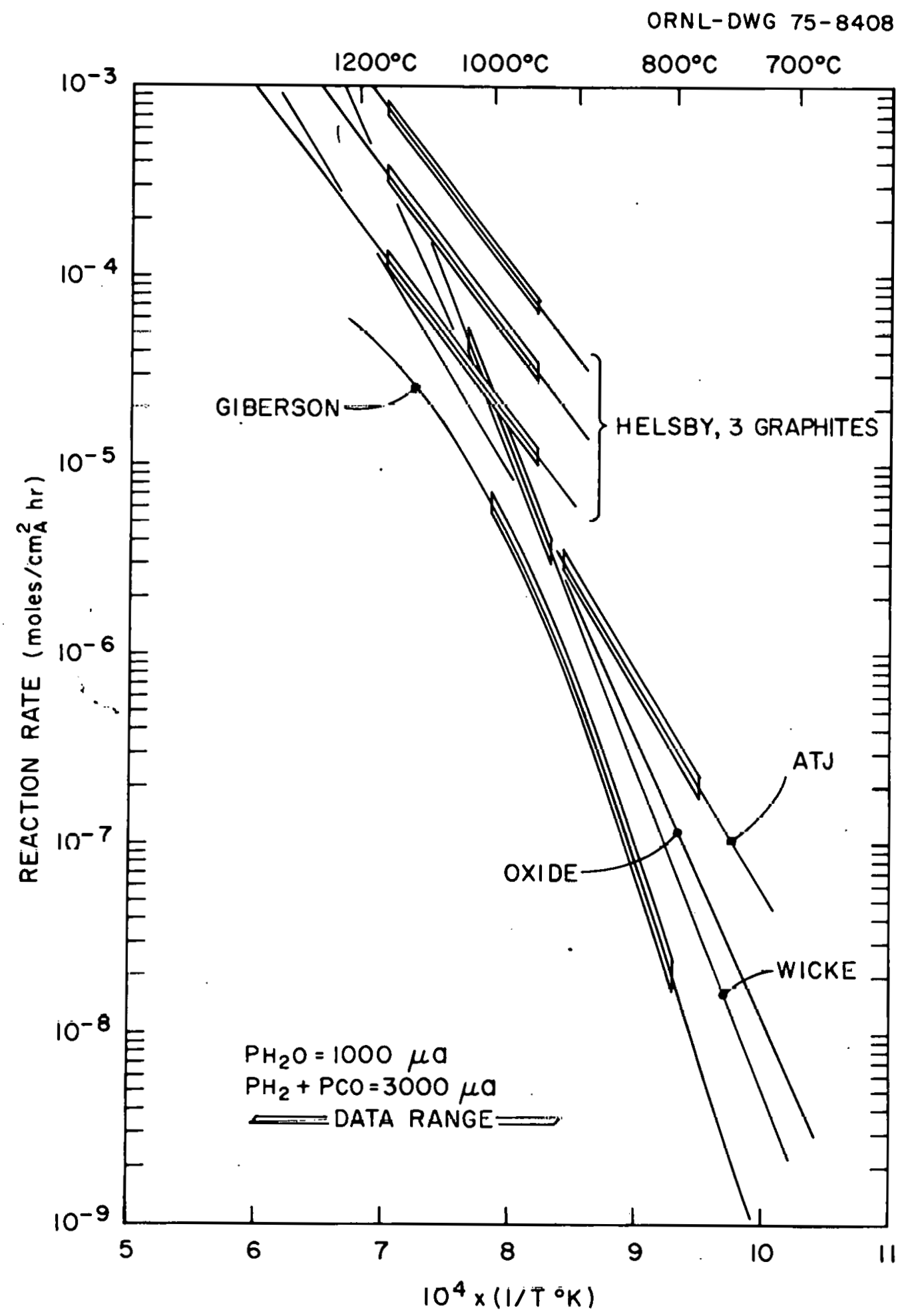

Fig. 4.6. Reaction rate vs $1 /$ temperature at $\mathrm{P}_{\mathrm{H}_{2} \mathrm{O}}=1000 \mathrm{\mu atm}$,
$\mathrm{P}_{\mathrm{H}_{2}}+\mathrm{P}_{\mathrm{CO}}=3000 \mu \mathrm{a}$. 


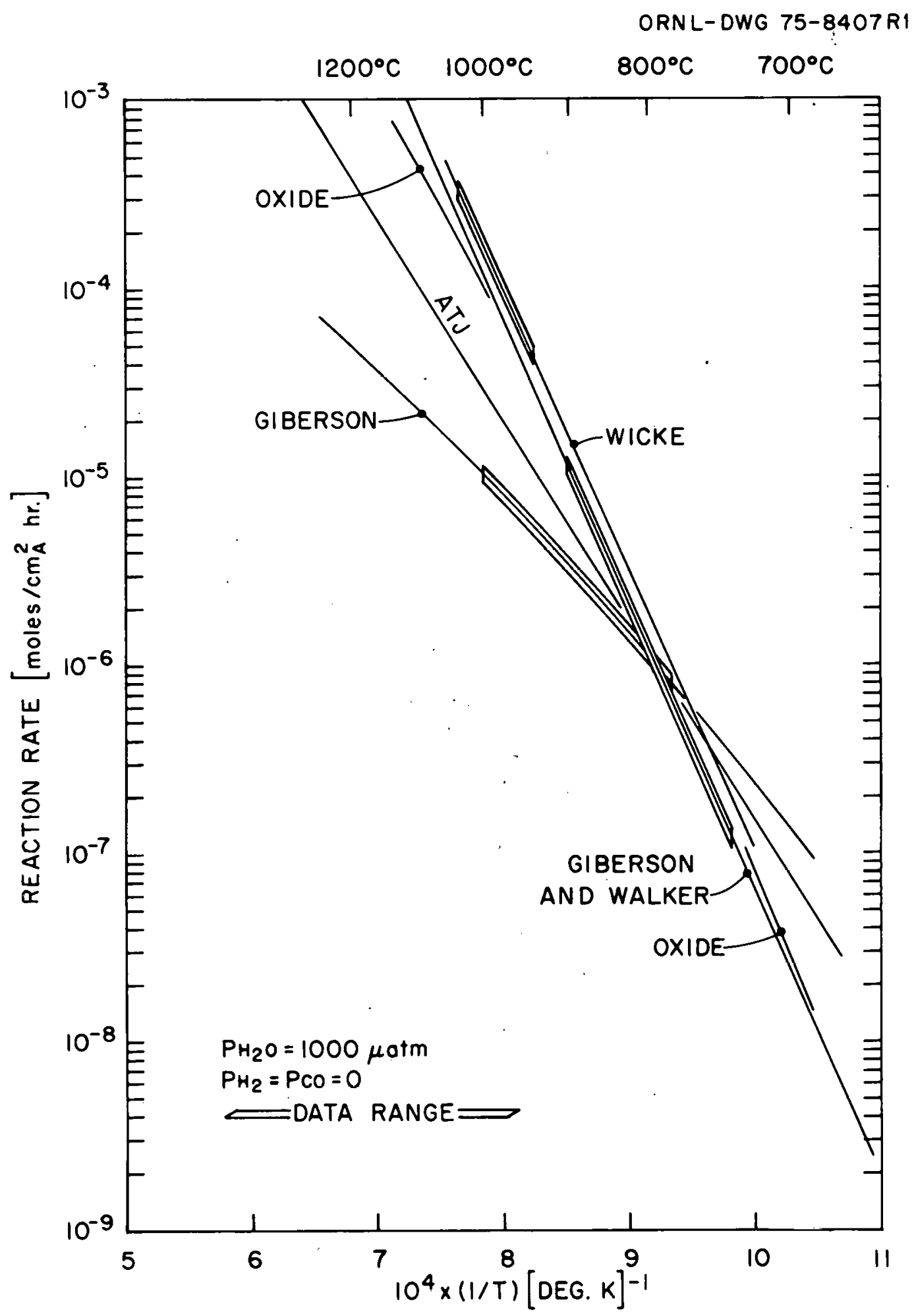

Fig, 4.7. Reaction rate vs $1 /$ temperature at $\mathrm{P}_{\mathrm{H}_{2} \mathrm{O}}=1000$ patm,
$+\mathrm{P}_{\mathrm{H}}=0$. $\mathrm{P}_{\mathrm{CO}}+\mathrm{P}_{\mathrm{H}_{2}}=0$. 


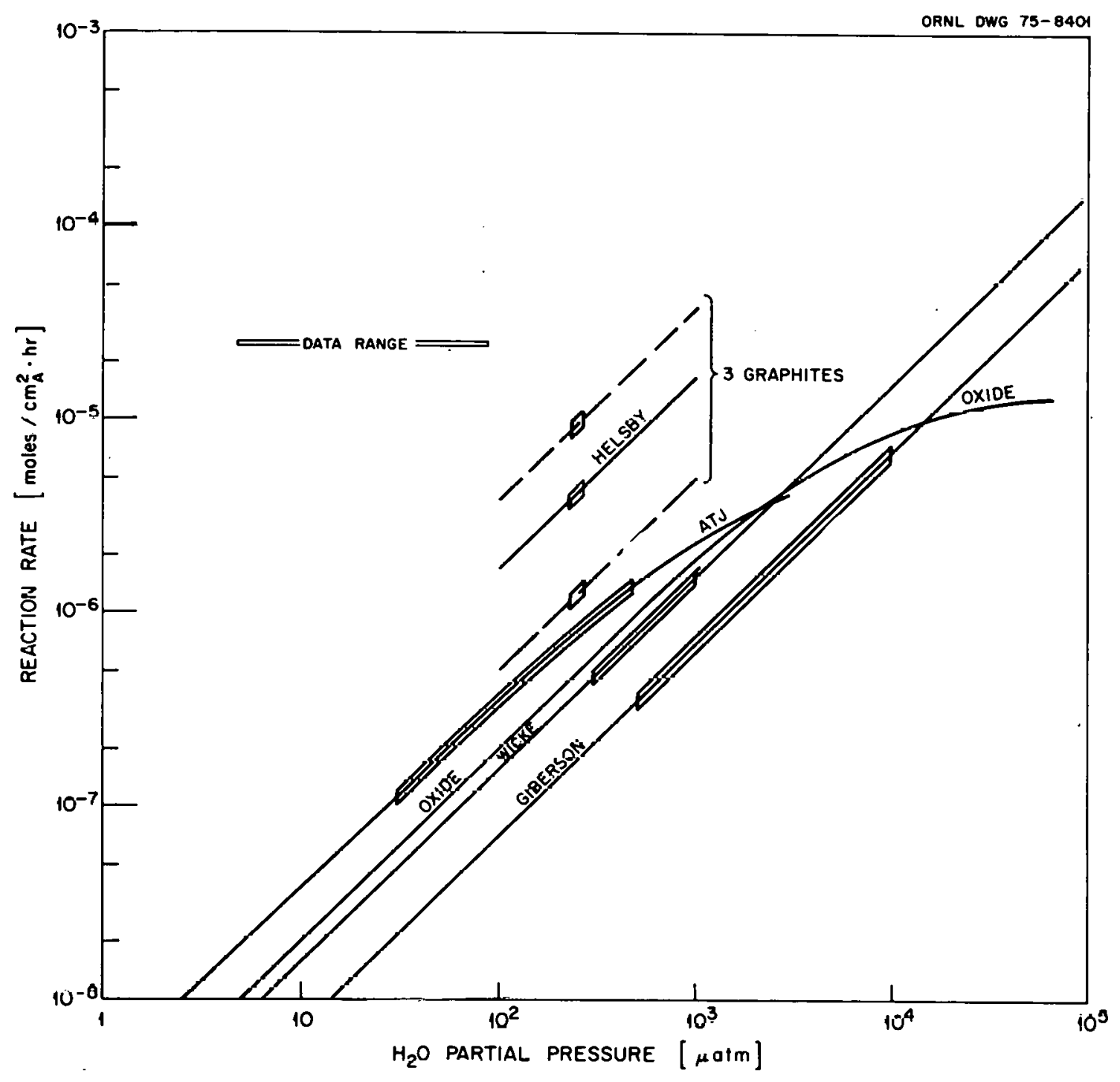

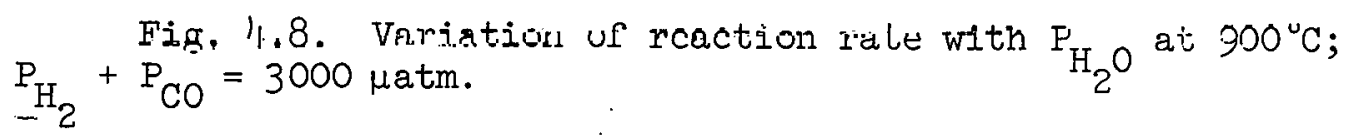


51

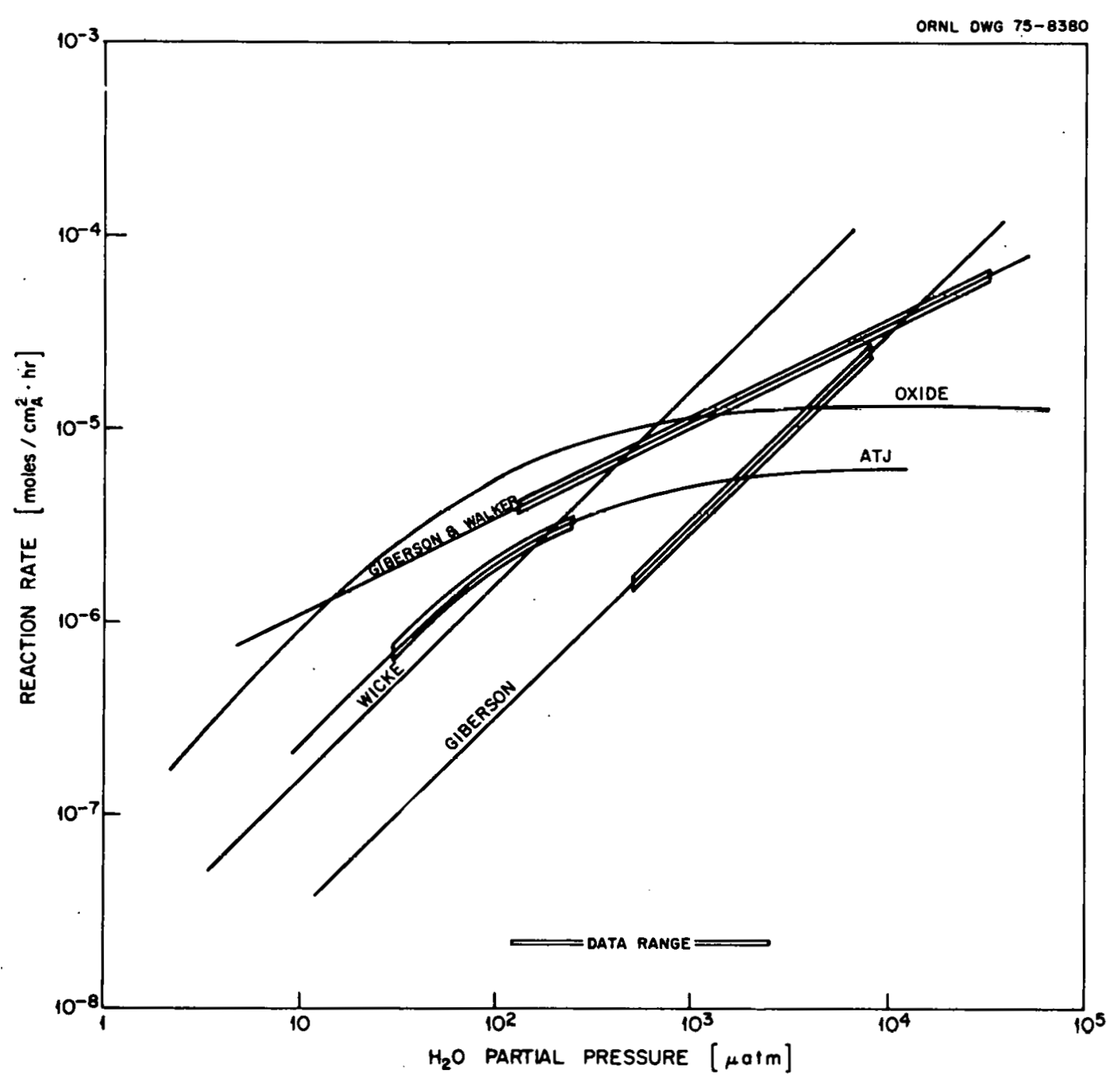

Fig. 4.9. Variation of reaction rate with $\mathrm{P}_{\mathrm{H}_{2} \mathrm{O}}$ at $900^{\circ} \mathrm{C}$;
$\mathrm{P}_{\mathrm{H}_{2}}=\mathrm{P}_{\mathrm{CO}}=0$. 


\subsection{Refererıces for Section 4}

1. J. P. Blakely and L. G. Overholser, "Oxidation of ATJ Graphite by Low Concentrations of $\mathrm{H}_{2} \mathrm{O}$ and $\mathrm{CO}_{2}$ in Helium, "Carbon $\underline{3}$, 269-75 (1965).

2. L. G. Overholser and J. P. Blakely, "Oxidation of Graphite by Low Concentrations of $\mathrm{H}_{2} \mathrm{O}$ and $\mathrm{CO}_{2}$ in Helium, "Carbon 2, 385-94 (1965).

3. J. I. Rutherford et al., Oxidation of Fueled and Infiueled Graphite Spheres by Steam, ORNL-3947 (May 1,66).

4. Nucleur Safety Program Annual Progress Report for Period Ending 12/31/66, W. B. Cottrel1, Prog. Div., ORNL-4071 (March 1967), pp. 104-106.

5. The Industrial Graphite Engineering Handbook, National Carbon Company, 1964.

6. C. Meyers and K. Koyama, Evaluation of Candidate Graphites for PSC Core Support Applications, GAMD-8371 (February 1968).

7. M. B. Peroomian, A. W. Barselz, and J. C. Daeger, OXIDE-3: A Computer Code for Analysis of HTGR Steam or Air Ingress Accidents, GA-Al2493 (GA Lil'-'1) (January 197ll), Fig. 3-9.

8. E. Wicke et al., Corrosion Rate of Graphites by $\mathrm{CO}_{2}$ and $\mathrm{H}_{2} \mathrm{O}_{2}$ D.P. Rep. 391 (January 1966).

9. M. R. Everett, D. V. Kinsey, and F. Römhers, "Carbon Tranoport Studies t'or Helium Cooled High Temperature Reactors, " in Chemistry and Mlysies of Carlupl, vol. 3, èd. by r. L. Walker, Marcel Dekker, New York, 1967.

10. G. H. llelsby and M. R. Everett, Some Graphite Corrosion Problems Related to Helium-Cooled HTR's, D.P. Rep. 566 (August 1968).

11. M. B. Peroomian, A. W. Barsell, and J. C. Saeger, OXIDE-3: A Computer Code for Analys is of HTGR Steam or Air Ingress Accidents, GA-A12493 (LTR-7) (January 1974).

12. R. C. Giberson, Rate Constants for the Reaction of $\mathrm{CO}_{2}$ and $\mathrm{H}_{2} \mathrm{O}$ with KC Graphite, BNWL-CC-1381 (August 1974).

13. R. C. Giberson and J. P. Walker, Reaction of TSX Graphite with Water Vapor, HW-SA-3439 (April 1964). 


\section{ESTIMATED IMPURITY IEVELS IN THE PRTMARY SYSTEM}

The first step in assessing the degree of core post damage caused by the corrosive effect of impurities in the primary system is to estimate their level and composition. Since the total steady-state impurity concentration depends solely on the relative rates of ingress and purification flow, the problem becomes that of distributing the total level between oxidizing species and the products of corrosion which act as inhibitors.

A considerable simplification is achieved if we may neglect the spatial dependence of impurity level within the primary system. That this is in fact the case is shown in the next section.

\subsection{Variation of Impurity Level with Axial Location in the Coolant Channel}

Since the circuit time of coolant in the primary system is quite short (i.e., somewhere between 3.7 and $7.1 \mathrm{sec}$, as discussed below) one may suspect that a valid approximation would be to treat the primary coolant as a mixed pot for the purpose of defining the corrosive atmosphere around the core support posts.

Section 5 of the Delmarva. Power and Light Preliminary Safety Analysis Report gives the circuit time of coolant in the primary system as $3.7 \mathrm{sec.}{ }^{1}$. A snmewhat higher value is obtained from the given total coolant flow of $7.48 \times 10^{6} 1 \mathrm{~b}_{\mathrm{m}} / \mathrm{hr}\left(3.39 \times 10^{6} \mathrm{~kg} / \mathrm{hr}\right)$ and helium inventory ${ }^{2}$ of $14,700 \mathrm{Ib}_{\mathrm{m}}$ $(6670 \mathrm{~kg})$, which yields a circuit time of 7.1 sec. A further intuitive judgment that primary system concentrations are more or less uniform is obtained by noting that the coolant transit time through the core is approximately 0.2 sec (core hcight $=26 \mathrm{ft}$ divided by an average velocity of about $150 \mathrm{ft} / \mathrm{sec})$.

A simple program termed TUBOX has been used to estimate the degree to which concentrations vary axially in the core. TUBOX divides a single coolant channel into ten axial sections, eight sections of $80 \mathrm{~cm}$ each for the active core, plus two sections for the top and bottom reflector. The graphite and coolant temperatures are specified for each of the ten zones as input data. Each of the ten zones are further subdivided into ten 
smaller subdivisions through which the impurity level change is computed Trom

$$
\begin{aligned}
& {\left[\mathrm{H}_{2} \mathrm{O}\right]_{i+1}=\left[\mathrm{H}_{2} \mathrm{O}\right]_{i}-\mathrm{R}_{i} \pi \alpha \Delta \mathrm{z} / \mathrm{Q}_{i},} \\
& {\left[\mathrm{H}_{2} \mathrm{O}\right]_{i+1}=\left[\mathrm{H}_{2}\right]_{i}+\mathrm{R}_{i} \pi d \Delta \mathrm{z} / \mathrm{Q}_{i},}
\end{aligned}
$$

where

$$
\begin{aligned}
\mathrm{R}_{i}\left(\mathrm{~mol} / \mathrm{cm}^{2}-\mathrm{sec}\right)= & \text { the reaction rate at the temperaturc opecified } \\
& \text { for the zone, } \\
\mathrm{a}= & \text { the rnnlant channcl diameler, } \\
\Delta \mathrm{z}= & \text { the incremental length, usually taken as } 8 \mathrm{~cm}, \\
\mathrm{Q}_{\dot{i}}= & \text { the volumetric flow computed for each zone from } \\
& \text { the specified coolant temperature and the mass } \\
& \text { flow rate. }
\end{aligned}
$$

Finally, the impurity levels at the inlet are needed, which are also specified as input.

Some typical TUBOX results are shown in Fig. 5.1. The graphite surface temperatures for earh of the tch axial zones are shown t'or an average channel from a region with approximately unity radial power factor. The mass coolant flow for such an average channel is $37.8 \mathrm{~g} / \mathrm{sec}$. The reaction rate, as computed using the Wicke rate equation [Eq. (15), in sect. 4] is seen to vary greatly in the coolant channel under the influence of the temperature variation. However, the partial pressure of $\mathrm{H}_{2} \mathrm{O}$, assumed here to be $10^{-3}$ atm at the inlet, changes very little. For this colculatiou, the reaction rate computed from Eq. (15) of the previous chapter has been reduced by the factor $1 / \sqrt{P_{T}}$, where $P_{T}$ is the total pressure in the coolant channel of $49 \mathrm{~atm}$. This correction is required because the original equation pertains to conditions at $I$ atm, at which rates are higher. The theoretical basis for the correction, which is given in a number of reviews (e.g., Walker et $a{ }^{3}{ }^{3}$ ) rests on the idealized assumption that gas-phase diffusion within the graphite pores controls the total reaction rate. This results in the prediction that the observed reaction rate is proportional to the square root of the effective diffusivity of $\mathrm{H}_{2} \mathrm{O}$ in helium. The final form of the corrective factor is obtained by noting that gas 


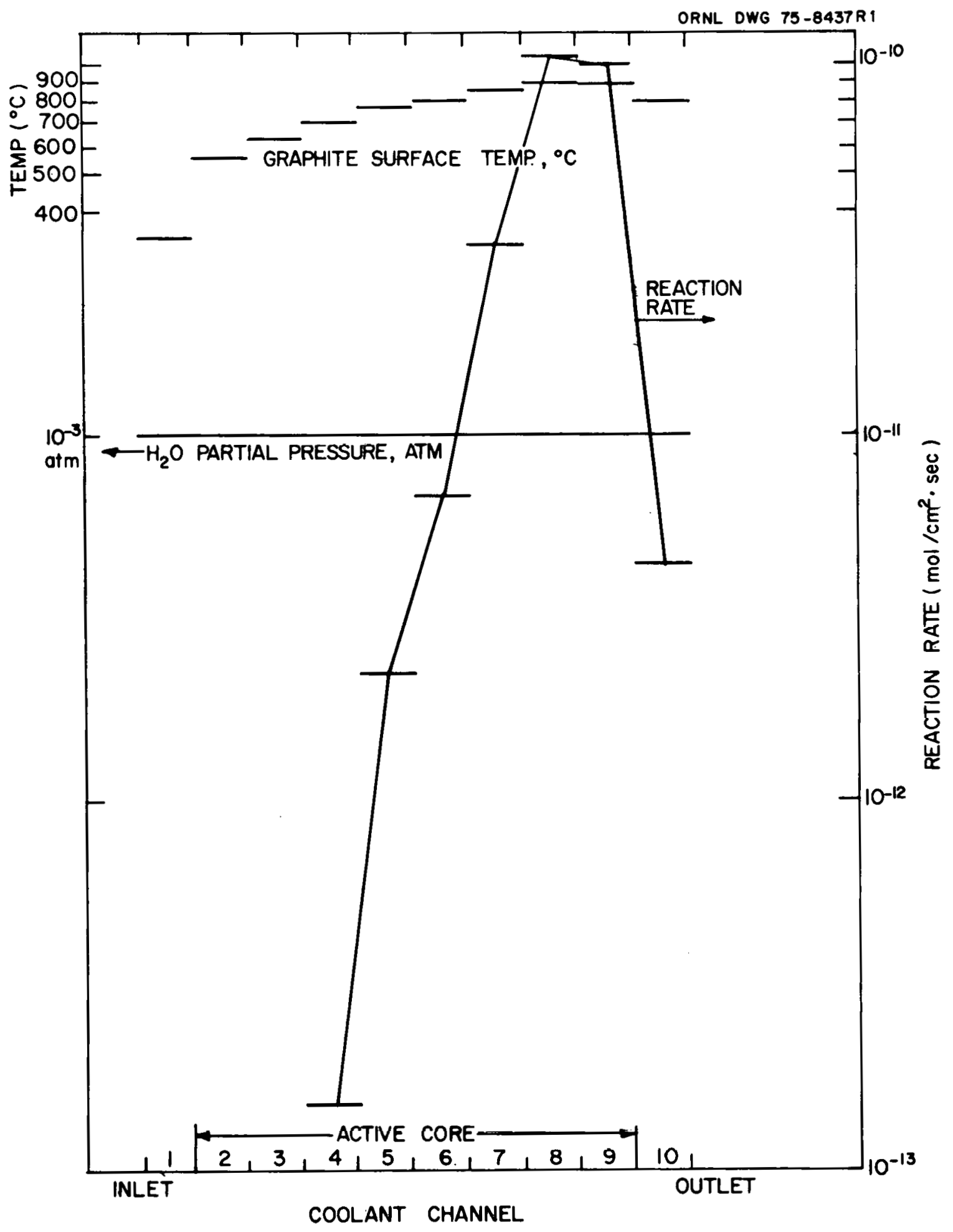

Fig. 5.1. Typical variation of $\mathrm{H}_{2} \mathrm{O}$ partial pressure and reaction rate in a coolant channel computed from TUBOX. 
phase diffusion coefficients vary approximately inversely with total pressure.

Results similar to those shown in Fig. 5.1 were obtained for a high power factor channel, where both the graphite temperatures and mass flows are higher, and also for the lowest radial power factors channels, where mass flows drop to $15.1 \mathrm{~g} / \mathrm{sec}$. We therefore conclude that the calculational simplification afforded by treating the primary system as a mixed pot for the purpose of determining the corrosive environment in the vicinity of the core support posts is valid.

\subsection{Impurity Concentrations Using Core Reactivity to Steam} Corrosion Derived from Dragon Steam Ingress Datia.

In the years 1966 through 1968, a series of impurity addition experiments, described by Carlyle and Kinsey, ${ }^{4}$ was conducted at the Dragon Reactor. The first of these was a series of four $\mathrm{H}_{2} \mathrm{O}$ additions at a rate of 2 to $3 \mathrm{~g} / \mathrm{hr}$, each extending for approximately $30 \mathrm{hr}$. Experimental conditions varied somewhat during the course of the experiments; however, the concentrations of $\mathrm{H}_{2} \mathrm{O}$ and reaction products began to level out about $12 \mathrm{hrs}$ after initiation of the experiment. Though the impurity levels ald not appear to be completely equilibrated in the 30-hr test duration, we will use the reported concentrations at the end of injection as an indicator of core reactivity to the steam corrosion reaction. Subsequently, by comparing Dragon and HIIGR primary loop sonditions, we ran ohtain a sorresponding reactivity of an HTGR core from which HTGR impurity levels will be estimated.

\subsubsection{Results of Dragon steam ingrcss experiments}

The results of four Dragon steam ingress runs are shown in Table 5.1 together with normal impurity levels experienced with no steam addition. 4 With no deliberate steam addition, the $\mathrm{H}_{2} \mathrm{O}$ concentration is measurable, but small; the $\mathrm{H}_{2}$ level is $\sim 1.4 \mathrm{vpm}$, somewhat higher than the normal $\mathrm{CO}$ level of $\sim 0.75 \mathrm{vpm}$. With $\mathrm{H}_{2} \mathrm{O}$ added deliberately, the sum of hydrogen content of the hydrogen bearing species,

$$
\Sigma[\mathrm{H}]=2\left[\mathrm{H}_{2} \mathrm{O}\right]+2\left[\mathrm{H}_{2}\right]+4\left[\mathrm{CH}_{4}\right]
$$


Table 5.1. Steady-state impurity levels established during Dragon steam ingress experinents, and normal impurity levels with zero ingress

\begin{tabular}{|c|c|c|c|c|c|c|c|c|c|}
\hline & \multirow{2}{*}{$\begin{array}{c}\text { Injection } \\
\text { rate } \\
\left(\frac{\mathrm{mol}}{\mathrm{hr}}\right)\end{array}$} & \multirow{2}{*}{$\begin{array}{l}\text { Purification } \\
\text { flow } \\
\left(\frac{g}{\sec }\right)\end{array}$} & \multicolumn{5}{|c|}{$\begin{array}{l}\text { Equilibrium concentrations } \\
\text { (vpm) }\end{array}$} & \multirow{2}{*}{$\begin{array}{l}\Sigma[\mathrm{H}] \\
(\mathrm{vpm})\end{array}$} & \multirow{2}{*}{$\begin{array}{l}\Sigma[0] \\
(v p m)\end{array}$} \\
\hline & & & $\overline{\mathrm{H}_{2} \mathrm{O}}$ & $\mathrm{H}_{2}$ & $\mathrm{CO}$ & $\mathrm{CO}_{2}$ & $\mathrm{CH}_{4}$ & & \\
\hline 1 & 0.153 & 9.0 & 6.0 & 6.3 & 2.37 & 0.91 & 0.38 & 26.1 & 8.19 \\
\hline 2 & 0.172 & 11.0 & 3.2 & 7.6 & 3.5 & 1.3 & 0.21 & 22.1 & 9.30 \\
\hline 3 & 0.172 & 7.5 & 4.2 & 13.1 & 7.0 & 2.1 & 0.45 & 36.4 & .15 .4 \\
\hline 4 & 0.122 & 7.0 & 3.6 & 7.3 & 5.7 & 1.5 & 0.35 & 23.2 & 12.3 \\
\hline- & 0 & (nominal) & $\sim 0.075$ & $\sim 1.4$ & $\sim 0.75$ & $\sim 0.02$ & $\sim 0.15$ & & \\
\hline
\end{tabular}


shown in the next to last column, is approximately twice the sum of oxygen in the oxygen bearing species, $\Sigma[0]$. This is as it should be since $H$ and 0 are added in this ratio. This feature lends some confidence in the reported results.

\subsubsection{Interpretation of Dragon steam ingress results}

In order to interpret the Dragon steam ingress data in terms of an effective core reactivity, we will assume that a first order reaction occurs between the core graphite and steam, forming $\mathrm{CO}$ and $\mathrm{H}_{2}$ as primary products. The data of Table 5.1, however, show significant $\mathrm{CO}_{2}$ formation which necessitates some interpretation in order to arrive at a single effective core reactivity. The smaller quantity of $\mathrm{CH}_{4}$ produced will be neglected.

The rate of the steam/graphite reaction is assumed to be represented by the first order expression

$$
\mathrm{R}=\mathrm{K}_{\mathrm{C}}\left[\mathrm{H}_{2} \mathrm{O}\right] \text {, }
$$

wliere

$$
\begin{aligned}
\mathrm{R} & =\text { reaction rate, } \mathrm{mol} / \mathrm{sec}, \\
\mathrm{K}_{\mathrm{C}} & =\text { core reactivity, } \mathrm{cm}^{3} / \mathrm{sec}, \\
{\left[\mathrm{H}_{2} \mathrm{O}\right] } & =\mathrm{H}_{2} \mathrm{O} \text { concentration in the primary system, } \mathrm{mol} / \mathrm{cm}^{3} .
\end{aligned}
$$

Thus, since $\mathrm{W} \mathrm{mol} / \mathrm{sec}$ of $\mathrm{H}_{2} \mathrm{O}$ enter the primary system and $\mathrm{Q}_{\mathrm{p}} \cdot\left[\mathrm{H}_{2} \mathrm{O}\right]$ leave, where $Q_{p}$ is the purification flow as $\mathrm{cm}^{3} / \mathrm{sec}$, we obtain the equilibrium $\mathrm{H}_{2} \mathrm{U}$ Level by a mass balance,

$$
\left[\mathrm{H}_{2} \mathrm{O}\right]=\frac{\mathrm{W}}{\mathrm{K}_{\mathrm{c}}+\mathrm{Q}_{\mathrm{p}}} \text {. }
$$

The concentration of any consitituent not altered by its residence in the core may be obtained from Eq. (4) with $\mathrm{K}_{\mathrm{c}}$ set, equal to zero; for example,

$$
\begin{aligned}
& \Sigma[0]=\frac{W}{Q_{p}} \text {, and } \\
& \Sigma[H]=\frac{2 W}{Q_{p}} .
\end{aligned}
$$


Rearranging Eq. (4) to solve for the core reactivity yields

$$
\mathrm{K}_{\mathrm{c}}=\frac{\mathrm{W}-\mathrm{Q}_{\mathrm{p}}\left[\mathrm{H}_{2} \mathrm{O}\right]}{\left[\mathrm{H}_{2} \mathrm{O}\right]} \text {. }
$$

Similarly, a mass balance for $\mathrm{H}_{2}$ yields the following, assuming $\mathrm{H}_{2}$ formation only from the reaction of steam with graphite,

$$
\left[\mathrm{H}_{2}\right]=\frac{\mathrm{K}_{\mathrm{c}}}{\mathrm{Q}_{\mathrm{p}}} \frac{\mathrm{W}}{\mathrm{K}_{\mathrm{c}}+\mathrm{Q}_{\mathrm{p}}} \text {. }
$$

Again, rearranging $\mathrm{Eq}$. (6) to solve for the core reactivity yields

$$
\mathrm{K}_{\mathrm{c}}=\frac{\mathrm{Q}_{\mathrm{p}}^{2}\left[\mathrm{H}_{2}\right]}{\mathrm{W}-\mathrm{Q}_{\mathrm{p}}\left[\mathrm{H}_{2}\right]} \text {. }
$$

We have assumed a highly simplified model in order to interpret the Dragon steam ingress data in terms of a single value for the core reactivity. However, the corrosion reaction is not first order as assumed here, and at least three constants are needed to specify the reaction rate. Additionally, the significant amounts of $\mathrm{CO}_{2}$ which show up indicate that reactions other then the assumed steam/graphite corrosion reaction takes place. Nevertheless, the small number and the uncertain precision of the data do not warrant the inclusion of these secondary considerations.

Effective inleakage rate. Table 5.2 illustrates one of the uncertainties in the interpretation of the Dragon steam inleakage data. Columns I and 2 record inleakage and purification flows given in Table 5.2 in new units, the volumetric purification flow being calculated from the mass flows of Table 5.1, assuming a mixed-mean primary loop temperature of $593^{\circ} \mathrm{C}$. [Dragon primary loop characteristics pertinent to this section are given in Table 5.5.] The third and fourth columns of Table 5.2 list the anticipated levels of the total oxygen and hydrogen-bearing species corresponding to the given values for $W$ and $Q_{p}$ calculated using Eqs. ( $4 a$ ) and ( $4 b$ ). Columns 5 and 6 record the corresponding measured values from Table 5.1, while the last two columns list the ratios of measured to expected values.

Note that for all cases, the measured value is less than the anticipated value for both oxygen and hydrogen bearing species. Several possible explanations for this observation follow: 
Table 5.2. Comparison of measured to anticipated impurity levels in the Dragon steam ingress experiment

\begin{tabular}{|c|c|c|c|c|c|c|c|}
\hline \multirow{2}{*}{$\left(\begin{array}{c}\mathrm{W} \\
\left(\frac{\mathrm{mol}}{\mathrm{sec}}\right)\end{array}\right.$} & \multirow{2}{*}{$\begin{array}{c}\mathrm{Q}_{\mathrm{p}} \\
\left(\frac{\mathrm{cm}^{3}}{\mathrm{sec}}\right)\end{array}$} & \multicolumn{2}{|c|}{ Anticipated } & \multicolumn{2}{|c|}{ Measured } & \\
\hline & & $\begin{array}{r}\Sigma[0] \\
(\mathrm{vpm})\end{array}$ & $\begin{array}{c}\Sigma[\mathrm{H}] \\
(\mathrm{vpm})\end{array}$ & $\begin{array}{r}\bar{\Sigma}[0] \\
(\mathrm{vpm})\end{array}$ & $\begin{array}{r}\Sigma[\mathrm{H}] \\
(\mathrm{vpm})\end{array}$ & $\begin{array}{c}\text { anti } \\
\Sigma[0]\end{array}$ & $\Sigma[\mathrm{H}]$ \\
\hline $4.25 \mathrm{E}-5$ & 8000 & 18.9 & 37.8 & 8.19 & 26.1 & 0.433 & 0.690 \\
\hline $4.78 \mathrm{E}-5$ & 9740 & 17.9 & 35.8 & 9.30 & 22.1 & 0.520 & 0.617 \\
\hline $4.78 \mathrm{E}-5$ & 6660 & 25.5 & 51.0 & 15.4 & 36.4 & 0.604 & 0.714 \\
\hline $3.39 \mathrm{E}-5$ & 6220 & 19.4 & 38.7 & 12.3 & 23.2 & 0.634 & 0.599 \\
\hline & & & & & $\mathrm{Av}$ & 0.548 & 0.655 \\
\hline
\end{tabular}

(1) A higher purification flow than recorded by Carlyle and Kinsey ${ }^{4}$ could account for the ouserved discrepancy. For example, if the normal fuel element purge flow ${ }^{2}$ of $7 \mathrm{~g} /$ sec were occurring and not included as a part of the effective stated purification flow as it should have been, the correction for this hypothesized oversight would bring the anticipated and measured impurlty levels into closer agreement.

(2) A large portion of the injected $\mathrm{H}_{2} \mathrm{O}$ may have been adsorbed in various locations in the primary system and, hence, contributed nothing to the impurity atmosphere. Indeed this is judged to be likely for a large scale experiment such as this; in fact, this is the explanation of the discrepancy put forth by Carlyle and Kinsey.

(3) Carlyle and Kinsey discuss other conceivable sources of error which may result from the analytical methods employed, such as errors in the reported concentrations obtained by gas chromatograph. Errors of this type may account for sume scatter but cannot account for the generally low values of impurity levels while maintaining the proper $\mathrm{H} / \mathrm{O}$ ratio. 
Thus, the second explanation is regarded as most likely. If we presume the lost portion of the injected water to be permanently adsorbed, we may simply subtract this portion from the stated ingress flow for the production of the observed gaseous corrosion products. Thus, the effective ingress flows listed below in Table 5.3 are $60.2 \%$ of those listed in Tables 5.1 and 5.2 (average of 54.8 and $65.5 \%$ ).

Table 5.3. Revised Dragon steam ingress data

\begin{tabular}{ccccc}
\hline $\begin{array}{c}\mathrm{H}_{2} \mathrm{O} \\
\text { ingress } \\
\begin{array}{c}\text { rate } \\
\left(\frac{\mathrm{mol}}{\mathrm{sec}}\right)\end{array}\end{array}$ & $\begin{array}{c}\text { Purification } \\
\text { flow } \\
\left(\frac{\mathrm{cm}^{3}}{\mathrm{sec}}\right)\end{array}$ & $\begin{array}{c}\mathrm{H}_{2} \mathrm{O} \\
(\mathrm{vpm})\end{array}$ & $\begin{array}{c}\text { Revised } \\
(\mathrm{vpm})\end{array}$ & $\begin{array}{c}\mathrm{H} \text { impurity levels } \\
\text { (vpm) }\end{array}$ \\
\hline $2.57 \mathrm{E}-5^{\mathrm{a}}$ & 8000 & 6.91 & 5.39 & 3.28 \\
$2.89 \mathrm{E}-5$ & 9740 & 4.3 & 6.3 & 4.8 \\
$2.89 \mathrm{E}-5$ & 6660 & 6.3 & 11.0 & 9.1 \\
$2.05 \mathrm{E}-5$ & 6220 & 5.1 & 5.8 & 7.2 \\
\hline
\end{tabular}

This notation signifies $2.57 \times 10^{-5}$.

Method of accounting for the $\mathrm{CO}_{2}$ production. The question arises on how to incorporate $\mathrm{CO}_{2}$ production into this simple framework which presumes a single value for the core reactivity for the reaction of graphite with $\mathrm{H}_{2} \mathrm{O}$ to form $\mathrm{CO}$ and $\mathrm{H}_{2}$. As seen in Table 5.1, significant amounts of $\mathrm{CO}_{2}$ were produced in the Dragon Experiments, evidently from the radiationcatalyzed shift reaction taking place in the gas phase, probably in the cooler portions of the primary loop.

$$
\mathrm{H}_{2} \mathrm{O}+\mathrm{CO} \rightarrow \mathrm{CO}_{2}+\mathrm{H}_{2} \text {. }
$$

Carbon dioxide is unstable at low partial pressures above $\sim 500^{\circ} \mathrm{C}$; hence, we expect the reverse of Eq. (8) to occur in hot zones. The net effect of the forward shift reaction is to replace $\mathrm{H}_{2} \mathrm{O}$ and $\mathrm{CO}$ with an equal amount of 00,2 and $H_{2}$ 
It is generally accepted that the thermally activated corrosive effect of $\mathrm{CO}_{2}$ on graphite via

$$
\mathrm{CO}_{2}+\mathrm{C} \rightarrow 2 \mathrm{CO}
$$

is slower than the corresponding reaction of $\mathrm{H}_{2} \mathrm{O}$. Clark et al. ${ }^{5}$ state that the steam-graphite reaction is about three times more rapid than the corresponding reaction with $\mathrm{CO}_{2}$. Wicke et al. ${ }^{6}$ report that for crushed, type $\mathrm{G}_{4}$ graphite, the corrosion rate with $\mathrm{H}_{2} \mathrm{O}$ was 6.4 times that for $\mathrm{CO}_{2}$ at $1000^{\circ} \mathrm{C}$ and $20 \mathrm{~atm}$ total pressure, with an impurity composition of $30 \mathrm{vpm}$ $\mathrm{CO}_{2}$, 20 vpm $\mathrm{H}_{7} \mathrm{U}$, $300 \mathrm{Vpm} \mathrm{CO}$, and 200 vpm $\mathrm{H}_{2}$. Wicke also observed that the rate of' the $\mathrm{H}_{2} \mathrm{O}$-graphite reaction is not markedly effected by the presence of $\mathrm{CO}_{2}$.

While the $\mathrm{CO}_{2}$-graphite thermal reaction is inherently slower than the $\mathrm{H}_{2} \mathrm{O}$-graphite reaction by approximately a factor of 5 , there is evidence that radiation enhances the corrosive effect of $\mathrm{CO}_{2}$ to a far greater degree then $\mathrm{H}_{2} \mathrm{O}$. Giberson and Tingey ${ }^{7}$ assume a G-value for the reaction of $\mathrm{CO}_{2}$ with graphite which is about four times the value for the $\mathrm{H}_{2} \mathrm{O}$ reaction: 1.35 molecules/100 ev for the $\mathrm{CO}_{3}+\mathrm{C}$ reaction, compared with 0.35 for $\mathrm{H}_{2} \mathrm{O}$.

In an HTGR coolant environment, radioactive energy is absorbed directly, primarily by the preponderant helium atoms which are thus driven into a variety of excited states. 7,8 These excited helium atoms then transmit their excitation energy either to impurity atoms, nonexcited helium atoms, or adjacent solid material. Evidently, radiolytic decomposition of $\mathrm{CO}_{2}$ to $\mathrm{CO}$ and highly reactive oxygen orsurs at a signifioant ratc, wheress the corresponding radiolysis of $\mathrm{H}_{2} \mathrm{O}$ occurs to a much lesser degree. 8 Therefore, there is good reason to anticipate radiolytic enhancement for the $\mathrm{CO}_{2}+\mathrm{C}$ redutions to a much greater degree than for $\mathrm{H}_{2} \mathrm{O}+\mathrm{C}$.

This is indicated to be the case for data reported by Everett et al., 8 who show an enormous enhancement by radiation for $\mathrm{CO}_{2}$ corrosion - a factor of 100 at $800^{\circ} \mathrm{C}$ and a factor of 10 at $900^{\circ} \mathrm{C}$ - compared with more modest enhancements for $\mathrm{H}_{2} \mathrm{O}$. Thus, it appears that at least approximately irradiative enhancement tends to equalize the corrosive effect of $\mathrm{CO}_{2}$ and $\mathrm{H}_{2} \mathrm{O}$ on core graphite. 
The shift reaction also substitutes $\mathrm{H}_{2}$ for an equal amount of $\mathrm{CO}$. Both of these are corrosion products which therefore may be expected to inhibit the corrosion reaction; however, there is some disagreement on this point. Of the four kinetics studies summarized in sect. 4.2 that were extensive enough to allow development of a kinetics equation, only one explicitly incorporates $\mathrm{CO}$ as an inhibitor. That one study, reported by Wicke et al., 9 seems to be the most extensive and careful $\mathrm{H}_{2} \mathrm{O}$-graphite experiment undertaken. In this study, the subject of co inhibition was explored explicitly in a series of runs at $1030^{\circ} \mathrm{C}$ and $1000-v p m \mathrm{H}_{2} \mathrm{O}$ in. which the $\mathrm{CO}$ and $\mathrm{H}_{2}$ inlet concentrations were varied separately. The conclusion was that both $\mathrm{CO}$ and $\mathrm{H}_{2}$ are intrinsically inhibitory to approximately the same degree. M. R. Everett et al. ${ }^{10}$ concurred with this conclusion after examining the same data.

Summarizing then, the effect of the gas phase shift reaction is to substitute $\mathrm{CO}_{2}$ for an equal amount of $\mathrm{H}_{2} \mathrm{O}$, both of which have approximately equivalent corrosive effect on graphite in a radiation field. Additionally, $\mathrm{H}_{2}$ is produced by the shift reaction, taking the place of an equal amount of $\mathrm{CO}$, and both species have an approximately equal inhibitory effect. Further, the shift reaction is most likely reversible, forming $\mathrm{H}_{2} \mathrm{O}$ and $\mathrm{CO}$ from $\mathrm{CO}_{2}$ and $\mathrm{H}_{2}$ in higher temperature areas where $\mathrm{CO}_{2}$ is not a thermodynamically stable species. Thus, since the shift reaction takes place in the gas phase and not with the graphite itself, and since its products have approximately equal corrosive and inhibition effects, we conclude that the most appropriate way to incorporate the shift reaction into our present simple framework is to computationally restore the products of this reaction by the original reactants.

\subsubsection{Estimated Dragon core reactivity}

Based on the discussion of the previous section, the data of Table 5.1 have been modified as indicated and presented in Table 5.3 . Steam ingress rates are $60.2 \%$ of the originally reported values, reflecting the estimated permanent loss of $39.8 \%$ of the injected moisture. The reported $\mathrm{CO}_{2}$ concentrations, presumed to arise from the gas phase shift reaction, plus an equal amount of $\mathrm{H}_{2}$ have been subtracted from the reported 
concentrations, and were redistributed as $\mathrm{H}_{2} \mathrm{O}$ and $\mathrm{CO}$. Thus, Table 5.3 reflects the situation if the shift reaction had not occurred. The smaller amounts of methane have been neglected.

Table 5.4 Iists the effective Dragon core reactivities to $\mathrm{H}_{2} \mathrm{O}$ corrosion based on these modified data. The values in column 2 are calculated from the $\mathrm{H}_{2} \mathrm{O}$ concentrations using $\mathrm{Eq}$. (5). Values listed in the last column are calculated from Eq. (7) using the average of the $\mathrm{H}_{2}$ and $\mathrm{CO}$ concentrations. The average reactivity calculated by each method is sufficiently close, so the eight values have been combined to vield an average core reactivity of $8610 \pm 2100 \mathrm{~cm}^{3} / \mathrm{sec}$.

Table 5.4. Dragon core reactivity to $\mathrm{H}_{2} \mathrm{O}$ corrosion

\begin{tabular}{|c|c|c|c|}
\hline $\begin{array}{c}\mathrm{H}_{2} \mathrm{O} \\
\text { concentration } \\
\left(\frac{\mathrm{mol}}{\mathrm{cm}^{3}}\right)\end{array}$ & $\begin{array}{c}\text { Core } \\
\text { reactivity } \\
\text { Eq. (5) } \\
\mathrm{K}_{\mathrm{c}} \\
\left(\frac{\mathrm{cm}^{3}}{\mathrm{sec}}\right)\end{array}$ & $\begin{array}{c}\text { Average } \mathrm{H}_{2} \text { and } \mathrm{CO} \\
\text { - concentration } \\
\left(\frac{\mathrm{mol}}{\mathrm{cm}^{3}}\right)\end{array}$ & $\begin{array}{c}\text { Core } \\
\text { reactivity } \\
\mathrm{Eq} \cdot(7) \\
\mathrm{K}_{\mathrm{c}} \\
\left(\frac{\mathrm{cm}^{3}}{\mathrm{sec}}\right)\end{array}$ \\
\hline $1.94 \mathrm{E}-9$ & 5250 & 1. $22 \mathrm{E}-\dot{y}$ & 4900 \\
\hline $1.21 \mathrm{E}-9$ & 9740 & $1.56 \mathrm{E}-9$ & 10800 \\
\hline $1.77 \mathrm{E}-9$ & 9670 & $2.84 \mathrm{E}-9$ & 12600 \\
\hline 1.43 E-9 & 8120 & $1.83 \mathrm{E}-9$ & 7770 \\
\hline & \multicolumn{2}{|c|}{$8190 \pm 1530$} & $9020 \pm 2680$ \\
\hline \multicolumn{4}{|c|}{ Average of 8 values: $K_{c}=8610 \pm 2100$} \\
\hline
\end{tabular}

\section{2 .4 HTGR core reactivity}

Since the $2000 \mathrm{MW}(t)$ HTGR core has about a factor of 100 larger surface area than Dragon, we expect a substantially larger core reactivity for the HTGR core. Partially tending to compensate for the larger core area is the higher coolant pressure and somewhat lower core average temperature of the HTGR, both of which tend to lower reactivity. 
We have defined the core reactivity, $\mathrm{K}_{\mathrm{c}}$, so that

$$
\mathrm{R}\left(\frac{\mathrm{mol}}{\mathrm{sec}}\right)=\mathrm{K}_{\mathrm{c}}\left[\mathrm{H}_{2} \mathrm{O}\right]
$$

where $R$ is the total core corrosion rate. On the other hand, kinetics equations based on tests conducted at 1 atm are written in the form,

$$
R\left(\frac{\mathrm{mol}}{\mathrm{cm}^{2} \cdot \mathrm{sec}}\right)=\frac{\mathrm{k}_{1} \cdot \exp \left(-\frac{\Delta \mathrm{H}}{\mathrm{RT}}\right) \cdot\left[\mathrm{H}_{2} \mathrm{O}\right]}{1+\Sigma \mathrm{k}_{i}[\mathrm{I}]_{i}}
$$

where $k_{1}$ is an intrinsic property of the graphite, and $k_{i}$ and [I] $i$ represent the various possible inhibition terms which are also temperature dependent, but to a lesser degree.

If the reaction rate were diffusion controlled, as virtually the entire corc is expected to be, the factor $I / \sqrt{P_{T}}$ is conventionally applied to allow for the variation of reaction rate with the total primary loop pressure, $P_{T}$. Thus from Eq. (II) and the definition of $\mathrm{K}_{\mathrm{c}}$, we obtain the following relationship between HTGR and Dragon core reactivities:

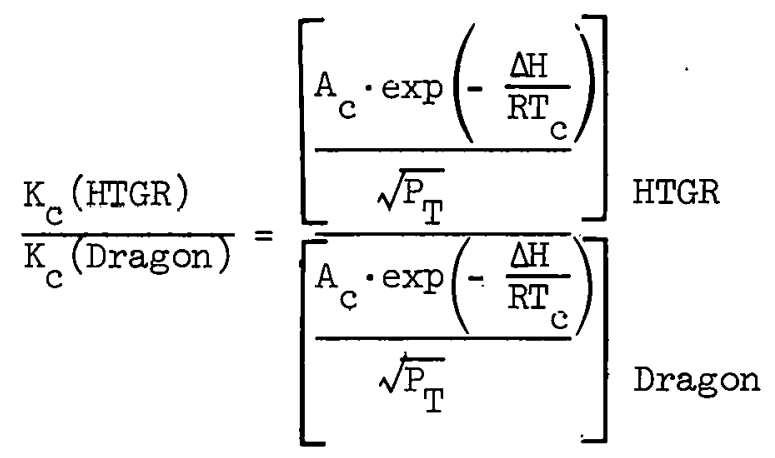

where approximately equivalent impurity levels resulting in approximately equal inhibition factors have been assumed, as well as approximately equal values for the intrinsic graphite reactivities, $k_{1}$. If the ratio of the intrinsic graphite reactivities were known, they should be used as a factor in Eq. (12). $A_{c}$ is the core surface area, and $T_{c}$ the average core surface temperature.

Table 5.5 lists the pertinent comparative characteristics of the Dragon and HTGR reactors needed to relate the estimated Dragon reactivity to the larger reactor. The HTGR data pertain to the $2000 \mathrm{MW}(\mathrm{t})$ reference 
reactor used for this study, and described in sect. 1.3. The Dragon data are taken from ref. 11 , and pertain to the core containing 37 elements designated as Mark VII.

Table 5.5. Comparison of Dragon and HTGR characteristics relating to core reactivities

\begin{tabular}{|c|c|c|}
\hline & $\begin{array}{c}\text { HTGR } \\
{[2000 \mathrm{MW}(\mathrm{t})]}\end{array}$ & Dragon \\
\hline Core surface area, $\mathrm{cm}^{2}$ & $9.57 \mathrm{E7}$ & 8.33 E5 \\
\hline \multicolumn{3}{|l|}{ Coolant temperatures, ${ }^{\circ} \mathrm{C}$} \\
\hline Inlet & 338 & 385 \\
\hline Outlet & 785 & 800 \\
\hline Coolant pressure, atm & 49 & 20 \\
\hline Average core heat flux, $\mathrm{W} / \mathrm{cm}^{2}$ & 19.6 & 24 \\
\hline Coolant Reynolds No. & 59,000 & $\sim 20,000$ \\
\hline $\begin{array}{l}\text { Average heat transfer coefficient, } \\
\text { BTU/hr-ft }-{ }^{\circ} \mathrm{F}\end{array}$ & 285 & 211 \\
\hline Average surface temperature, ${ }^{\circ} \mathrm{C}$ & 689 & 793 \\
\hline
\end{tabular}

The average core surface temperature given in the last line is computed from the average coolant temperature plus the surface temperature rise

$$
T_{c}=\frac{1}{2}\left(T_{\text {inlet }}+T_{\text {outlet }}\right)+\frac{\mathrm{g}_{\mathrm{W}}}{\mathrm{h}},
$$

where $q_{W}$ is the average surface heat flux and $h$ the average heat transfer coefficient: $\mathrm{T}_{C}$ for the HTGR is $103{ }^{\circ} \mathrm{C}$ lona than for Dragon.

Substituting the appropriate values into Eq. (12), and assuming $\Delta \mathrm{H}=50,000 \mathrm{cal} / \mathrm{mol}$ yields,

$$
\frac{K_{c}\left(H^{\prime} L^{\prime} G R\right)}{K_{C}(\text { Dragon })}=115 . \times 0.0799 \times 0.639=5.87 \text {, }
$$

where the first factor, 115, is the area ratio, the second factor results 
from the HTGR's cooler core, and the last factor results from the higher pressure of the HTGR. Therefore, using $K_{c}$ (Dragon) $=8610 \pm 2100 \mathrm{~cm}^{3} / \mathrm{sec}$, as derived in sect. 5.2.3, yields for the HTGR,

$$
\mathrm{K}_{\mathrm{c}}(\text { HTGR })=50,600 \pm 12,300 \mathrm{~cm}^{3} / \mathrm{sec} \text {. }
$$

5.2.5 Estimated HTGR impurity levels derived from Dragon steam ingress data

A value for the HTGR core reactivity of $50,600 \pm 12,300 \mathrm{~cm}^{3} / \mathrm{sec}$ was estimated in Sect. 5.2 .4 corresponding to a range between $K_{c, \max }=62,900$ and $K_{c, \min }=38,300$, roughly a factor of 2 . The uncertainties of this estimate are probably larger than indicated by this range, which is a result solely of scatter from the four experiments involving eight determinations. For example, there is uncertainty as to the relative intrinsic graphite reactivities that involve relative values of the constants $k_{1}$ in Eq. (II) between HTGR and Dragon graphite. Another source of uncertainty relates to the $40 \%$ of added moisture which was presumed "Iost" in the steam ingress experiment (i.e., did not produce detectable gaseous corrosion products):

We will express the impurity levels dependent on purification and assumed steam ingress as follows: The concentration of total oxygen-bearing species, $\left[\mathrm{O}_{\mathrm{T}}\right]$ may be obtained from $\mathrm{Eq}$. (4a),

$$
\left[\mathrm{O}_{\mathrm{T}}\right]_{\mathrm{vpm}}=10^{6} \cdot \frac{\mathrm{KT}}{\mathrm{P}_{\mathrm{T}}} \cdot \frac{\mathrm{W}}{\mathrm{Q}_{\mathrm{p}}} .
$$

The fraction of total oxygen-bearing species which exists as oxidant, $\mathrm{H}_{2} \mathrm{O}$, is obtained by dividing Eq. (4a) by Eq. (4),

$$
\frac{\left[\mathrm{H}_{2} \mathrm{O}\right]}{\left[\mathrm{O}_{\mathrm{T}}\right]}=\frac{\mathrm{Q}_{\mathrm{p}}}{\mathrm{K}_{\mathrm{c}}+\mathrm{Q}_{\mathrm{p}}} \text {. }
$$

Calculated levels of total oxygen, $\mathrm{H}_{2} \mathrm{O}$, CO, and $\mathrm{H}_{2}$ concentration for the reference HTGR are listed in Table 5.6 using the upper and lower estimates of core reactivity of 62,900 and $38,300 \mathrm{~cm}^{3} / \mathrm{sec}$. Cases I through 4 show the effect of varying ingress rate at the nominal purification flow, whereas in cases 5 through 8 the purification flow is varied from on-half to ten times the nominal value at a constant ingress of $0.01 \mathrm{~g} / \mathrm{sec}$ of 
Tajle 5.6. HTaR impurity levels at various assumed ingress flows and purification rates estimatec from Iragon steam ingress data

\begin{tabular}{|c|c|c|c|c|c|c|c|c|}
\hline & \multirow{2}{*}{$\begin{array}{l}\text { Steam } \\
\text { ingrass } \\
\text { rate } \\
\left(\frac{g}{\mathrm{sec}}\right)\end{array}$} & \multicolumn{2}{|c|}{$\begin{array}{l}\text { Purificatiom } \\
\text { rate }\end{array}$} & \multirow{2}{*}{$\begin{array}{c}\text { Total } \\
\text { cxygen } \\
\text { concentraticn } \\
\text { (vpm) }\end{array}$} & $\begin{array}{l}\mathrm{In} \\
\mathrm{K}_{\mathrm{c}}=6 \\
\end{array}$ & $\begin{array}{l}\text { ty concent } \\
0 \mathrm{~cm}^{3} / \mathrm{sec} \\
\end{array}$ & $\begin{array}{l}\text { ation } r \\
\mathrm{~K}_{e}=3\end{array}$ & $0 \mathrm{~cm}^{3} / \mathrm{sec}$ \\
\hline & & $\left(\frac{\mathrm{cm}^{3}}{\mathrm{sec}}\right)$ & $\frac{\text { assumeã }}{\text { nomnal }}$ & & $\frac{\left[\mathrm{H}_{2} \mathrm{O}\right]}{\left[\mathrm{O}_{\mathrm{T}}\right]}$ & $\frac{\left[\mathrm{H}_{2}\right]}{\left[\mathrm{O}_{\mathrm{T}}\right]}$ & $\frac{\left[\mathrm{H}_{2} \mathrm{O}\right]}{\left[\mathrm{D}_{T}\right]}$ & $\frac{\left[\mathrm{H}_{2}\right]}{\left[\mathrm{O}_{\mathrm{T}}\right]}$ \\
\hline 1 & 0.001 & 91,300 & $=$ & C. 85 & 0.592 & 0.408 & 0.704 & 0.296 \\
\hline 2 & 0.01 & & 1 & $\varepsilon .5$ & & 1 & 1 & 1 \\
\hline 3 & 0.1 & & & 85.0 & & & & \\
\hline 4 & 1.0 & 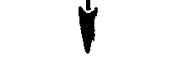 & 1 & $85 C .0$ & & 1 & 1 & $y$ \\
\hline 5 & 0.01 & 45,500 & $1 / 2$ & 17.0 & 0.420 & 0.580 & 0.544 & 0.456 \\
\hline 6 & 1 & 91,300 & 1 & 8.5 & 0.592 & 0.408 & 0.704 & 0.296 \\
\hline 7 & & 365,200 & $L$ & 2.1 & 0.853 & 0.147 & 0.305 & 0.095 \\
\hline 8 & $\hat{y}$ & 913,000 & כיבו & 0.85 & 0.936 & 0.064 & 0.960 & 0.040 \\
\hline
\end{tabular}


moisture. These values are plotted in Figs. 5.2 and 5.3. Figure 5.2 and Table 5.6 show that at the nominal purification flow, about $65 \%$ of the incoming moisture remains as $\mathrm{H}_{2} \mathrm{O}$ at equilibrium. A feature of the simple, first-order model assumed in this section is that this percentage remains comstant with varying assumed rates of ingress, which is not the case in the following section.

Figure 5.2 shows the effect of changing purification flow at a constant ingress rate of $0.01 \mathrm{~g} / \mathrm{sec}$. Note that inhibitors, $\mathrm{H}_{2}$ and $\mathrm{CO}$, diminish in level as well as oxidant with.increasing purification rate. Hènce, it is not possible to categorically state that modest increases in purification flow will always tend to protect the core posts from steam corrosion.

\section{5:3 Impurity Concentrations Using TIMOX}

TIMOX is a program used to compute transient and steady state values of $\mathrm{H}_{2} \mathrm{O}, \mathrm{H}_{2}$, and $\mathrm{CO}$ concentrations which result from assumed, steady rates of steam ingress into the primary system. The general features of the program are illustrated in Fig. 5.4. Initially, concentrations of $\mathrm{H}_{2} \mathrm{O}$, $\mathrm{H}_{2}$, and $\mathrm{CO}$ are set to zero, at which time a steady steam ingress rate of $\mathrm{W}$ (mol/sec) is assumed to begin. The incoming steam mixes thoroughly with the primary system coolant and reacts with the core graphite in each zone at a rate specified by the assumed kinetics equation, the exposed surface area of the zone, and its characteristic temperature. The products of corrosion are also assumed to be well mixed and removed with $\mathrm{H}_{2} \mathrm{O}$ in the purification flow, $Q_{p}$. The new concentrations of $\mathrm{H}_{2} \mathrm{O}$ and $\mathrm{H}_{2}$ or $\mathrm{CO}$ at the lapse of a time increment $\delta t$ are determined from

$$
\begin{aligned}
& {\left[\mathrm{H}_{2} \mathrm{O}\right]_{i+1}=\left[\mathrm{H}_{2} \mathrm{O}\right]_{i}+\left(\frac{\mathrm{W}-\mathrm{R}-\mathrm{Q}_{\mathrm{p}}\left[\mathrm{H}_{2} \mathrm{O}\right]_{i}}{V}\right) \delta t,} \\
& {\left[\mathrm{H}_{2}\right]_{i+1}=\left[\mathrm{H}_{2}\right]_{i}+\left(\frac{\mathrm{R}-\mathrm{Q}_{\mathrm{p}}\left[\mathrm{H}_{2}\right]_{i}}{\mathrm{~V}}\right) \delta t,}
\end{aligned}
$$

where $R$ is the total reaction rate computed for the four zones, and $V$ is the primary s.ystem volume. Concentration changes of $\mathrm{H}_{2} \mathrm{O}, \mathrm{H}_{2}$, and $\mathrm{CO}$ are influenced by the steam ingress flow, varying reaction rate with the 


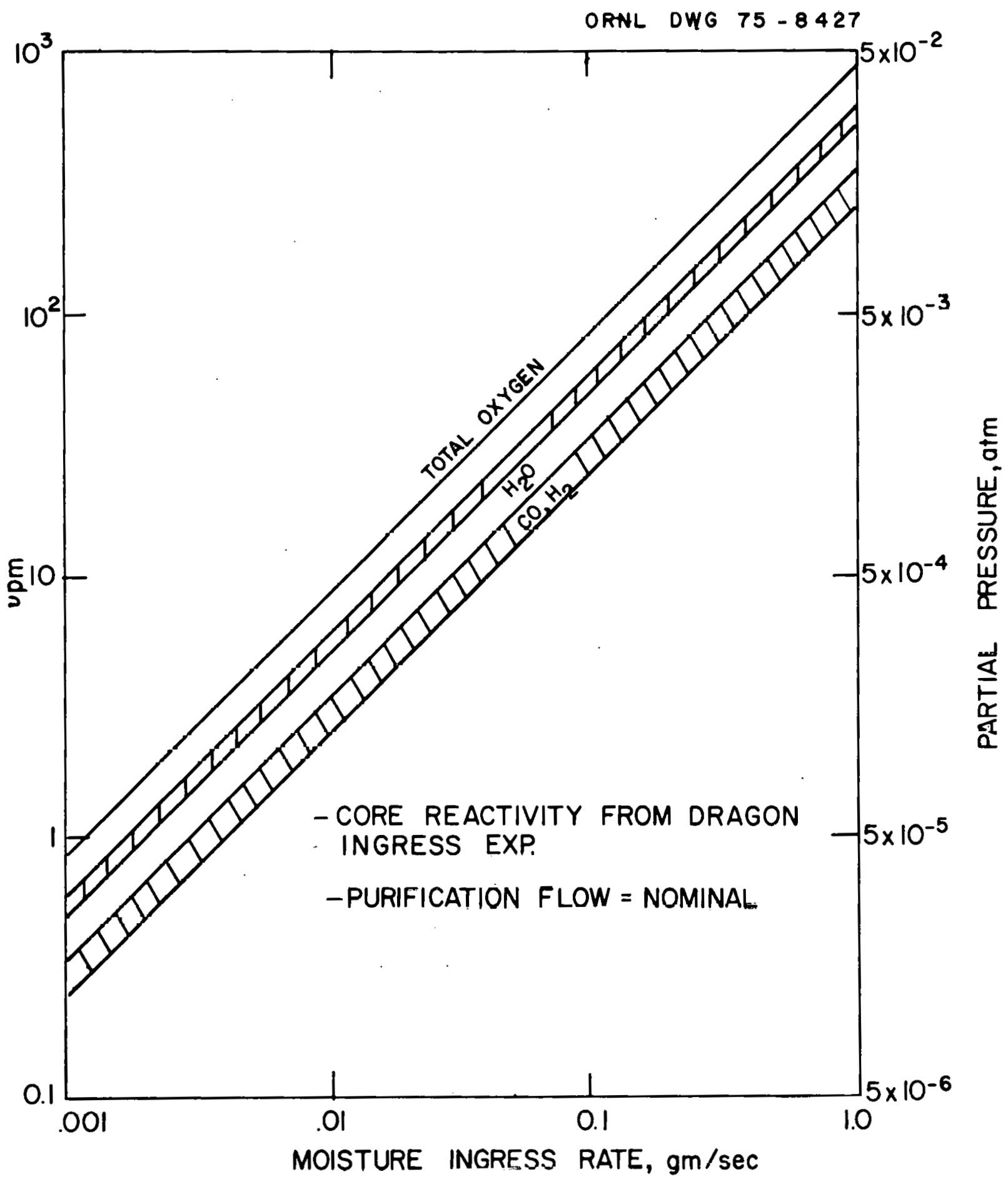

Fig. 5.2. Impurity levels vs $\mathrm{H}_{2} \mathrm{O}$ ingress rate. 


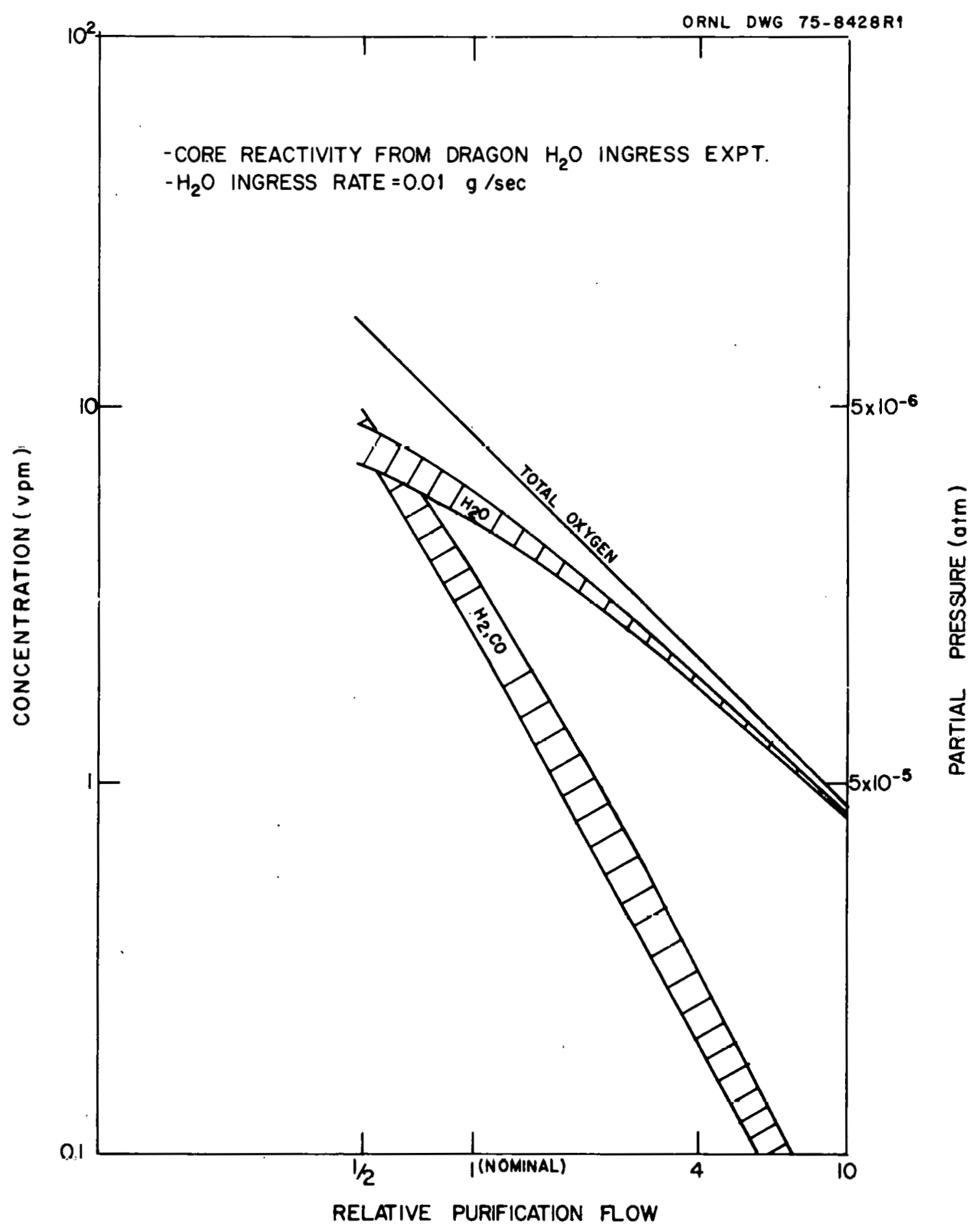

Fig. 5.3. Impurity level vs purification flow. 
ORNL DWG 75-8438

PURIFICATION FLOW

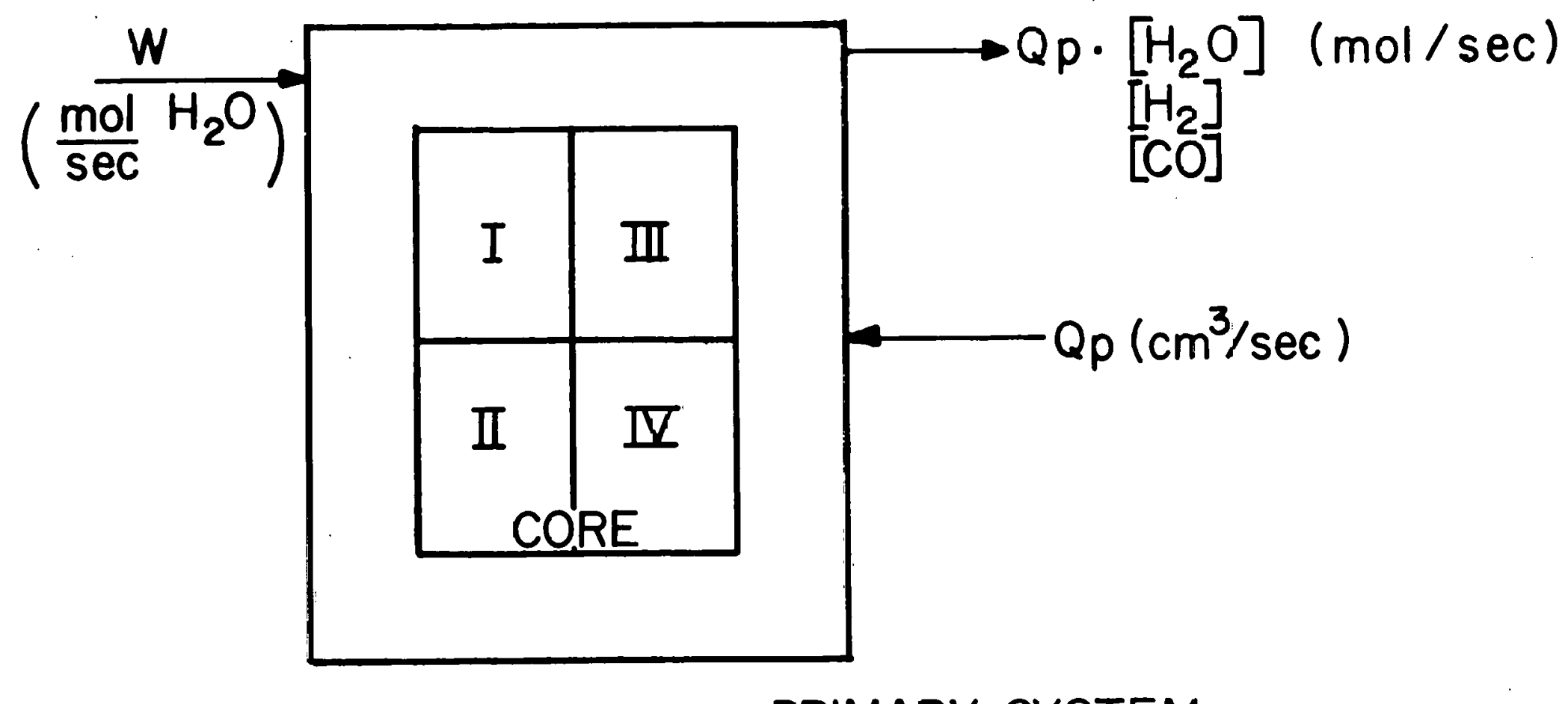

PRIMARY SYSTEM

Fig. 5.4. Schematic diagram of TIMOX. 
graphite, and varying removal rate with the purification flow. When both the $\mathrm{H}_{2} \mathrm{O}$ and total oxygen gains and losses differ by less than $0.1 \%$, the program is terminated and the steady state values are printed.

The transient concentrations, reaction rates, and removal rates with the purification flow of $\mathrm{H}_{2} \mathrm{O}, \mathrm{CO}$, and $\mathrm{H}_{2}$ are stored and may be plotted as time if desired.

\subsubsection{Primary system parameters used in TIMOX}

Primary system parameters used are those given in Table 1.1 describing the reference reactor assumed for this study.

Pressure correction for the corrosion rate expressions. The program may be run with any presumed corrosion rate equation modified to yield a rate in terms of moles per exposed surface area per unit time. There may be simultaneous input for three such expressions, and the three cases are carried along in parallel. Present results are based on the Wicke, OXIDE-3, and Giberson rate expressions, given in Eqs. (15), (17), and (18), in Sect. 4.2, each adjusted to account for the high pressure HTGR environment relative to the 1 atm conditions on which these expressions are based. The commonly accepted form of this pressure correction is an inverse dependence on the square root of the total pressure; that is, HTGR primary system corrosion rates are expected to be about a. factor of " Lower than predicted by correlations based on 1 atm.

A number of review articles (e.g., ret. 3) describe the highly idealized model of graphite corrosion which leads to an inverse square root dependency on pressure. To arrive at this result, it is assumed that the distribution of $\mathrm{H}_{2} \mathrm{O}$ within the graphite is governed by an effective diffusion coefficient for $\mathrm{H}_{2} \mathrm{O}$, and a volumetric loss rate to the corrosion reaction proportional to the $\mathrm{H}_{2} \mathrm{O}$ concentration. These two assumptions lead to

$$
R_{s}\left(\frac{m o l}{c m^{2}-h r}\right)=\sim \sqrt{D_{e f f}} .
$$

One then further assumes that the oxidant is transported via diffusion in the graphite void spaces, and employs the theoretical prediction that gas 
phase diffusivity varies inversely with total pressure. This leads to the stated result,

$$
\mathrm{R}_{\mathrm{s}}\left(\frac{\mathrm{mol}}{\mathrm{cm}^{2}-\mathrm{hr}}\right)=\sim \frac{I}{\sqrt{\mathrm{P}_{\mathrm{T}}}} .
$$

In view of this simplified picture, perhaps it is surprising that observed corrosion rates do vary with total pressure almost as indicated above. This treatment not only drastically simplifies the observed nonlinear dependency of rate with oxidant concentration, but also ignores inhibition effects of $\mathrm{CO}$ and $\mathrm{H}_{2}$, transport of $\mathrm{CO}$ and $\mathrm{H}_{2}$, and adsorptivity effects of reactant and products on graphite. Nevertheless, data exist which conform closely to the inverse square-root relationship; for example, Ashworth et al. ${ }^{12}$ state that results of one particular series of experiments conducted at $900^{\circ} \mathrm{C}$ were correlated by

$$
R_{S}=\sim P_{T}^{-0.62}
$$

This result is quite close to the highly theoretical Eq. (2I); neverthelèss, signiticicant errors are introduced when attempting to extrapolate predictions from 1 atm test data. For example, using Eq. (2l) to extrapolate from 1 atm to 49 atm leads to a corrosion rate which is $59 \%$ higher than an extrapolation based on Eq. (22).

Thus, TIMOX employs a pressure correction which probably tends to overestimate corrosion rates when extrapolating upward in pressure. However, since this correction was also applied to the estimated core supportpost rate of corrosion, errors thereby introduced would tend to concel each other. That is, a high estimate for the core graphite corrosion rate would yield a low-side value for the oxidant level, which in turn tends to be compensated by the corresponding high estimated core post corrosion rate.

The next sections describe the method of arriving at the characteristic temperatures for each of the four core zones.

Core graphite and coolant temperatures. The core temperatures used in this study were computed using the OXIDE-3 program for the $2000 \mathrm{MW}(t)$ case. OXIDE-3 divides the core into 20 temperature regions, each of 
which are made up of 10 fuel element rows. Thus a total of 200 temperatures specify the core temperature distribution. These 200 OXIDE-3 core zones are combined in TIMOX into four zones. The relationships between the TIMOX, OXIDE-3, and HTGR fueling zones are summarized in Table 5.7.

Three representative temperatures for each of the 200 OXIDE-3 locations are listed in Table 5.8. The top temperature of each group refers to the coolant, and the bottom value refers to the average temperature of the combined graphite and fuel stick material. These two values were taken from Barsell. ${ }^{13}$ The middle temperature of each set of three values in Table 5.7 represents the average graphite surface temperature at each indicated location, computed by using intraregion temperature distributions. ${ }^{14}$ Graphite surface temperature is here defined as the temperature representative of the radial sections 2 and 3 , referring to Fig. 5.5, which shows the cross-sectional detail used within OXIDE-3 to compute region average temperatures. ${ }^{13}$ sections $2-13$ represent the graphite moderator between the fuel (shown as sections 14-17) and the coolant channel, represented by section 1 .

From temperature distributions computed in ref. 14, it can be shown that the difference between the graphite surface temperature and the coolant temperature at that location is approximately 0.662 times the difference between the average graphite plus fuel stick temperature and the coolant; that is,

$$
T_{\text {surf }}-{ }^{T} T_{c o o l}=0.66 \%\left(T_{a v} \text { "graph" }-T_{c o o l}\right) \text {. }
$$

Since the OXIDE-3 program listings include $\mathrm{T}_{\mathrm{av}}$ "graph" and $\mathrm{T}_{\text {cool }}$, the graphite surface temperature may be calculated from Eq. (23).

Reaction-average region temperatures. Since the steam-graphite reaction is strongly temperature dependent - a $30^{\circ} \mathrm{C}$ temperature change alters the reaction rate by about a factor of 2 at $800^{\circ} \mathrm{C}$ - the question arises as to how to determine the appropriate characteristic temperature for each of the four TIMOX zones. A flat, space average will yield too low a value since the higher temperature regions, where a disproportionate part of the total reaclion takes place, must bc given added weight. 
Table 5.7. Relation between TIMOX and OXIDE-3 regions and $2000 \mathrm{MW}(t)$ HTGR refuelịng zones

\begin{tabular}{|c|c|c|}
\hline $\begin{array}{l}\text { TIMOX } \\
\text { region }\end{array}$ & $\begin{array}{l}\text { OXIDE-3 } \\
\text { region }\end{array}$ & $\begin{array}{l}2000 \mathrm{MW}(t) \text { HTGR } \\
\text { refueling zones }\end{array}$ \\
\hline & 1 & 3, 6 (without hottest column) \\
\hline$I$ & 2 & 3, 6 (hottest column) \\
\hline (Rows 1-5) & 3 & $3 b, 34$ \\
\hline & 4 & 13,19 \\
\hline II & 5 & 21,30 \\
\hline \multirow[t]{6}{*}{ (Rows 6-10) } & 6 & 23,32 \\
\hline & 7 & 42,48 \\
\hline & 8 & 50,53 \\
\hline & 9 & $4,7,9,15$ \\
\hline & 10 & 11,17 \\
\hline & 11 & 2,5 \\
\hline IIT & 12 & $1,43,49$ \\
\hline (Rows 1-5) & 13 & $26,28,35,37$ \\
\hline & $1 /$ & 24,33 \\
\hline IV & 15 & 20,29 \\
\hline \multirow[t]{5}{*}{ (Rows 6-10) } & 16 & $22,27,31,36$ \\
\hline & 17 & $10,16,39,41,45,117$ \\
\hline & 18 & $8,12,14,18$ \\
\hline & 19 & $40,46,52,55$ \\
\hline & 20 & $38,44,51,54$. \\
\hline
\end{tabular}


Table 5.8. Core colant, graphite-surface, and graphite average temperature (top, middle, and bottcon numbers, respectively) for the 20 OXIDE-3 regions and 10 fuel elements rows

\begin{tabular}{|c|c|c|c|c|c|c|c|c|c|c|}
\hline \multicolumn{5}{|l|}{$\begin{array}{l}\text { OXIDE-3 } \\
\text { region }\end{array}$} & \multicolumn{5}{|c|}{ OXIDE-3 region temps $\left({ }^{\circ} \mathrm{C}\right)$} & \multirow[b]{2}{*}{$\begin{array}{l}764.9 \\
764.6 \\
764.4\end{array}$} \\
\hline $\begin{array}{l}1 \\
1 \\
1\end{array}$ & $\begin{array}{l}338.0 \\
333.0 \\
338.0\end{array}$ & $\begin{array}{l}367.8 \\
525.4 \\
605.9\end{array}$ & $\begin{array}{l}425.7 \\
592.6 \\
677.9\end{array}$ & $\begin{array}{l}486.2 \\
655.9 \\
742.5\end{array}$ & $\begin{array}{l}548.2 \\
719.5 \\
807.0\end{array}$ & $\begin{array}{l}606.0 \\
752.3 \\
826.9\end{array}$ & $\begin{array}{l}658.9 \\
799.0 \\
870.5\end{array}$ & $\begin{array}{l}708.8 \\
837.5 \\
903.3\end{array}$ & $\begin{array}{l}749.5 \\
840.8 \\
887.4\end{array}$ & \\
\hline $\begin{array}{l}2 \\
2 \\
2\end{array}$ & $\begin{array}{l}338.0 \\
338.0 \\
338.0\end{array}$ & $\begin{array}{l}373.9 \\
569.6 \\
669.4\end{array}$ & $\begin{array}{l}44+.3 \\
652.5 \\
753.8\end{array}$ & $\begin{array}{l}519.9 \\
731.1 \\
839.4\end{array}$ & $\begin{array}{l}595.9 \\
820.5 \\
920.0\end{array}$ & $\begin{array}{l}668.4 \\
852.3 \\
946.2\end{array}$ & $\begin{array}{r}735.0 \\
911.2 \\
1001.2\end{array}$ & $\begin{array}{r}798.2 \\
960.3 \\
1043.0\end{array}$ & $\begin{array}{r}850.2 \\
966.1 \\
1025.3\end{array}$ & $\begin{array}{l}872.2 \\
874.4 \\
875.5\end{array}$ \\
\hline $\begin{array}{l}3 \\
3 \\
3\end{array}$ & $\begin{array}{l}338.0 \\
338.0 \\
338.0\end{array}$ & $\begin{array}{l}369.0 \\
532.3 \\
615.7\end{array}$ & $\begin{array}{l}429.3 \\
602.5 \\
690.9\end{array}$ & $\begin{array}{l}492.7 \\
668.7 \\
758.6\end{array}$ & $\begin{array}{l}557.5 \\
735.4 \\
826.3\end{array}$ & $\begin{array}{l}618.3 \\
770.2 \\
847.8\end{array}$ & $\begin{array}{l}673.8 \\
819.4 \\
893.7\end{array}$ & $\begin{array}{l}726.3 \\
860.1 \\
928.4\end{array}$ & $\begin{array}{l}769.2 \\
864.2 \\
912.8\end{array}$ & $\begin{array}{l}786.0 \\
786.0 \\
786.0\end{array}$ \\
\hline $\begin{array}{l}4 \\
4 \\
4\end{array}$ & $\begin{array}{l}338.0 \\
338.0 \\
338.0\end{array}$ & $\begin{array}{l}369.0 \\
531.7 \\
614.8\end{array}$ & $\begin{array}{l}529.3 \\
601.8 \\
689.9\end{array}$ & $\begin{array}{l}492.5 \\
668.0 \\
757.5\end{array}$ & $\begin{array}{l}557.4 \\
734.7 \\
825.2\end{array}$ & $\begin{array}{l}618.2 \\
769.5 \\
846.8\end{array}$ & $\begin{array}{l}673.7 \\
818.7 \\
892.7\end{array}$ & $\begin{array}{l}726.2 \\
859.4 \\
927.4\end{array}$ & $\begin{array}{l}769.0 \\
863.7 \\
912.0\end{array}$ & $\begin{array}{l}785.5 \\
785.5 \\
785.5\end{array}$ \\
\hline $\begin{array}{l}5 \\
5 \\
5\end{array}$ & $\begin{array}{l}338.0 \\
338.0 \\
338.0\end{array}$ & $\begin{array}{l}369.1 \\
531.5 \\
614.4\end{array}$ & $\begin{array}{l}429.5 \\
601.7 \\
689.6\end{array}$ & $\begin{array}{l}492.9 \\
668.0 \\
757.4\end{array}$ & $\begin{array}{l}557.9 \\
734.8 \\
825.1\end{array}$ & $\begin{array}{l}618.7 \\
769.8 \\
846.9\end{array}$ & $\begin{array}{l}674.4 \\
819.1 \\
892.9\end{array}$ & $\begin{array}{l}726.9 \\
859.9 \\
927.8\end{array}$ & $\begin{array}{l}769.9 \\
864.4 \\
912.7\end{array}$ & $\begin{array}{l}786.6 \\
786.6 \\
786.6\end{array}$ \\
\hline $\begin{array}{l}6 \\
6 \\
6\end{array}$ & $\begin{array}{l}338.0 \\
338.0 \\
338.0\end{array}$ & $\begin{array}{l}369.0 \\
528.1 \\
609.4\end{array}$ & $\begin{array}{l}429.3 \\
598.0 \\
684.2\end{array}$ & $\begin{array}{l}492.6 \\
664.1 \\
751.7\end{array}$ & $\begin{array}{l}557.5 \\
730.8 \\
819.3\end{array}$ & $\begin{array}{l}618.3 \\
766.3 \\
841.8\end{array}$ & $\begin{array}{l}673.8 \\
815.5 \\
887.9\end{array}$ & $\begin{array}{l}726.3 \\
856.5 \\
923.0\end{array}$ & $\begin{array}{l}769.2 \\
861.7 \\
909.0\end{array}$ & $\begin{array}{l}786.0 \\
786.0 \\
786.0\end{array}$ \\
\hline $\begin{array}{l}7 \\
7 \\
7\end{array}$ & $\begin{array}{l}338.0 \\
338.0 \\
338.0\end{array}$ & $\begin{array}{l}369.0 \\
520.9 \\
598.5\end{array}$ & $\begin{array}{l}429.3 \\
590.3 \\
672.5\end{array}$ & $\begin{array}{l}492.5 \\
656.2 \\
739.8\end{array}$ & $\begin{array}{l}557.3 \\
722,7 \\
807.2\end{array}$ & $\begin{array}{l}618.0 \\
759.2 \\
831.3\end{array}$ & $\begin{array}{l}673.4 \\
808.7 \\
877.8\end{array}$ & $\begin{array}{l}725.9 \\
850.2 \\
913.6\end{array}$ & $\begin{array}{l}768.7 \\
857.0 \\
902.1\end{array}$ & $\begin{array}{l}785.5 \\
785.5 \\
785.5\end{array}$ \\
\hline $\begin{array}{l}8 \\
8 \\
8\end{array}$ & $\begin{array}{l}338.0 \\
338.0 \\
338.0\end{array}$ & $\begin{array}{l}369.0 \\
517.1 \\
592.7\end{array}$ & $\begin{array}{l}429.3 \\
586.3 \\
666.4\end{array}$ & $\begin{array}{l}492.5 \\
652.1 \\
733.5\end{array}$ & $\begin{array}{l}557.3 \\
718.5 \\
800.8\end{array}$ & $\begin{array}{l}617.9 \\
755.6 \\
825.8\end{array}$ & $\begin{array}{l}673.4 \\
805.2 \\
872.5\end{array}$ & $\begin{array}{l}725.8 \\
846.9 \\
908.7\end{array}$ & $\begin{array}{l}768.5 \\
854.6 \\
898.5\end{array}$ & $\begin{array}{l}784.9 \\
784.9 \\
784.9\end{array}$ \\
\hline $\begin{array}{l}9 \\
9 \\
9\end{array}$ & $\begin{array}{l}338.0 \\
338.0 \\
338.0\end{array}$ & $\begin{array}{l}369.3 \\
495.2 \\
559.4\end{array}$ & $\begin{array}{l}429.7 \\
563.1 \\
631.2\end{array}$ & $\begin{array}{l}493.0 \\
628.6 \\
697.8\end{array}$ & $\begin{array}{l}558.0 \\
694.9 \\
764.8\end{array}$ & $\begin{array}{l}6.8 .8 \\
735.7 \\
795.3\end{array}$ & $\begin{array}{l}674.4 \\
786.3 \\
843.4\end{array}$ & $\begin{array}{l}727.0 \\
829.7 \\
882.2\end{array}$ & $\begin{array}{l}769.9 \\
842.9 \\
880.2\end{array}$ & $\begin{array}{l}786.6 \\
786.6 \\
786.6\end{array}$ \\
\hline $\begin{array}{l}10 \\
10 \\
10\end{array}$ & $\begin{array}{l}338.0 \\
338.0 \\
338.0\end{array}$ & $\begin{array}{l}369.3 \\
495.7 \\
560.2\end{array}$ & $\begin{array}{l}429.5 \\
563.5 \\
631.9\end{array}$ & $\begin{array}{l}492.8 \\
629.0 \\
698.5\end{array}$ & $\begin{array}{l}557.8 \\
695.2 \\
765.4\end{array}$ & $\begin{array}{l}618.4 \\
735.8 \\
795.7\end{array}$ & $\begin{array}{l}674.0 \\
786.3 \\
843.7\end{array}$ & $\begin{array}{l}726.5 \\
829.7 \\
882.3\end{array}$ & $\begin{array}{l}769.3 \\
842.6 \\
880.0\end{array}$ & $\begin{array}{l}786.0 \\
786.0 \\
786.0\end{array}$ \\
\hline $\begin{array}{l}11 \\
11 \\
11\end{array}$ & $\begin{array}{l}338.0 \\
338.0 \\
338.0\end{array}$ & $\begin{array}{l}369.2 \\
494.3 \\
558.1\end{array}$ & $\begin{array}{l}429.4 \\
561.9 \\
629.6\end{array}$ & $\begin{array}{l}492.6 \\
627.2 \\
696.0\end{array}$ & $\begin{array}{l}557.4 \\
693.3 \\
762.8\end{array}$ & $\begin{array}{l}618.0 \\
734.0 \\
793.3\end{array}$ & $\begin{array}{l}673.4 \\
784.5 \\
841.2\end{array}$ & $\begin{array}{l}725.8 \\
827.8 \\
879.9\end{array}$ & $\begin{array}{l}768.5 \\
841.0 \\
878.0\end{array}$ & $\begin{array}{l}784.9 \\
784.9 \\
784.9\end{array}$ \\
\hline $\begin{array}{l}12 \\
12 \\
12\end{array}$ & $\begin{array}{l}338.0 \\
338.0 \\
338.0\end{array}$ & $\begin{array}{l}369.3 \\
486.9 \\
547.0\end{array}$ & $\begin{array}{l}429.5 \\
554.2 \\
617.8\end{array}$ & $\begin{array}{l}492.8 \\
619.4 \\
684.0\end{array}$ & $\begin{array}{l}557.7 \\
685.5 \\
750.7\end{array}$ & $\begin{array}{l}618.3 \\
727.4 \\
783.0\end{array}$ & $\begin{array}{l}673.8 \\
778.2 \\
831.5\end{array}$ & $\begin{array}{l}726.2 \\
822.1 \\
871.0\end{array}$ & $\begin{array}{l}768.9 \\
837.1 \\
871.9\end{array}$ & $\begin{array}{l}785.2 \\
785.3 \\
785.4\end{array}$ \\
\hline $\begin{array}{l}13 \\
13 \\
13\end{array}$ & $\begin{array}{l}338.0 \\
338.0 \\
338.0\end{array}$ & $\begin{array}{l}369.3 \\
488.6 \\
549.5\end{array}$ & $\begin{array}{l}429.7 \\
556.1 \\
620.6\end{array}$ & $\begin{array}{l}493.0 \\
621.4 \\
687.0\end{array}$ & $\begin{array}{l}557.9 \\
687.6 \\
753.8\end{array}$ & $\begin{array}{l}618.7 \\
729.3 \\
785.8\end{array}$ & $\begin{array}{l}674.2 \\
780.1 \\
834.2\end{array}$ & $\begin{array}{l}726.7 \\
824.0 \\
873.7\end{array}$ & $\begin{array}{l}769.5 \\
838.7 \\
874.0\end{array}$ & $\begin{array}{l}786.0 \\
786.0 \\
786.0\end{array}$ \\
\hline $\begin{array}{l}14 \\
14 \\
1 / 1\end{array}$ & $\begin{array}{l}338.0 \\
338.0 \\
338.0\end{array}$ & $\begin{array}{l}369.2 \\
490.5 \\
552.4\end{array}$ & $\begin{array}{l}429.4 \\
558.0 \\
623.6\end{array}$ & $\begin{array}{l}492.6 \\
623.2 \\
689.9\end{array}$ & $\begin{array}{l}557.4 \\
689.2 \\
756.5\end{array}$ & $\begin{array}{l}618.0 \\
730.5 \\
787: 9\end{array}$ & $\begin{array}{l}673.4 \\
78.1 .1 \\
836.1\end{array}$ & $\begin{array}{l}725.8 \\
82.4 .7 \\
875.2\end{array}$ & $\begin{array}{l}768.5 \\
838.8 \\
874.7\end{array}$ & $\begin{array}{l}784.9 \\
784.9 \\
784.9\end{array}$ \\
\hline $\begin{array}{l}15 \\
15 \\
15\end{array}$ & $\begin{array}{l}338.0 \\
338.0 \\
338.0\end{array}$ & $\begin{array}{r}369.2 \\
486.2 \\
545.9\end{array}$ & $\begin{array}{l}429.4 \\
553.3 \\
616.5\end{array}$ & $\begin{array}{l}492.5 \\
618.4 \\
682.7\end{array}$ & $\begin{array}{l}557.3 \\
684.3 \\
749.2\end{array}$ & $\begin{array}{l}617.8 \\
726.2 \\
781.5\end{array}$ & $\begin{array}{l}673.2 \\
776.9 \\
829.9\end{array}$ & $\begin{array}{l}725.4 \\
820.8 \\
869.4\end{array}$ & $\begin{array}{l}768.1 \\
835.8 \\
870.4\end{array}$ & $\begin{array}{l}784.5 \\
784.5 \\
784.5\end{array}$ \\
\hline $\begin{array}{l}16 \\
16 \\
16\end{array}$ & $\begin{array}{l}338.0 \\
338.0 \\
338.0\end{array}$ & $\begin{array}{l}369.2 \\
489.8 \\
551.4\end{array}$ & $\begin{array}{l}429.4 \\
557.1 \\
622.4\end{array}$ & $\begin{array}{l}492.5 \\
622.3 \\
688.6\end{array}$ & $\begin{array}{l}557.2 \\
688.3 \\
755.2\end{array}$ & $\begin{array}{l}617.7 \\
729.6 \\
786.7\end{array}$ & $\begin{array}{l}673.0 \\
780.1 \\
834.8\end{array}$ & $\begin{array}{l}725.4 \\
823.7 \\
873.9\end{array}$ & $\begin{array}{l}768.0 \\
837.9 \\
873.6\end{array}$ & $\begin{array}{l}784.4 \\
784.4 \\
784.4\end{array}$ \\
\hline $\begin{array}{l}17 \\
17 \\
17\end{array}$ & $\begin{array}{l}338.0 \\
338.0 \\
338.0\end{array}$ & $\begin{array}{l}369.2 \\
483.7 \\
542.1\end{array}$ & $\begin{array}{l}429.3 \\
550.6 \\
612.5\end{array}$ & $\begin{array}{l}492.4 \\
625.5 \\
678.4\end{array}$ & $\begin{array}{l}557.0 \\
681.4 \\
744.8\end{array}$ & $\begin{array}{l}617.5 \\
723.6 \\
777.8\end{array}$ & $\begin{array}{r}672.8 \\
774.3 \\
826.2\end{array}$ & $\begin{array}{l}725.0 \\
818.3 \\
865.9\end{array}$ & $\begin{array}{l}767.7 \\
833.9 \\
867.7\end{array}$ & $\begin{array}{l}784.0 \\
784.0 \\
784.0\end{array}$ \\
\hline $\begin{array}{l}18 \\
18 \\
18\end{array}$ & $\begin{array}{l}338.0 \\
338.0 \\
338.0\end{array}$ & $\begin{array}{l}369.3 \\
483.0 \\
541.1\end{array}$ & $\begin{array}{l}429.6 \\
550.0 \\
611.5\end{array}$ & $\begin{array}{l}492.8 \\
615.2 \\
677.7\end{array}$ & $\begin{array}{l}557.7 \\
681.2 \\
744.2\end{array}$ & $\begin{array}{l}618.3 \\
723.7 \\
777.5\end{array}$ & $\begin{array}{l}673.8 \\
774.6 \\
865.1\end{array}$ & $\begin{array}{l}726.2 \\
818.8 \\
866.1\end{array}$ & $\begin{array}{l}768.9 \\
834.7 \\
868.3\end{array}$ & $\begin{array}{l}785.3 \\
785.3 \\
785.3\end{array}$ \\
\hline $\begin{array}{l}19 \\
19 \\
19\end{array}$ & $\begin{array}{l}338.0 \\
338.0 \\
338.0\end{array}$ & $\begin{array}{l}369.3 \\
483.2 \\
541.3\end{array}$ & $\begin{array}{l}429.6 \\
550.2 \\
611.8\end{array}$ & $\begin{array}{l}492.8 \\
615.3 \\
677.9\end{array}$ & $\begin{array}{l}557.7 \\
681.3 \\
744.4\end{array}$ & $\begin{array}{l}618.3 \\
723.8 \\
777.7\end{array}$ & $\begin{array}{l}673.8 \\
774.7 \\
826.3\end{array}$ & $\begin{array}{l}726.2 \\
818.9 \\
866.3\end{array}$ & $\begin{array}{l}768.9 \\
834.8 \\
868.4\end{array}$ & $\begin{array}{l}785.3 \\
785.3 \\
785.3\end{array}$ \\
\hline $\begin{array}{l}20 \\
20 \\
20\end{array}$ & $\begin{array}{l}338.0 \\
338.0 \\
338.0\end{array}$ & $\begin{array}{l}369.3 \\
482.4 \\
540.1\end{array}$ & $\begin{array}{l}429.5 \\
549.3 \\
610.5\end{array}$ & $\begin{array}{l}492.7 \\
614.4 \\
676.5\end{array}$ & $\begin{array}{l}557.5 \\
680.3 \\
743.0\end{array}$ & $\begin{array}{l}618.0 \\
733.2 \\
776.4\end{array}$ & $\begin{array}{l}673.5 \\
773.8 \\
825.0\end{array}$ & $\begin{array}{l}725.9 \\
818.0 \\
865.0\end{array}$ & $\begin{array}{l}768.5 \\
834.0 \\
867.4\end{array}$ & $\begin{array}{l}784.9 \\
784.9 \\
784.9\end{array}$ \\
\hline
\end{tabular}


ORNL DWG 75-8439

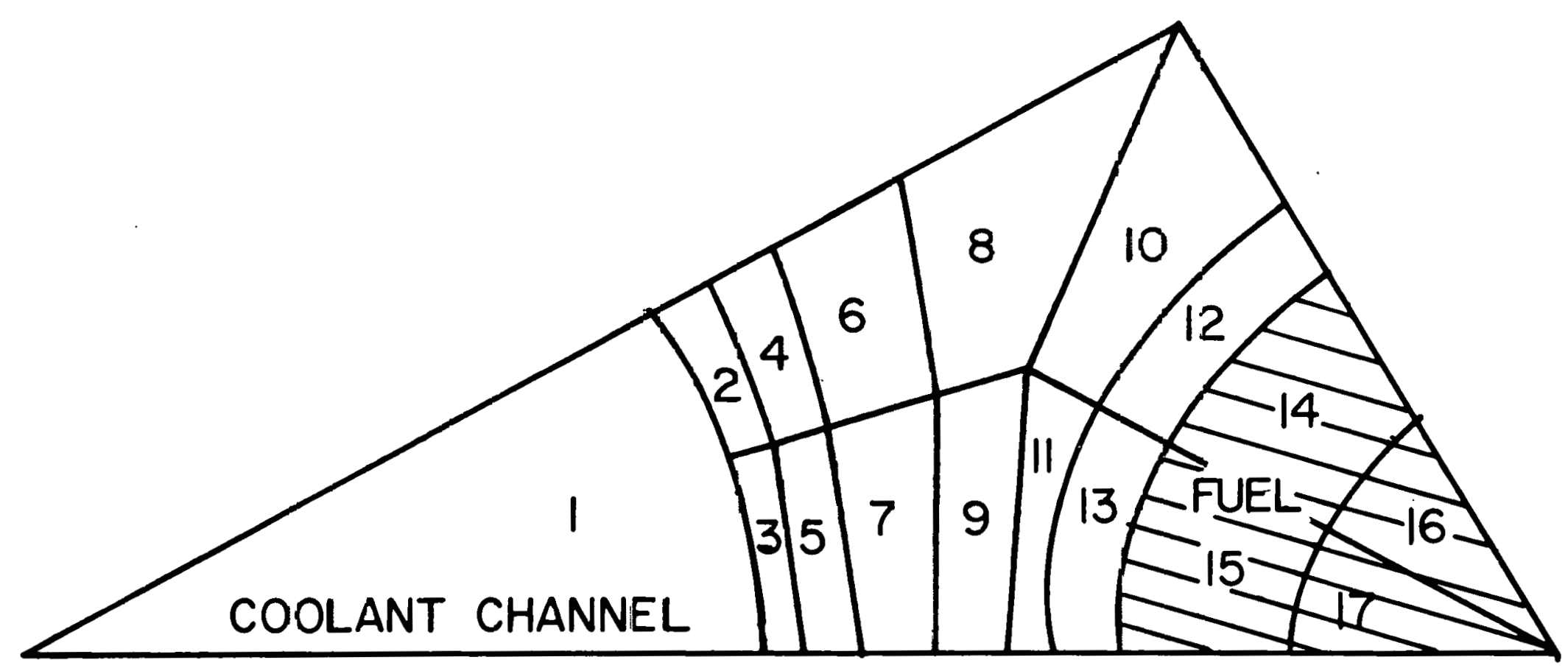

Iig. 5.5. Repeating triangular sections for numerical analysis used by OXIEE-S. 
Another problem is whether the OXIDE-3 region temperatures given in Table 5.8 appropriately characterize the smaller OXIDE-3 regions when considering a highly temperature-dependent process (i.e., a thermally activated corrosion rate). The given temperatures are flat averages over regions ranging in size from $\sim 1$ to $\sim 3 \mathrm{~m}^{3}$ (except region 2, which is much smaller) within which substantial temperature variation may exist.

The appropriate region-average temperature, $\overline{\mathrm{T}}_{\mathrm{A}}$, of a total region, $A_{T}$, in which the average corrosion rate is $R_{T}\left(\bar{T}_{A}\right)$ mol $/ \mathrm{cm}^{2}-\mathrm{sec}$, may be determined by noting

$$
A_{T} R_{T}\left(\bar{T}_{A}\right)=\sum_{i} R_{i}\left(T_{i}\right) \cdot A_{i},
$$

where the subscript $i$ refers to the subregions comprising $A_{T}$, each of which are sufficiently small (or sufficiently uniform in temperature) to be characterized by a single temperature, $T_{i}$. Since

$$
R\left(T_{i}\right)=\sim \exp \left(-\frac{\Delta H}{R T_{i}}\right)
$$

appropriately describes the variation of reaction rate with temperature throughout regions where $\mathrm{H}_{2} \mathrm{O}, \mathrm{H}_{2}$, and $\mathrm{CO}$ levels are approximately equal, substituting Eq. (25) into Eq. (24) and solving for $\overline{\mathrm{T}}_{\mathrm{A}}$ gives

$$
\bar{T}_{A}=\frac{-\left(\frac{\Delta H}{R}\right)}{\ln \left[\sum_{i=1}^{N} \exp \left(\frac{-\Delta H}{R_{i}}\right)\left(\frac{A_{i}}{A_{T}}\right)\right]} .
$$

Equation (26) shows that the reaction-average temperature of a region comprised of $\mathrm{N}$ subregions of more-or-less uniform temperature, $\mathrm{T}_{i}$, depends on the activation enerey for the reaction, $\Delta H$.

The validity of using the region-average temperature specified by OXIDE-3 to characterize the corrosion rate within that region was tested using detailed intraregional temperature distributions available for the Fort St. Vrain Reactor (FSV). ${ }^{15}$ The detail of these data is such that 56 temperature va.lues are given within each fueling zone; hence, a minimum of 112 values for each OXIDE-3 region are available. The results for six 
selected locations within the FSV reactor and times after startup are shown in Table 5.9. Note that the reaction-rate average temperature exceeds the flat space-average by an average of $3.7^{\circ} \mathrm{C}$ when the activation energy is assumed to be $40,000 \mathrm{cal} / \mathrm{mol}$, and 6.4 when $\Delta H=67,000$. Since a temperature increment of $10^{\circ} \mathrm{C}$ represents about a $25 \%$ change in reaction rate, use of flat, region-average temperatures given by OXIDE-3 should be correct for specifying the corrosion rate in the region to within $25 \%$ of the true value.

TIMOX region-average temperatures. The reaction-rate average temperature for each of the four TIMOX zones were computed by applying Eq. (26) to the surface temperatures within the region given in Table 5.8. The fractional areas, $A_{i} / A_{T}$, of each OXIDE-3 zone are listed in Table 5.10. The results showing the comparison of the reaction-rate average temperature with the flat average for each of the four TIMOX zones are given in Table 5.11. In the next section, calculations for primary 10op impurity levels were based on the higher average region temperatures where the activation energy of $68,000 \mathrm{cal} / \mathrm{mol}$ was assumed.

\subsubsection{Impurity levels in the primary system for steady steam ingress using TIMOX}

Equilibrium impurity levels. Predicted concentrations of $\mathrm{H}_{2} \mathrm{O}, \mathrm{H}_{2}$, and Co under various assumed steady-steam ingress conditions are listed in Tables 5.12-5.14, and are plotted in Figs. 5.6-5.10. Three sequences of runs are presented. Table 5.12 and Figs. 5.6 and 5.7 illustrate the effect of varying steam ingress rates at the nominal purification flow. Ingress rates of 0.001 to $1.0 \mathrm{~g} / \mathrm{sec}$ are assumed in steps of a factor of 10 . It should be noted that an ingress rate of $0.0116 \mathrm{~g} / \mathrm{sec}(0.091 \mathrm{~b} / \mathrm{hr})$ is the maximum acceptable steady rate of steam ingress presumed in the Delmarva PSAR. 16

At the lowest assumed inleakage rate of $0.001 \mathrm{~g} / \mathrm{sec}$, the range of predicted $\mathrm{H}_{2} \mathrm{O}$ concentration is 0.14 to $0.63 \mathrm{vpm}$, about a factor of 5 , depending on whether the Wicke, OXIDE-3, or Giberson kinetic equation is used to determine the core reactivity. At higher inleakage rates, differences 
Table 5.9. Comparison of region-average and reaction-rate average temperatures, Eq. (25), for OXIDE-3 specified regions, using FSV reactor temperature distributions

\begin{tabular}{|c|c|c|}
\hline Location in FSV reactor, and & $\begin{array}{l}\text { Region- } \\
\text { average } \\
\text { surface }\end{array}$ & $\begin{array}{l}\text { Reaction-rate average } \\
\text { temperature; increment } \\
\text { over region-average }\end{array}$ \\
\hline time after startup & $\begin{array}{c}\text { temperature } \\
\left({ }^{\circ} \mathrm{C}\right)\end{array}$ & $\begin{array}{cc}\Delta \mathrm{H} & (\mathrm{cal} / \mathrm{mole}) \\
40,000 & 68,000 \\
\left({ }^{\circ} \mathrm{C}\right) & \left({ }^{\circ} \mathrm{C}\right)\end{array}$ \\
\hline
\end{tabular}

1. Region 1; cols. 1,$3 ; z^{2}=28-34 \mathrm{~m}$

$$
\mathrm{T}^{\mathrm{b}}=0 \text { days }
$$

$889.4+6.2+10.6$

2. Region 1 ; cols. 1,$3 ; Z=28-34 \mathrm{~m}$

$$
\mathrm{T}=310 \text { days } \quad 850.8+2.2+3.8
$$

3. Region 1; cols. 1, 3; $\mathrm{Z}=35-41 \mathrm{~m}$

$$
\mathrm{T}=0 \text { days } 907.1+5.9+10.1
$$

4. Region 1 ; cols. 1,$3 ; \mathrm{Z}=35-41 \mathrm{~m}$

$$
\mathrm{T}=310 \text { days } \quad 888.4+0.8+1.5
$$

5. Region 7 ; cols. $1-7 ; z=24-31 \mathrm{~m}$

$$
T=310 \text { days }
$$

$764.1+5.0$

$+8.6$

6. Region 7; cols. $1-7 ; z=41-48 \mathrm{~m}$

$$
T=310 \text { days }
$$

$856.3+2.3$ +4.0
+6.4

$a_{\text {Distance from top of active core. }}$

$b_{\text {Time after startup of new core. }}$ 
Table 5.10. Fractional areas, $A_{i} / A_{T}$, for computing reaction-average temperature from $\mathrm{Eq}$. (26)

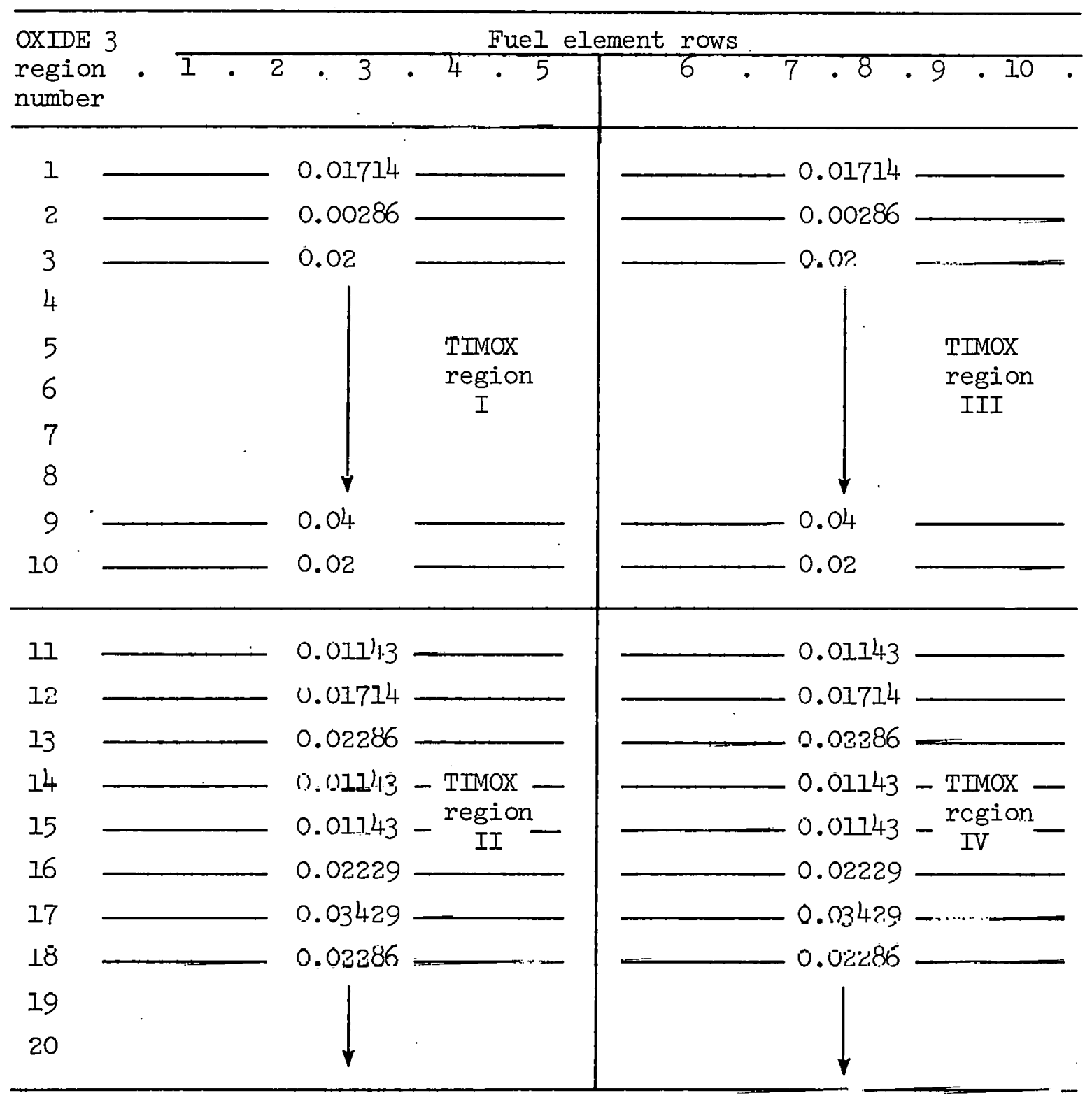


Table 5.11. Reaction-rate average temperature for each TIMOX region

\begin{tabular}{cccc}
\hline TIMOX region & $\begin{array}{c}\text { Flat, area-average } \\
\text { temperature } \\
\left({ }^{\circ} \mathrm{C}\right)\end{array}$ & $\begin{array}{c}\text { Reaction-rate average temperature } \\
\Delta \mathrm{HH}(\mathrm{68}, 000 \\
\left({ }^{\circ} \mathrm{C}\right)\end{array}$ & $\begin{array}{c}\Delta \mathrm{H}=40,000 \\
\left({ }^{\circ} \mathrm{C}\right)\end{array}$ \\
\hline 1 & 563.1 & 685.2 & 660.7 \\
3 & 810.2 & 833.1 & 822.9 \\
4 & 537.5 & 645.2 & 625.4 \\
\hline
\end{tabular}


Table 5.12. Impurity levels in the primary system for steady steam ingress rates corputed using TIMOX. Steam leak series, nominal purification flow

\begin{tabular}{|c|c|c|c|c|c|c|c|c|c|}
\hline \multirow[b]{2}{*}{ Case } & & \multirow[b]{2}{*}{$\begin{array}{c}\text { Steam } \\
\text { inleakage } \\
(\mathrm{g} / \mathrm{sec})\end{array}$} & \multirow[b]{2}{*}{$\begin{array}{l}\text { Purification } \\
\text { rete }\end{array}$} & \multicolumn{4}{|c|}{ Impurity levels } & \multirow[b]{2}{*}{$\begin{array}{l}\text { Fraction } \mathrm{H}_{2} \mathrm{O} \\
\text { to purifica- } \\
\text { tior. }\end{array}$} & \multirow[b]{2}{*}{$\begin{array}{l}\text { Total } \\
\text { reaction } \\
\text { rate } \\
\left(\frac{\mathrm{mol}}{\mathrm{sec}}\right)\end{array}$} \\
\hline & & & & $(\mathrm{atm})$ & $2^{0}(\mathrm{vpm})$ & $\begin{array}{l}\mathrm{P}_{\mathrm{H}_{2}}{ }^{\prime} \\
(\operatorname{atm})^{2}\end{array}$ & $\begin{array}{l}P_{\mathrm{CO}} \\
(\mathrm{vpm})\end{array}$ & & \\
\hline \multirow[t]{3}{*}{1.} & $w^{a}$ & 0.001 & nominal & $1.4 \mathrm{E}-5$ & 0.29 & $3.4 \mathrm{E}-5$ & 0.29 & 0.30 & $3.9 \mathrm{E}-5$ \\
\hline & $0^{b}$ & & & $6.7 \mathrm{E}-5$ & 0.14 & $4.1 E-5$ & 0.84 & 0.14 & $4.8 \mathrm{E}-5$ \\
\hline & $G^{c}$ & $\downarrow$ & $\downarrow$ & $3.1 \mathrm{E}-5$ & 0.63 & $2.7 \mathrm{E}-5$ & 0.35 & 0.65 & $1.9 \mathrm{E}-5$ \\
\hline \multirow[t]{3}{*}{2.} & $\mathrm{~W}$ & 0.0174 & nominal & $2.6 \mathrm{E}-4$ & 5.3 & $2.9 \mathrm{E}-4$ & 5.9 & 0.47 & $3 \cdot 3 \mathrm{E}-4$ \\
\hline & 0 & & & $2.4 \mathrm{E}-4$ & 4.9 & $3.1 \mathrm{E}-4$ & 6.3 & 0.43 & $3.6 \mathrm{E}-4$ \\
\hline & G & & & 4.4 E-1+ & 9.0 & $1.1 \mathrm{E}-4$ & 2.2 & 0.80 & $1.3 \mathrm{E}-4$ \\
\hline \multirow[t]{3}{*}{3.} & W & 0.1 & nominal & $3.5 \mathrm{E}-3$ & 71.0 & $1.3 \mathrm{E}-3$ & 27.0 & c. 73 & $1.5 \mathrm{E}-3$ \\
\hline & 0 & & & $3.7 \mathrm{E}-3$ & 76.0 & $1.1 \mathrm{E}-3$ & 22.0 & 0.78 & $1.2 \mathrm{E}-3$ \\
\hline & G & $\downarrow$ & 4 & $4.3 \mathrm{E}-3$ & 88.0 & $5.3 \mathrm{E}-4$ & 11.0 & 0.89 & $6.2 \mathrm{E}-4$ \\
\hline \multirow[t]{3}{*}{4.} & W & 1.0 & nominal & $4.3 \mathrm{E}-?$ & 880.0 & $4.8 \mathrm{E}-3$ & 98.0 & 0.90 & $5.6 \mathrm{E}-3$ \\
\hline & 0 & & & $4.6 \mathrm{E}-3$ & 940.0 & $1.7 \mathrm{E}-3$ & 35.0 & 0.91 & $2.0 \mathrm{E}-3$ \\
\hline & G & $\downarrow$ & $\downarrow$ & $4.5 \mathrm{E}-2$ & 920.0 & $2.6 \mathrm{E}-3$ & 53.0 & $0.9 !$ & $3.1 \mathrm{E}-3$ \\
\hline
\end{tabular}

assuming Wicke equat:on, Eq. (-5): sect. 4.2.

$\mathrm{b}_{\text {Assuming }}$ OXIDE-3 rate equation, Eq. (17), sect. 4.2 .

CAssuming Giberson rate equation, Eq. (18), sect. 4.2 . 
Table 5.13. Impurity levels in the primary system for steady steam ingress rates computed using TIMOX. Purification flow series

\begin{tabular}{|c|c|c|c|c|c|c|c|c|c|}
\hline \multirow{2}{*}{\multicolumn{2}{|c|}{ Case }} & \multirow{2}{*}{$\begin{array}{l}\text { Steam } \\
\text { ingress } \\
\text { rate } \\
(\mathrm{g} / \mathrm{sec})\end{array}$} & \multirow[b]{2}{*}{$\begin{array}{l}\text { Purification } \\
\text { rate }\end{array}$} & \multicolumn{4}{|c|}{ Impurity levels } & \multirow{2}{*}{$\begin{array}{c}\text { Fraction } \\
\mathrm{H}_{2} \mathrm{O} \\
\text { to } \\
\text { purification }\end{array}$} & \multirow{2}{*}{$\begin{array}{l}\text { Total } \\
\text { reaction } \\
\text { rates } \\
\left(\frac{\mathrm{mol}}{\mathrm{sec}}\right)\end{array}$} \\
\hline & & & & (atm) & (vpm) & $\begin{array}{r}{ }_{\mathrm{H}_{2}}{ }^{\mathrm{P}} \\
(\text { atm) }\end{array}$ & $\begin{array}{l}P_{\mathrm{CO}} \\
(\mathrm{vpm})\end{array}$ & & \\
\hline & $W^{a}$ & 0.0114 & $1 / 2 \times$ nominal & $4.6 \mathrm{E}-4$ & 9.4 & $6.2 \mathrm{E}-4$ & 13.0 & 0.43 & $3.6 \mathrm{E}-4$ \\
\hline & $D^{b}$ & & & $4.3 E-4$ & 8.8 & $6.6 \mathrm{E}-4$ & 14.0 & 0.40 & $3.8 \mathrm{E}-4$ \\
\hline & $G^{C}$ & $\downarrow$ & $\downarrow$ & $8.1 \mathrm{E}-4$ & 17.0 & $2.7 \mathrm{E}-4$ & 5.5 & 0.75 & $1.6 \mathrm{E}-4$ \\
\hline \multirow[t]{3}{*}{2.} & $\mathrm{~N}$ & 0.0114 & nominal & $2.6 \mathrm{E}-4$ & 5.3 & $2.9 \mathrm{E}-4$ & 5.9 & 0.47 & $3 \cdot 3 \mathrm{E}-4$ \\
\hline & D & 1 & & $2.4 \mathrm{E}-4$ & 4.9 & $3.1 \mathrm{E}-4$ & 6.3 & 0.43 & $3.6 \mathrm{E}-4$ \\
\hline & 9 & & $\downarrow$ & $4.4 \mathrm{E}-4$ & 9.0 & $1.1 \mathrm{E}-4$ & 2.2 & 0.80 & $1.3 \mathrm{E}-4$ \\
\hline \multirow[t]{3}{*}{3.} & $\bar{W}$ & 0.0114 & $4 \times$ nominal & $8.8 \mathrm{E}-5$ & 1.8 & $4.8 \mathrm{E}-5$ & 1.0 & 0.65 & $2.2 \mathrm{E}-4$ \\
\hline & 0 & 1 & & $6.9 \mathrm{E}-5$ & 1.4 & $6.7 \mathrm{E}-5$ & 1.4 & 0.50 & $3.1 \mathrm{E}-4$ \\
\hline & G & $\downarrow$ & $\downarrow$ & $1.2 \mathrm{E}-4$ & 2.4 & $1.6 \mathrm{E}-5$ & 0.33 & 0.88 & $7.4 \mathrm{E}-5$ \\
\hline
\end{tabular}

assuming Wicke rate equation, Eq. (15), sect. 4.2.

${ }^{b}$ Assuming OXIDE-3 rate equation, Eq. (17), sect. 4.2 .

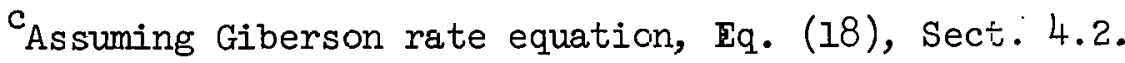


Table 5.14. Impurity -evels in the primary system for steady steam ir.gress rates using TIMOX. Tempərature level series; steam ingress rate $=0.0114 \mathrm{~g} / \mathrm{sec}$, purification flow = rominal

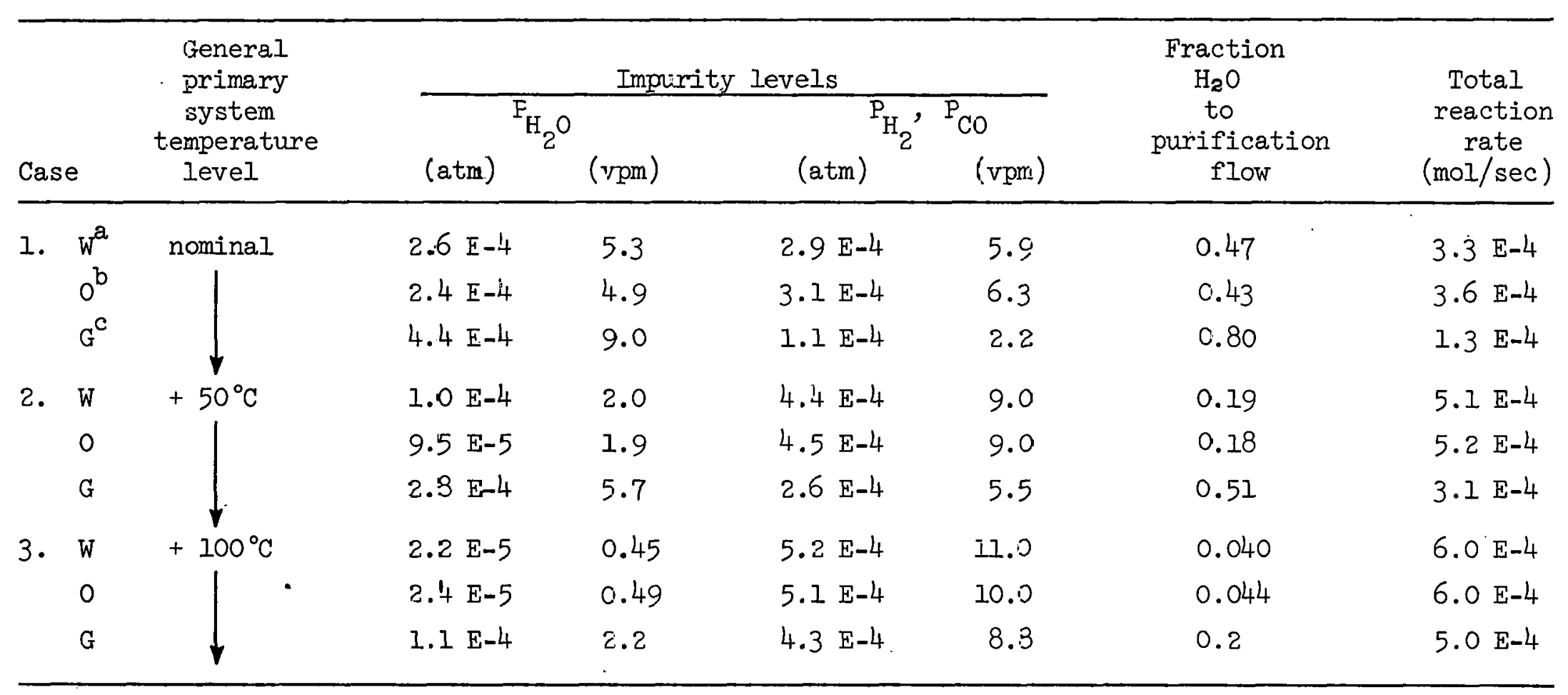

assuming Wicke rate equation, $\mathbb{E} q$. (15), Sect. 4.2 .

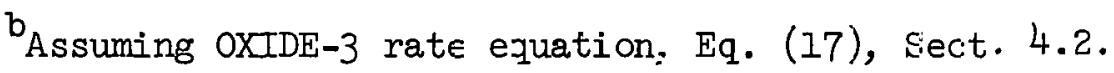

${ }^{c}$ Assuming Gibersan rate equajion, Eq. (18), sect. 4.2. 


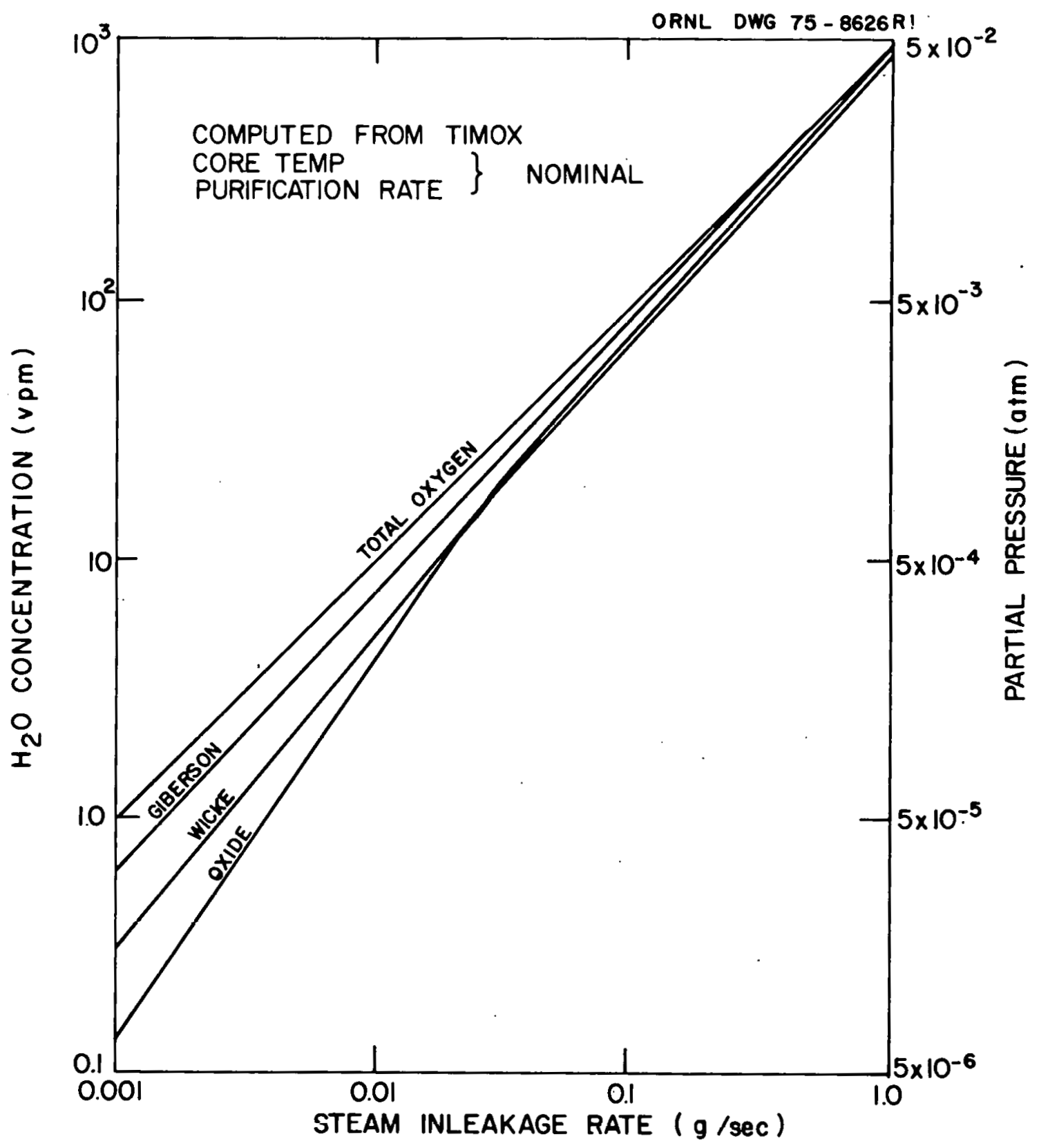

Fig. 5.6. Equilibrium $\mathrm{H}_{2} \mathrm{O}$ concentration vs steam inleakage rate computed using TIMOX. 


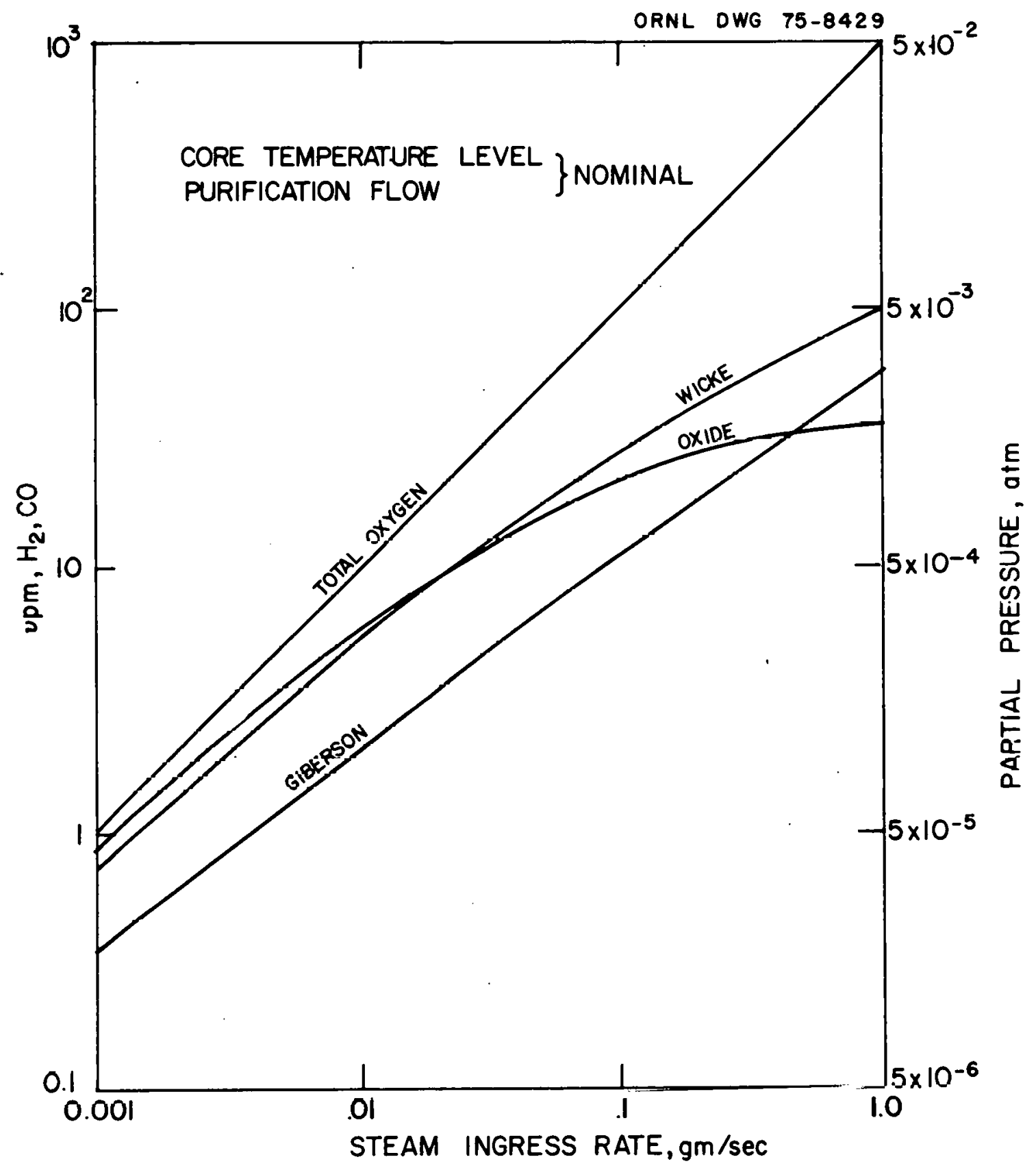

Fig. 5.7. Equilibrium $\mathrm{H}_{2}$ and $\mathrm{CO}$ concentration vs steam inleakage rate computed using TMMOX. 
ORNL OWG 75-8430R1

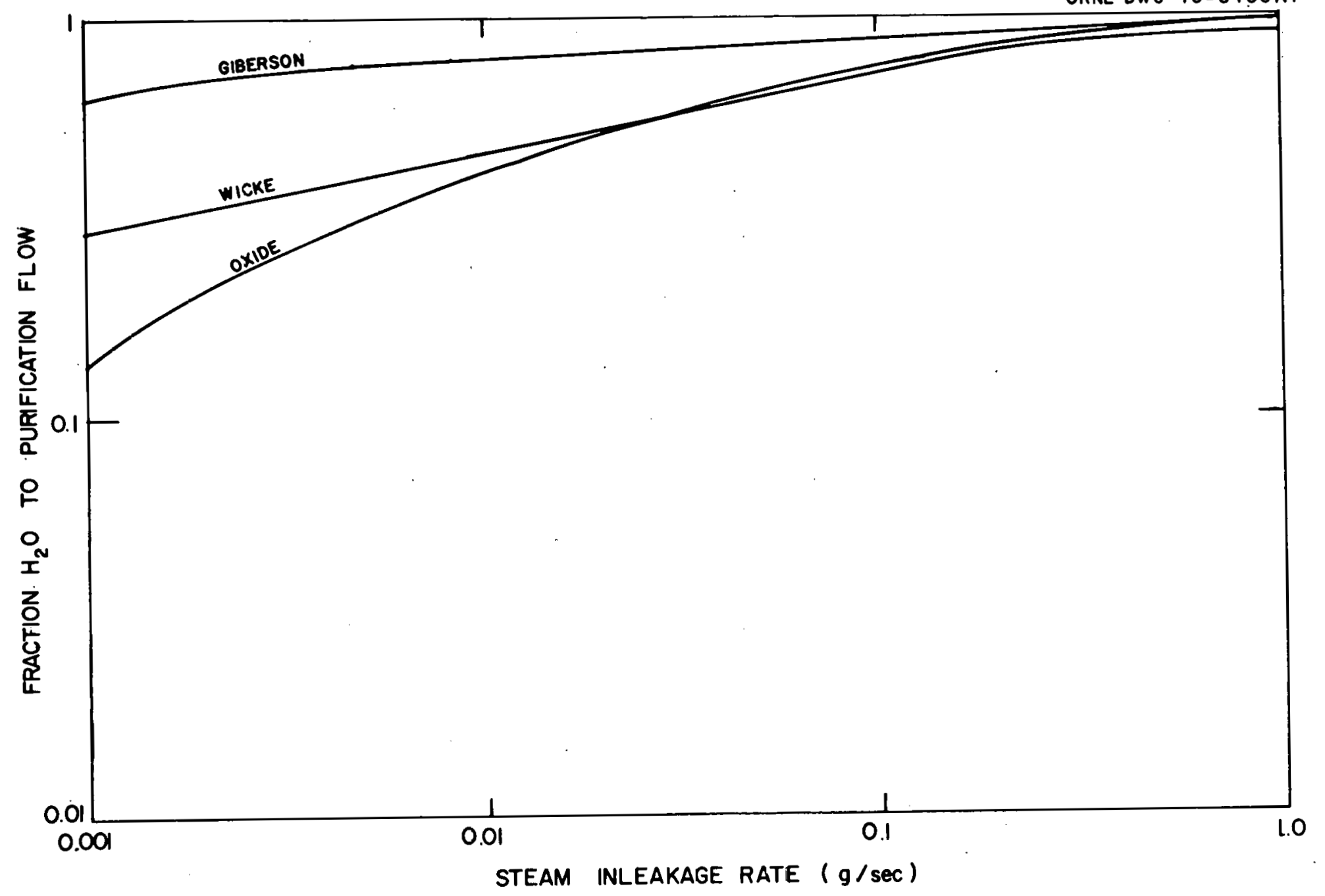

Fig. 5.8. Fraction $\mathrm{H}_{2} \mathrm{O}$ to puritication flow vs steam inleakage rate computed using TIMOX. 


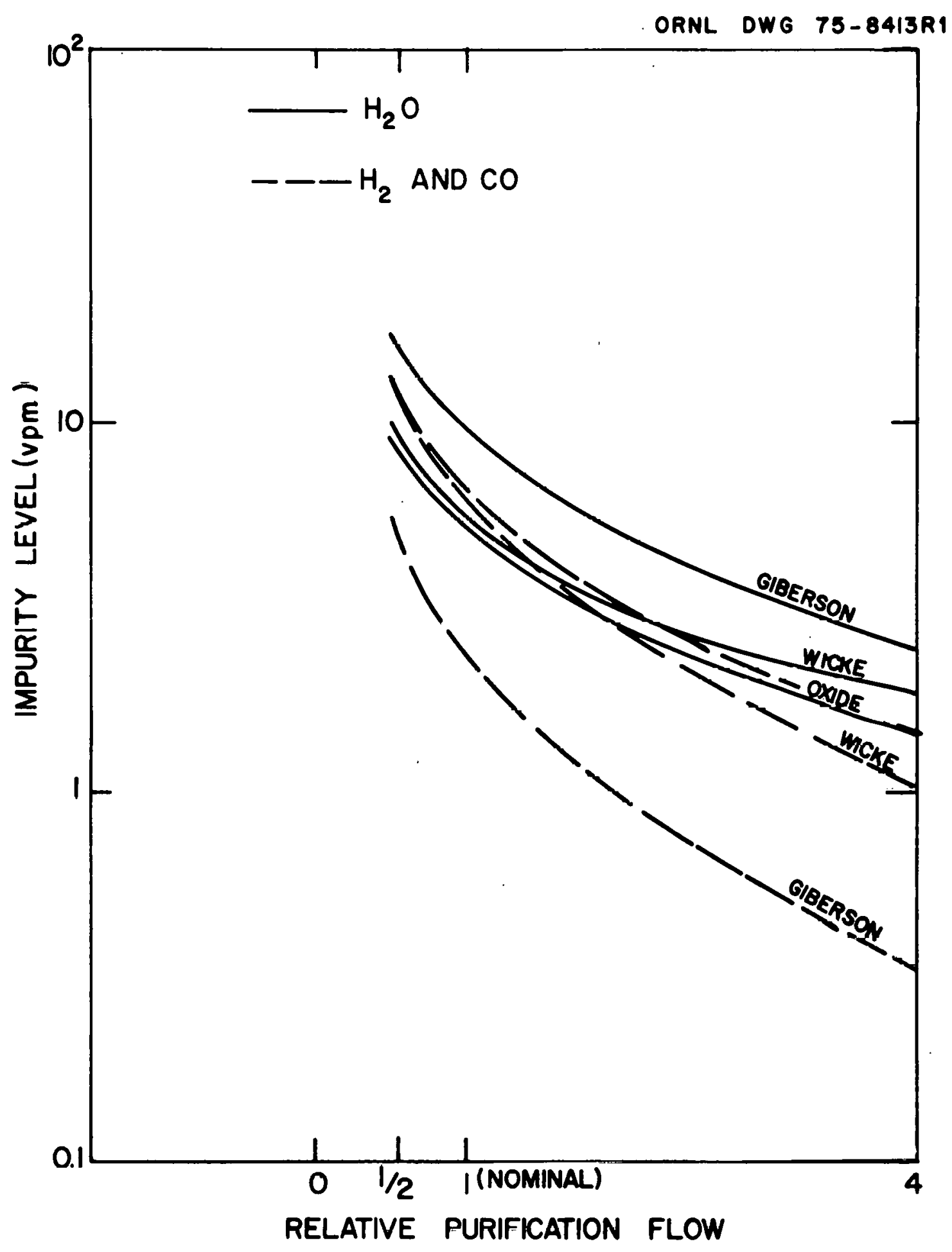

Fig. 5.9. Effect of purification rate on impurity levels. Steam inleakage rate $=0.001 \mathrm{~g} / \mathrm{sec}$, computed using TIMOX. 


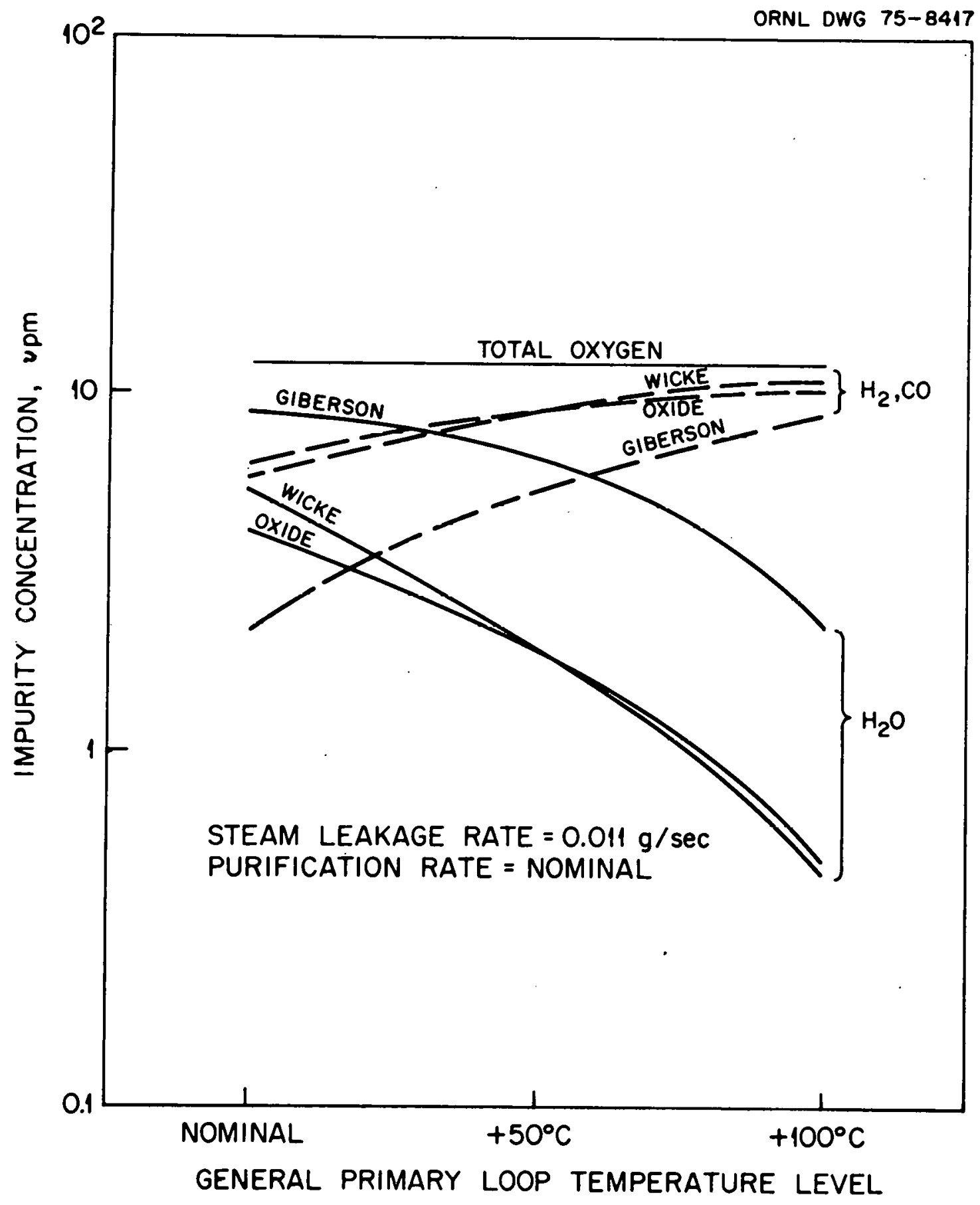

Fig. 5.10. Effect of general temperature level on impurity concentrations. Steam inleakage rate $=0.011 \mathrm{~g} / \mathrm{sec}$. 
between predicted levels using the three rate equations diminishes as the fraction of $\mathrm{H}_{2} \mathrm{O}$ captured by the purification flow increases.

In comparing impurity levels predicted using Dragon core reactivity data (shown in Fig. 5.2 and Table 5.5) with the TIMOX predictions, note that Dragon-derived reactivities predict about $65 \%$ of the total oxygenbearing species in the primary system to be $\mathrm{H}_{2} \mathrm{O}$, independent of the assumed ingress rate. The TIMOX results show a variation of the $\mathrm{H}_{2} \mathrm{O} / \mathrm{O} \mathrm{O}$ ratio with steam ingress rate due to the nonlinearity of the kinetics equations used in TIMOX as opposed to the simple first-order kinetics used in interpretating the Dragon data. For an ingress rate of $0.001 \mathrm{~g} / \mathrm{sec}$, TIMOX predicts a range of 14 to $64 \%$ of the total oxygen to be $\mathrm{H}_{2} \mathrm{O}$, At an ingress rate of $0.0114 \mathrm{~g} / \mathrm{sec}$, the ratio rises to a range of 44 to $80 \%$; at the higher ingress rate of $0.1 \mathrm{~g} / \mathrm{sec}$, from 72 to $90 \%$ of the oxygen exists as $\mathrm{H}_{2} \mathrm{O}$. Apparently, there is a reasonable agreement between the Dragon-based and TIMOX predictions in this regard.

Table 5.13 and Fig. 5.9 illustrate the effect of changing the purification rate from one-half to four times the nominal value for an assumed ingress rate of $0.0114 \mathrm{~g} / \mathrm{sec}$. These results are used in sect. 6 to determine the effect of varying purification flow on the rate post corrosion. At this point, it is not obvious that a modest increase in purification flow is beneficial to core post corrosion, since reaction inhibitors as well as oxidant are reduced in concentration.

Table 5.14 and Fig. 5.10 show the effect of the general temperature level in the primary system on the impurity atmosphere. Cases 2 and 3 in Table 5.14 assume all core and coolant temperatures to be 50 and $100^{\circ} \mathrm{C}$ higher than the reference design, while assuming a nominal purification flow and an inleakage rate of $0,0114 \mathrm{~g} / \mathrm{sec}$. As expected, the $\mathrm{H}_{2} \mathrm{O}$ levels drop with increasing primary loop temperature; that is, the core becomes a superior oxidant getter and, hence, more protective of the core posts. Counterbalancing this improved protection are the inherent increased core post corrosion rates for these higher temperatures. In sect. 6, these opposing tendencies are weighed, and it is found that modest increases in primary system temperature level may have a net beneficial effect on core post corrosion in some cases. 
Transient impurity levels computed using TIMOX. TIMOX computes the equilibrium impurity levels presented in the previous section by assuming an initially clean primary system and following the transient levels after the initiation of a steam leak to their steady state values. For the slow leak cases considered in this report, these transients are only of secondary interest, and are discussed briefly. Table 5.15 lists the durations involved following leak initiation until equilibrium levels are established. The times required to establish equilibrium are relatively independent of assumed kinetics equation and steam ingress rates, and run about $37 \mathrm{hr}$ at the nominal purification flow. Equilibrium time is defined as the time to reach $99 \%$ of the ultimate concentration, a point conveniently noted by following the relative oxygen ingress and purification rates. The purification flow effects the equilibration time, and the general temperature level has less of an effect.

Table 5.15. Time to reach equilibrium ${ }^{2}$ impurity levels following initiation of a slow steam leak. Computed from TIMOX

\begin{tabular}{|c|c|c|c|}
\hline $\begin{array}{l}\text { Steam } \\
\text { ingress } \\
\text { rate } \\
\text { (g/sec) }\end{array}$ & $\begin{array}{l}\text { Purification } \\
\text { rate }\end{array}$ & $\begin{array}{l}\text { Primary } \\
\text { system } \\
\text { temperature } \\
\text { level }\end{array}$ & $\begin{array}{c}\text { Equilibrium } \\
\text { time } \\
\text { (hr) }\end{array}$ \\
\hline 0.001 & nominal & nominal & 35 \\
\hline 0.0174 & 1 & 1 & 37 \\
\hline 0.1 & & & 37 \\
\hline 1.0 & $\downarrow$ & $\downarrow$ & 37 \\
\hline 0.0114 & $1 / 2 \times$ nominal & nominal & 74 \\
\hline 1 & nominal & 1 & 37 \\
\hline$\downarrow$ & $4 \times$ nominal & $\downarrow$ & 15 \\
\hline 0.0114 & nominal & nominal & 37 \\
\hline & 1 & $+50^{\circ} \mathrm{C}$ & 63 \\
\hline$\downarrow$ & $\downarrow$ & $+100^{\circ} \mathrm{C}$ & 63 \\
\hline
\end{tabular}

aefined as time to reach $99 \%$ of ultimate concentration. 
An option of TIMOX is the capability to plot transient impurity levels and flows to the purification plant. Figures 5.11 and 5.12 illustrate one such optional plot for the case $0.0114 \mathrm{~g} / \mathrm{sec}$ ingress flow, nominal purification rate, and assumed Wicke kinetics equations.

\subsection{References for Section 5}

1. Delmarva Power and Light Preliminary Safety Analysis Report, Table 5.3.1-1.

2. Delmarva Power and Light Preliminary Safety $\Lambda$ nalysis Report, Tablè $1.3-2$.

3. P. L. Walker et al., "Gas Reactions of Carbon," in Advances in Catalysis, XI, Section V, Part C, Academic, 1959.

4. M. Carlyle and D. V. Kinsey, Results of the Injection of Impurities Into the Dragon Reactor Primary Coolant, D.P. Rep. 544 (June 1969).

5. T. J. Clark, R. E. Woodley, and D. R. Halas, "Gas-Graphite Systems," p. 149, in Nuclear Graphite, ed. by E. R. Nightingale, Academic, $1,62$.

6. E. Wicke et al., Corrosion Rate of Graphites by $\mathrm{CO}_{2}$ and $\mathrm{H}_{2} \mathrm{O}$ Vapor 'laking Into Account In-Pore Diffusion and Temperature Gradients, D.P. Rep. 391, pp. 23-24 (January 1966).

7. R. C. Giberson and G. L. Tingey, Reaction of Gaseous Impurities in an HTGR, BNWL-974, pp. 6-7 (December 1968).

8. M. R. Everett, D. V. Kinsey, and E. Römberg, Carbon Transnort Studiog for HTGR's, D.P. Rep. 491, pp. 46-59 (November 1966).

9. E. Wicke et al., Corrosion Rate nf Graphiteg by CO z.nd. II 2 Q Vapur Taking Into Account In-Pore Diffusion and Temperature Gradients, D.P. Rep. 391, p. 21 (January 1966).

10. M. R. Everett, D. V. Kinsey, and E. Römberg, Carbon Transporl Studies for HTGR's, D.P. Rep. 491, pp. 19-20 (November 1966).

11. Dragon High Temperature Reactor Project, First Annual Report 19591960 (July 1960). Appendix VI, Table II, pertaining to core with 37 Mark VII fuel elements. 


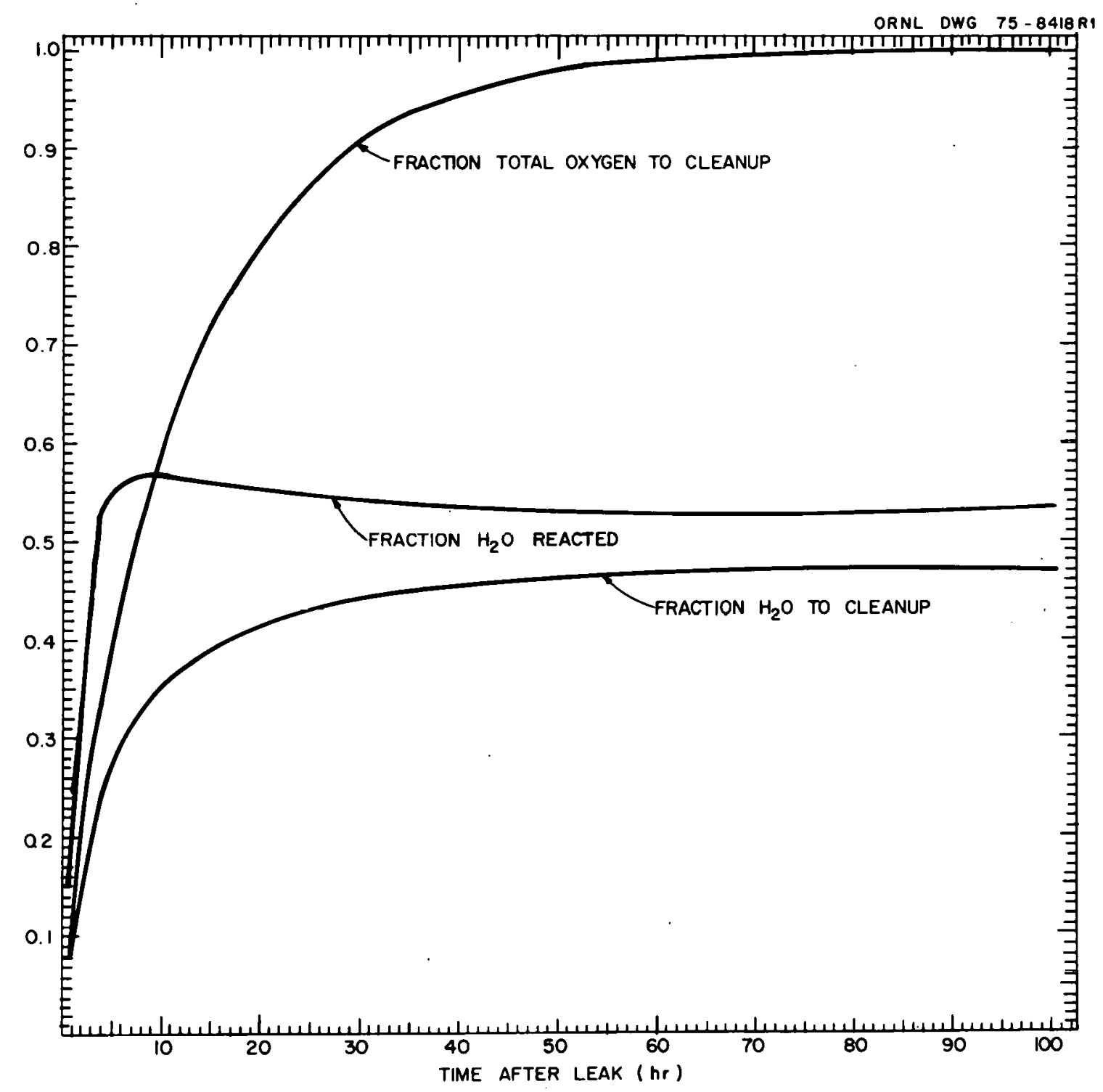

Fig. 5.11. Transient fractional purification and reaction rates relative to stean ingress rate. 
GRNL-DWG 75-8448

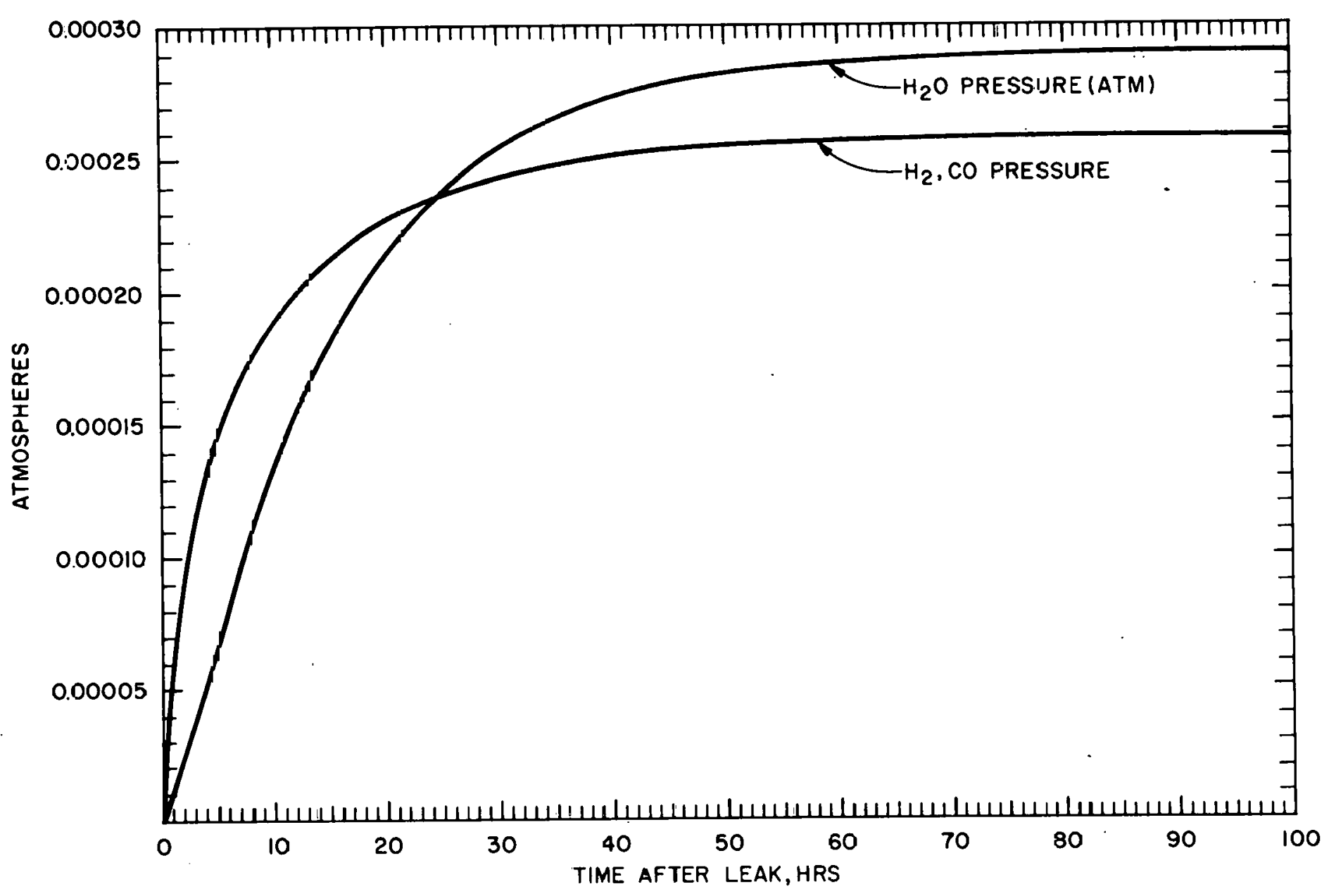

Fig. F.12. Transient impurity levels. Ingress flow $=0.01 \mathrm{~g} / \mathrm{sec}$; purification rate $=$ nominal. 
12. F. P. O. Ashworth, J. Kirk, and H. J. de Nordwall, "Gas-Cooled Reactor Safety Technology," Internal Dragon Project memo.

13. A. W. Barsell and M. B. Peroomian, Consequences of Water Ingress Into the HTGR Primary Coolant, GA-Al371 (April 1975).

14. M. B. Peroomian, A. W. Barsell, and J. C. Saeger, OXIDE-3: A Computer Code for the Analysis of HTGR Steam or Air Ingress Accidents, Sect. 3.2.2 and 9, in GA-Al2493, GA-LTR-7 (January 1974).

15. W. E. Thomas, ORNL Reactor Division, personal communication, Feburary 1975.

16. Delmarva Power and Light Preliminary Safety Analysis Report, Chapter 15. 
THIS PAGE

\section{WAS INTENTIONALLY LEFT BLANK}




\section{CORE POST STRENGTH LOSS}

Some general features of high-temperature graphite corrosion have been discussed in sect. 4. At high temperatures, the oxidant penetrates diffusively to a depth, $\Delta h$, which diminishes with increasing temperature. For one type of graphite, the reaction zone was found to decrease linearly with temperatures between 950 and $1040^{\circ} \mathrm{C}$. If this relationship also holds for core post material, and if it is permissible to extrapolate downward in temperature to the core post region, the reaction depth in the core posts would range from about 2.2 to $2.7 \mathrm{~mm}$.

The corrosion rate is highest in the outer portions of the reaction zone where the oxidant concentration is the highest. Therefore, as time progresses, the corrosion reaction tends to form a characteristic burnoff profile with a gradual increase in density from a minimum at the outside up to the initial graphite density at the inner boundary of the reaction zone. When approximately half the graphite is burned off in the reaction zone, an equilibrium profile is achieved; further corrosion proceeds by an inward movement of the reaction zone leaving behind some graphite residue with a density of about $10 \%$ of the original material.

Ultimately, one would hope that a rational theory of graphite strength loss due to corrosion would be developed which connects the details of the corrosion process with the microstmuctural basis of graphite strength. At this time there is insufficient knowledge in either area for much theorizing towards this goal. Therefore, we will adopt a purely empirical approach and develop a correlation which describes most of the available strength loss data reasonably well but which has no theoretical basis.

\section{I Empirical Strength Loss Correlation Based on Data of Helsby and Everett ${ }^{1}$}

The graphite reactivity and burnoff profile aspects of the work of Helsby and Everett ${ }^{1}$ have been discussed in Sect. 4.2. In addition to the burnoff studies described, the tensile strength of some specimens was measured before and after being subjected to steam corrosion in order to determine the effect of corrosion on strength. 
The material used for the tensile tests was a molded, isotropic Gilsocarbon-based graphite, designated as reference No. $\mathscr{6}$. Gilsocarbon is a naturally occurring pitch in globular form, which, when graphitized yields an isotropic grist particle. Reference No. 96 graphite is triply pitch impregnated with a density of $1.81 \mathrm{~g} / \mathrm{cm}^{3}$, a tensile strength of 2180 psi, a compressive strength of 10,000 psi, and a total ash content of $790 \mathrm{ppm}$. The specimens, as previously described, were annular in shape with a 4-mm wall thickness and a $14 \mathrm{~mm}$ OD. The corrosion surface was the inner diameter.

The corroded camples were mounted in Araldite, and the tensile strength was determined on a Hounsfield Beam Tensometer. The change in tensile strength for a range of burnoffs was studied for specimens corroded at $950^{\circ} \mathrm{C}, 1070^{\circ} \mathrm{C}$, and $1130^{\circ} \mathrm{C}$. The reported results are reproduced in Fig. 6.1. A given degree of corrosion has the most deleterious effect on the tensile strength at the lowest of the three temperatures. This behavior is generally consistent with the concept of a reaction zone depth which increases with diminishing temperature. A given degree of corrosion is confined to a narrower zone at higher temperatures, and causes a smaller degree of strength loss than if it had occurred at a lower temperature where a larger volume of graphite would be damaged.

The degree of corrosion needed to establish the equilibrium burnoff profile is indicated in Fig. 6.1 for each temperature. These estimates were obtained from the active corrosion depths given in Table 4.5 as a function of temperature and an approximation of the burnoff pxofile within the corrosion zone. 'The burnof't' profiles were obtained using a semitheoretical, phenomenological development ${ }^{2}$ which yields approximately the observed profiles shown in F'ig. 4.5 within the reactive zone. Effectively, these burnoff profiles could be assumed to be linear with no significant change in the computed amount of graphite removed.

After the fully developed corrosion profile has been developed at the indicated degrees of burnoff shown by the arrows in Fig. 6.I, corrosion proceeds inward by movement of the reactive zone, leaving behind a graphite skeleton of perhaps $10 \%$ of the original density. Thus, for 


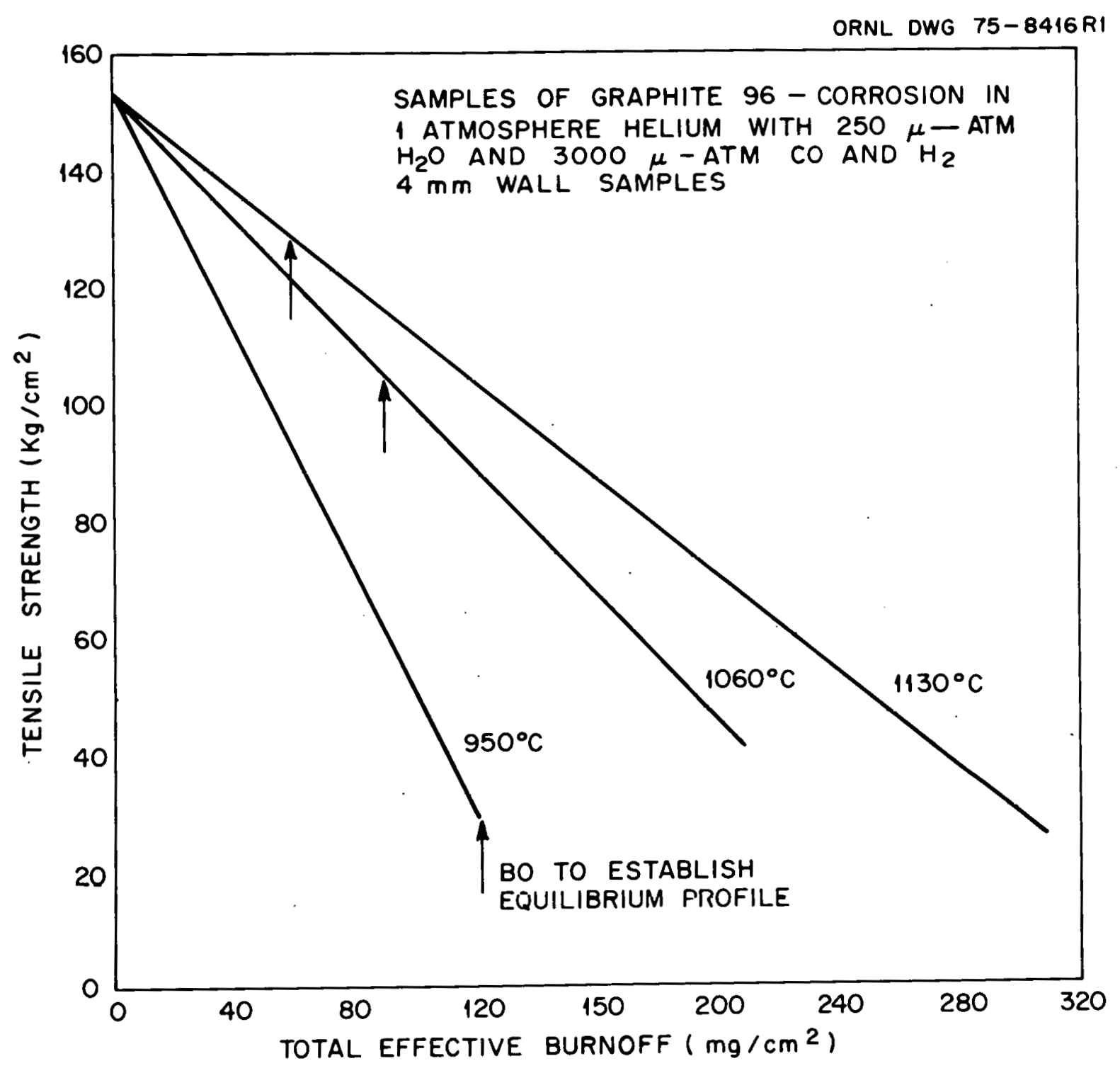

Fig. 6.1. Tensile strength vs burnoff for various temperatures. ${ }^{1}$ 
burnoffs to the right of the indicated arrows, we should distinguish between the depth of the active zone, which is temperature dependent, and the total depth which depends additionally on exposure time.

The estimated total depth of corrosion at the straight line extrapolation to $100 \%$ strength loss for each of the three cases shown in Fig. 6.1 are listed in Table 6.1. For each case, the total predicted corrosion at the burnoff causing 100\% strength loss is less than the 4-mm width of the sample. This indicates that the mechanical strength of graphite is damaged by surface corrosion to a greater depth than the obvious or superficial depth of the corrosion. The sma.li extent of the information, however, does not warrant further analysis beyond these more-or-less speculative generalizations.

Table 6.1. Total corrosion depths at $100 \%$ strength los: for 4-mm thick samples

\begin{tabular}{ccccc}
\hline $\begin{array}{c}\text { Temperature } \\
\left({ }^{\circ} \mathrm{C}\right)\end{array}$ & $\begin{array}{c}\text { Burnoff to reach } \\
\text { equilibrium } \\
\text { profile } \\
\left(\mathrm{mg} / \mathrm{cm}^{2}\right)\end{array}$ & $\begin{array}{c}\text { Burnoff } \\
\left(\mathrm{mg} / \mathrm{cm}^{2}\right)\end{array}$ & $\begin{array}{c}\text { Predicted depth of corrosion } \\
\text { at loo\% strength loss }\end{array}$ \\
\hline 950 & 120 & 150 & $\begin{array}{c}\text { Active } \\
(\mathrm{mm})\end{array}$ & $\begin{array}{c}\text { Tutal } \\
\text { depth } \\
(\mathrm{mm})\end{array}$ \\
1060 & 93 & 290 & 1.9 & 2.0 \\
1130 & 61 & 370 & 1.4 & 2.6 \\
\hline
\end{tabular}

The linear strength Ioss variation with hurnoff depioted in Fig. 6.I may be organized in an empirical equation of the form

$$
F S I=P(T) \cdot \frac{B O}{\rho_{b 0}} \cdot \frac{1}{W},
$$

where

FSI = fractional strength loss,

$P(T)=$ penetration depth multiplier which increases with decreasing temperature, 


$$
\begin{aligned}
\mathrm{BO}= & \text { burnoff, } \mathrm{g} / \mathrm{cm}^{2}, \\
\rho_{\mathrm{bo}}= & \text { original density less the density of graphite which } \\
& \text { remains after complete burnoff } \approx 1.6 \mathrm{~g} / \mathrm{cm}^{3}, \\
\mathrm{~W}= & \text { specimen width, } \mathrm{cm} .
\end{aligned}
$$

The factor $\mathrm{BO} / \mathrm{p}_{\mathrm{bo}}$ would be the corrosion depth if the burnoff were totally drawn from the surface. The temperature dependent factor, $P(T)$, is the required multiplier onto the calculated surface corrosion to yield the observed fractional strength loss shown in Fig. 6.1. Values for the penetration factor at the three test temperatures which yield a fit for the observed degree of strength loss are listed in Table 6.2.

Table 6.2. Burnoff penetration factors as a function of temperature

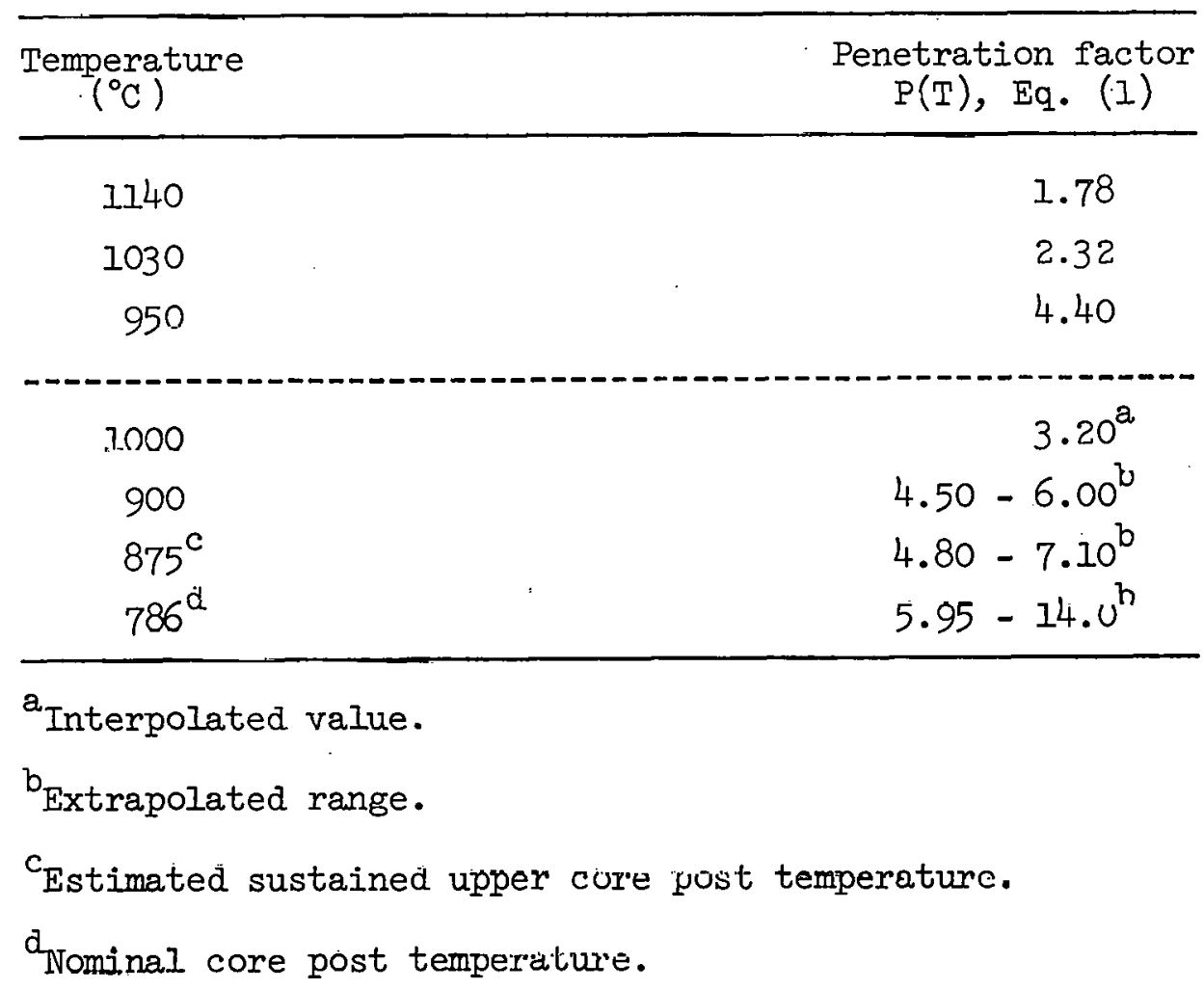

The problem remains of extrapolating values of $P(T)$ down to the core post temperature region. The lowest test temperature of $950^{\circ} \mathrm{C}$ is $164^{\circ} \mathrm{C}$ above the nominal core post temperature and $76^{\circ} \mathrm{C}$ above the estimated 
continuous maximum. The penetration factors shown in Table 6.2 for the core post temperature range were obtained by plotting the calculated points and extrapolating graphically. The lower of the two values given for $786^{\circ} \mathrm{C}$ and $874^{\circ} \mathrm{C}$ represent a straight line extrapolation, whereas the upper range represents a pessimistic upward trend.

Equation (1) and the penetration multipliers given in Table 6.2 form the basis of the means for determining core post strength loss. The correlation is compared in the next section with strength loss data of $1 / 2-i n$.diam specimens of $\mathrm{H}-327$ corroded at $900^{\circ} \mathrm{C}$, and sperimens of $\mathrm{H}-3,38, \mathrm{~S}-9567$, and TS -688 corroded at $1000^{\circ} \mathrm{C}$. Tn mnst cases, prodiatcd atiength 1uss compared rea.sonahly well with modourcd values leaulis some confidence to the predictive method.

\subsection{Comparison of Strength Loss Correlation with Data for H-327, $\mathrm{H}-328, \mathrm{~S}-9567$, and $\mathrm{TS}-688$}

Strength loss data for H-327 graphite undergoing accelerated corrosion by steam in helium at $900^{\circ} \mathrm{C}$ and 1 atm are shown in Fig. 6.2. The data were reported in ref. 3 and are reproduced also in GASSAR. ${ }^{4}$ Both tensile and compressive strength loss data for the 1/2-in.-diam specimens appear to fall on the same smooth curve.

'Whe first stcp in comparing lhe strength loss correlation with the data is to convert percent burnoff shown in the figure to surface burnoff used in the strength loss correlation. A simple mass balance yields,

$$
\mathrm{BO}_{1} \cdot \pi \mathrm{DL}=\rho \cdot \frac{\pi}{4} \mathrm{D}^{2} \mathrm{~L} \mathrm{BO}_{2} \text {, }
$$

Where $\mathrm{BO}_{2}$ is the fractional burnoff of a cylindrical specimen of diameter. $D$ and density $\rho$, whish is equivalent to a ourface burnorf of $\mathrm{BO}_{1}, \mathrm{~g} / \mathrm{cm}^{2}$. Thus,

$$
\mathrm{BO}_{1}\left(\frac{\mathrm{g}}{\mathrm{cm}^{2}}\right)=\frac{\mathrm{D} \rho}{4} \mathrm{BO}_{2} .
$$

The fractional strength loss, FSL, of a cylinder of diameter $D$ is obtained from the ratio of the area damaged by corrosion to an estimated 


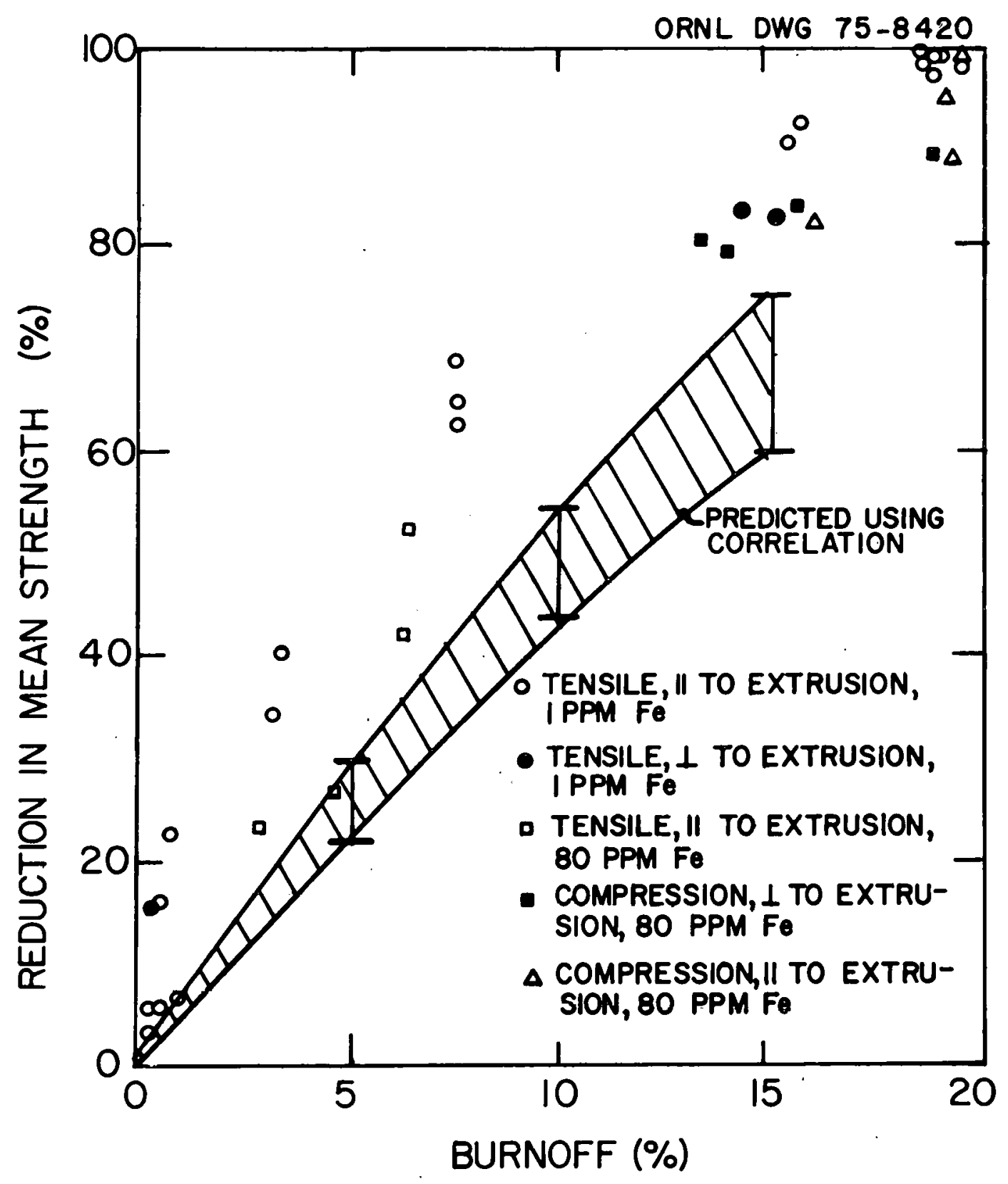

Fig. 6.2. Changes in strength of $1 / 2$-in.-diam samples of $\mathrm{H}-327$ graphile after aocelerated steam oxidation at $900^{\circ} \mathrm{C}$. 
depth $\mathrm{P}\left(\mathrm{I}^{\prime}\right) \cdot \mathrm{BO}_{1} / \mathrm{P}_{\mathrm{BO}}$, to the original specimen cross-sectional area. For cylindrical geometry this yields:

$$
\text { FSL }=1-\left(1-\frac{2 \mathrm{P}(\mathrm{T}) \mathrm{BO}_{I}}{\rho_{\mathrm{bo}} \mathrm{D}}\right)^{2} \text {. }
$$

Using the extrapolated range of values for $\mathrm{P}(\mathrm{T})$ for $900^{\circ} \mathrm{C}$ given in Table 6.2 of $4.5<P(T)<6.0$, yields the indicated band of predicted streily lil loss shown in Fig. 6.2. The predicted values fall about $20 \%$ below the measured data. This is thought to ue gnnd agrccment becuuse the specimen shape, temperature, and graphite type all differ from the original study on which the correlation is based.

Figure $6.3,^{5}$ shows tensile strength loss data for 1/2-in.-diam specimens of $\mathrm{H}-328, \mathrm{~S}-9567$, and TS -688 corroded by steam at $1000^{\circ} \mathrm{C}$. The scatter here is rather large, and the envelopes enclosing the S-9567 and TS-688 data were drawn to assist visualization. The predicted strength loss lines were drawn using the penetration parameter value of 3.2 listed in Table 6.2 appropriate for $1000^{\circ} \mathrm{C}$. The starting point for the curve was laken as the average tensile strength shown for o\% burnoff.

Despile the sratter of the data, the predicted variatiun of strength loss generally agrees with the observed trend for H-328 and TS-688 graphites; S-9567 graphite shows a superior behavior under steam corrosion compared with the four other graphites tested. The envelope cnclosing the $5-9567$ data shows a more parallel trend with the axis than either the other data or the prediction by the correlation; but the reason fon this bchavius ls not understood.

\subsection{Cure Post Loads and Temperatures Under Normal Operating Conditions (NOC)}

\subsubsection{Core post loads under normal operating conditions}

The core support structure must support the core during all normal, upset, emergency, and test conditions. We are concerned solely with the requirements for normal operation which are defined in ref. 6 : 


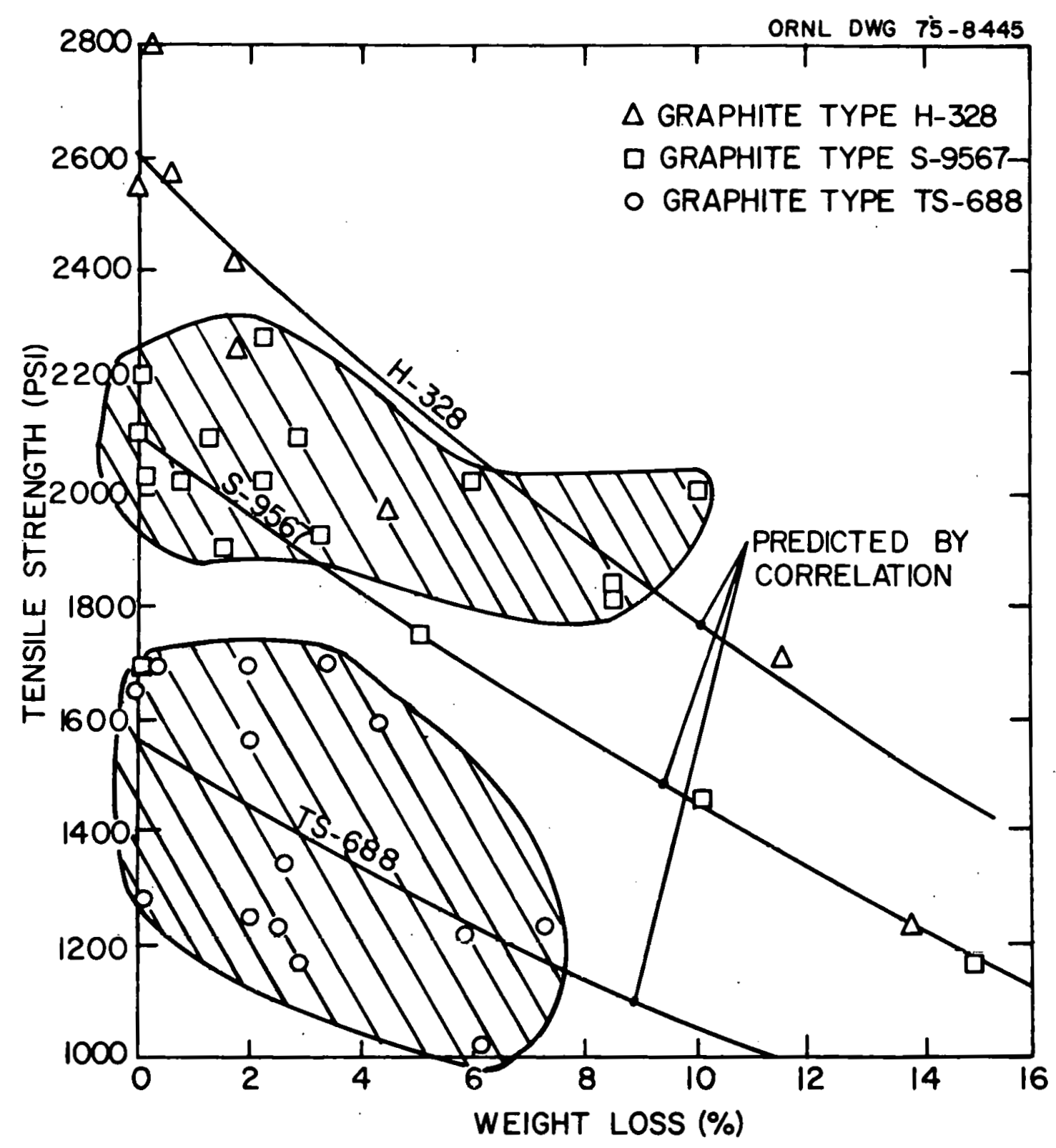

Fig. 6.3. Effect of oxidative weight loss by steam attack at $1000^{\circ} \mathrm{C}$ on the tensile strength of $1 / 2-i n .-d i a m$ graphite specimens. 


\begin{abstract}
"During normal operating conditions, the structure shall have an ultimate static load capacity of five times the primary design load, which consists of the weight of the core support structure, the weight of the core and other supported components, and the core pressure drop. The primary design loads shall include the effects of possible uneven or eccentric load distribution caused by relative displacements of the support members resulting from construction tolerances, PCRV movements, refueling, and thermal expansion."
\end{abstract}

The portion of the NOC core post load consisting of the static loads and core pressure drop is easily estimated, and may be thought of as an idealized core post load. Under normal operating conditions, many core posts must bear an additional load due to the other factors mentioned above, all of which may be categorized generally as being due to a nonideal load distribution. The effect of non-ideal load distribution has not been estimated.

The judgment adopted in this study is that non-ideal load distributions can cause a factor of 2 load increase for a significant number of core posts. This is in fair accord with an estimate in CASSAR which stațes: ${ }^{7}$
"During NOC, the statically determinate load on a typical core post will be about $12,400 \mathrm{lb}_{f}$ with a possible unpermbound statically indeterminate load of about $20,000 \mathrm{Ib}_{\mathrm{f}^{\circ}}$ "

In our terminology, non-ideal load distributions may cause a factor of 20,000/12,400, or 1.6 increase in load according tu rer. 6.

NOC core post stresses are estimated to be 1000: psi, as indicated by statistics shown in Table 6.3. The weight of the core and supporting structures were taken from the Delmarva Power and Light PSAR 8 instead of GASSAR, ${ }^{6}$ since we have adopted a $2000 \mathrm{MW}(t)$ HTGR for this study.

The core pressure drop of 11.3 psi must be applied over the entire plenum area including the active core and permanent side reflectors. This area is estimated here simply as the inner PCRV cavity diameters of 
Table 6.3. Core post loads and stresses

Weight of core

Weight of support structure

Core pressure drop

Applied over area

Force due to coolant flow

Total ideal NOC load

$$
\begin{gathered}
2,000,000 \mathrm{Ib}_{f} \\
250,000
\end{gathered}
$$

$\frac{11.3}{838 \mathrm{ft}^{2 \mathrm{f}}} / \mathrm{in} .^{2}$

No. of core posts

3 for each of 55 fuel zones (which

include some radial reflector blocks)

165

Assume 3 posts for each of 30 permanent

side reflector blocks

Total number core posts

Ideal load per core post

Idea.1 compressive stress

Total compressive stress

Ultimate compressive strength of ATJ (clean, cold) b $^{\mathrm{b}}$

$\frac{1,610,0001 b_{f}}{3,610,0001 b_{f}}$

Safety factor

90

255

\footnotetext{
${ }^{a}$ Pertains to cavity diameter of 32 ft 8 in.

$\mathrm{b}_{\text {Sect. }}$ 4.2.
}

$32 \mathrm{ft} 8 \mathrm{in}$. This is slightly high because the thermal barriers are evidently supported by the PCRV and hence do not add to the core post load.

As shown in Table 6.3, a total NOC core post stress of 1000 psi is estimated, which when compared with the ultimate compressive stress for ATJ graphite of 10,000 psi, yields a safety factor of 10 . It should be noted that GASSAR ${ }^{6}$ also estimates an initial safety factor of 10 for the core posts ${ }^{6}$ for the $3000 \mathrm{MW}(t)$ HTGR using the results of model tests. The core post strength loss due to corrosion may reach as high as $50 \%$ before the initial safety factor of 10 is reduced to the minimum specified value of 5 . 


\subsubsection{Core post temperature regime}

The nominal core post temperature in the reference reactor chosen for this study is $786^{\circ} \mathrm{C}$, which is simply the average coolant exit temperature from the core for this particular design. The average core exit temperature in the GASSAR reference reactor and also in the Delmarva Power and Light Company reactor is $30^{\circ} \mathrm{C}$ lower, or $756^{\circ} \mathrm{C}$, whereas $786{ }^{\circ} \mathrm{C}$ is representative of the Fort St. Vrain reactor.

Tt will be ohown in Becl. 6.4.3 that these modest differences in agoumed nomilid cure post temperatures do not significantly effect results in spite of the rapid change in reactor rate with temperature - the reaction rate changes by a factor of 2 for about a $30^{\circ} \mathrm{C}$ temperature change at these temperatures. However, the core posts are buffered with respect to any modest temperature variability as long as the temperature differences reflect general primary system temperature level differences. The reason for this behavior is that for a given ingress rate a generally hotter primary system will, with its higher core temperatures, be an improved getter for the oxidant. A modest elevation in the primary system temperature would result in lower equilibrium oxidant levels which approximately compensates for the intrinsically elevated corrosion rate at the higher. lemperature.

The key temperature parameter, and indeed one of the key parameters of this study, is the maximum temperature elevation above the average continually sustained by a significant portion of the core post material.

GASBAR" at one point gives the maximum core post "design" temperature as $1040^{\circ} \mathrm{C}\left(1918^{\circ} \mathrm{H}^{\prime}\right)$, referred to nominal $770^{\circ} \mathrm{C}\left(1418^{\circ} \mathrm{F}\right.$ ) for a maximum sustained temperature elevation of $278^{\circ} \mathrm{O}$. This appears to be excessively conservative (i.e., tro high) for the cure posts. No supporting calculations or discussions are offered to justify this high value.

Two factors seem to have a major influence on sustained core post temperature deviations from the mean. First, there are deviations due to departures from the ideal coolant-flow control valve setting for the refueling region. The design of the sensing probe in the core exit thermocouple well is stated in ref. 10 to yield an estimated error of 
$\pm 25^{\circ} \mathrm{C}\left(45^{\circ} \mathrm{F}\right)$ in the region exit temperature. However, a later design basis given by GASSAR is not as specific. GASSAR states ${ }^{17}$ that the mixed mean coolant temperature for a region will be limited to $827^{\circ} \mathrm{C}\left(1520^{\circ} \mathrm{F}\right)$ for steady state operation. This represents an allowable deviation of $+57^{\circ} \mathrm{C}\left(103^{\circ} \mathrm{F}\right)$ referred to the maximum permissible core average exit temperatures for steady state operations of $770^{\circ} \mathrm{C}$.

A second factor influencing the maximum sustained core post temperature elevations is hot streaking due to intraregion power tilting. The flow issuing from the coolant channels begins to $\mathrm{mix}$ in the exit plenum of the replaceable bottom reflector as shown in Fig. 6.4 (taken from GASSAR). The mixing process continues in the permanent bottom reflector and in the core support block where coolant flows from the seven columns within the zone first begin to mix. The problem of assessing the hot-streaking effect at the core posts is quite complex. Not only is the hydraulic configuration unusual and tortuous, particularly in the support block, but the radial temperature distribution may vary with time during the 4-year life of the fuel elements within the zone.

One indication of the hot-streaking effect at the core posts may be obtained from the results of the steam generator inlet hot streak analysis, the results of which are given in GASSAR, ${ }^{12}$ and with somewhat more detail in ref. 13. These results indicate a maximum steam generator "inlet streak temperature" of $790^{\circ} \mathrm{C}\left(1454^{\circ} \mathrm{F}\right)$ at steady state. However, it is not clear whether this refers to the design inlet temperature of $723^{\circ} \mathrm{C}\left(1330^{\circ} \mathrm{F}\right)$, which yields a hot streak temperature rise of $67^{\circ} \mathrm{C}$, or if this refers to $751^{\circ} \mathrm{C}\left(1383^{\circ} \mathrm{F}\right)$, which is the maximum anticipated sustained coolant temperatures from one of the four coolant loops. If the latter interpretation is correct, the hot streak temperature rise would be only $39^{\circ} \mathrm{C}$. Thus, the value of the hot streak temperature rise at the steam generator inlet lies between 39 and $67^{\circ} \mathrm{C}$, depending on interpretation.

A second estimate of the hot streak temperature rise at the core posts may be obtained from the OXIDE-3 computations given in Table 5.8. As noted in Table 5.4, region 2 of the OXIDE-3 program is the hottest column within refueling zones 3 or 6 . These results show that the coolant exits the 
ORNL DWG 75-8409

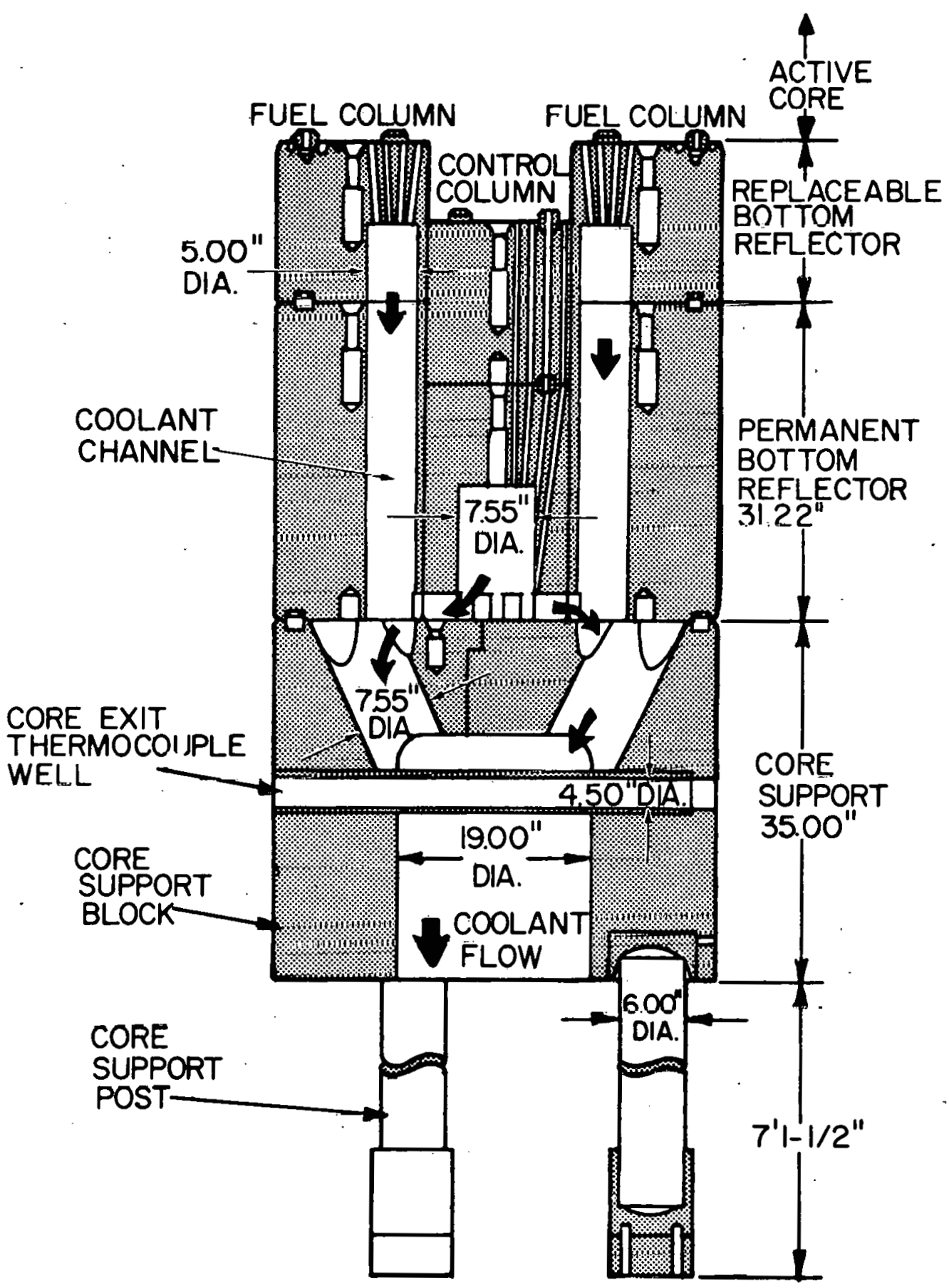

Fig. 6.4. Bottom reflector and core support details. 
hottest column in these two refueling zones, $87^{\circ} \mathrm{C}$ hotter than the core average exit temperatures. This estimate may be high due to the mixing affected in the support block with coolant from the other columns within the region, or it may be low compared with values that might be obtained from other regions. Regions 3 and 6 were selected for this special treatment by the OXIDE-3 program, because the highest radial power factor averaged over one refueling cycle occurs in these two regions. However, other regions with lower average radial power factors may have larger intraregional power variations, and cause a higher hot streaking effect.

A low value of the hot streaking effect at the core posts may be estimated to be $64^{\circ} \mathrm{C}$. This is obtained by summing the thermocouple error of $25^{\circ} \mathrm{C}$ at the region exit, which determines the value of the regional coolant flow, and $39^{\circ} \mathrm{C}$, the low estimate for the hot streak rise at the steam generator.

A higher, reasonable hot streak estimate is obtained by summing the effects of thermocouple error $\left(25^{\circ} \mathrm{C}\right)$ with the hot, column temperature increment of $87^{\circ} \mathrm{C}$ computed for refueling zones 3 and 6 . This yields a hot streak effect of $112^{\circ} \mathrm{C}$.

Still higher values may be obtained. For example, use of the maximum permissible regional exit temperature elevation of $57^{\circ} \mathrm{C}$, instead of solely the thermocouple component of this deviation of $25^{\circ} \mathrm{C}$, would add $27^{\circ} \mathrm{C}$ to the above estimates. At his point, it should perhaps be emphasized that we seek the maximum hot streak effect on a significant portion of the core posts averaged over the 40-year reactor life. Several factors could combine to yield temperature elevations of $112^{\circ} \mathrm{C}$ or above for times short that are with respect to the 40-year lifetime; however, it may not be reasonable to expect these factors to coincide for the entire 40 years. The time-average hot streak temperatures could be significantly lower than that obtalned by simply suming the maximum contributions estimated from each source. Section 6.4 will show that the maximum, continually sustained core post temperature is one of the most sensitive parameters of this study. The attention thus far devoted to a realistic estimate of this parameter has not been adequate. A more careful appraisal would require thermalhydraulic measurements or analyses such as those performed for the steam 
generator hot streak work, combined with intraregional power distribution information, and a reappraisal of the anticipated maximum sustained departure from the ideal regional coolant distribution; all of these effects should be combined and averaged over a sufficiently long time period.

For this study, a judgment has been exercised based on the information presented, that a reasonable estimate of the maximum sustained core post temperature excess over the mean is $90^{\circ} \mathrm{C}$. Thus for this study, the nominal core post temperature is $786^{\circ} \mathrm{C}$, and the maximum sustained core post temperature is taken to be $876^{\circ} \mathrm{C}$.

\subsection{Predicted Core Post Burnoffs and Strength Loss at End of Reactor Life}

\subsubsection{Eftect of steam ingress rate}

The predicted core post burnoffs that result from 40 years of continuous steam ingress are shown in Fig. 6.5 for the core post at the assumed nominal temperature of $786^{\circ} \mathrm{C}$, and assuming nominal purification flow. The burnoffs, expressed as $\mathrm{mg} / \mathrm{cm}^{2}$, were computed using Eq. (10) Rerived in dect. 4.1.3 Irom ATJ corrosion data. The four curves slluwn pertain to the four different estimates of the impurity atmosphcre at the stated ingress rale. The surve labcled "Drayurl" refers to burnoffs calculated from HTGR impurity levels predicted using Dragon steam ingress data as the basis for predicting core reactivity to $\mathrm{H}_{2} \mathrm{O}$. The impurity levels used to obtain this curve are given in Fig. 5.2 and Table 5.6. 'Lhe remaining three curves were ohtained from impurity levels predicted using "IDMOX for three assumed corrnsion ratc cxpressivis for the core graphite. These are derived in sect. 5.3, and the impurity levels on which these burnoff predictions are based are shown in Figa. 5.8 and 5.9, and l'able 5.6 .

Figure 6.5 shows that at low steam ingress rates, predicted burnoffs range through about a factor of 5, depending on the asomed core reactivity that determines the environment experienced by the core post. The range begins to narrow for assumed ingress rates of about $0.004 \mathrm{~g} / \mathrm{sec}$ and reaches only about $50 \%$ for ingresses of $0.04 \mathrm{~g} / \mathrm{sec}$ and above. This is because the 


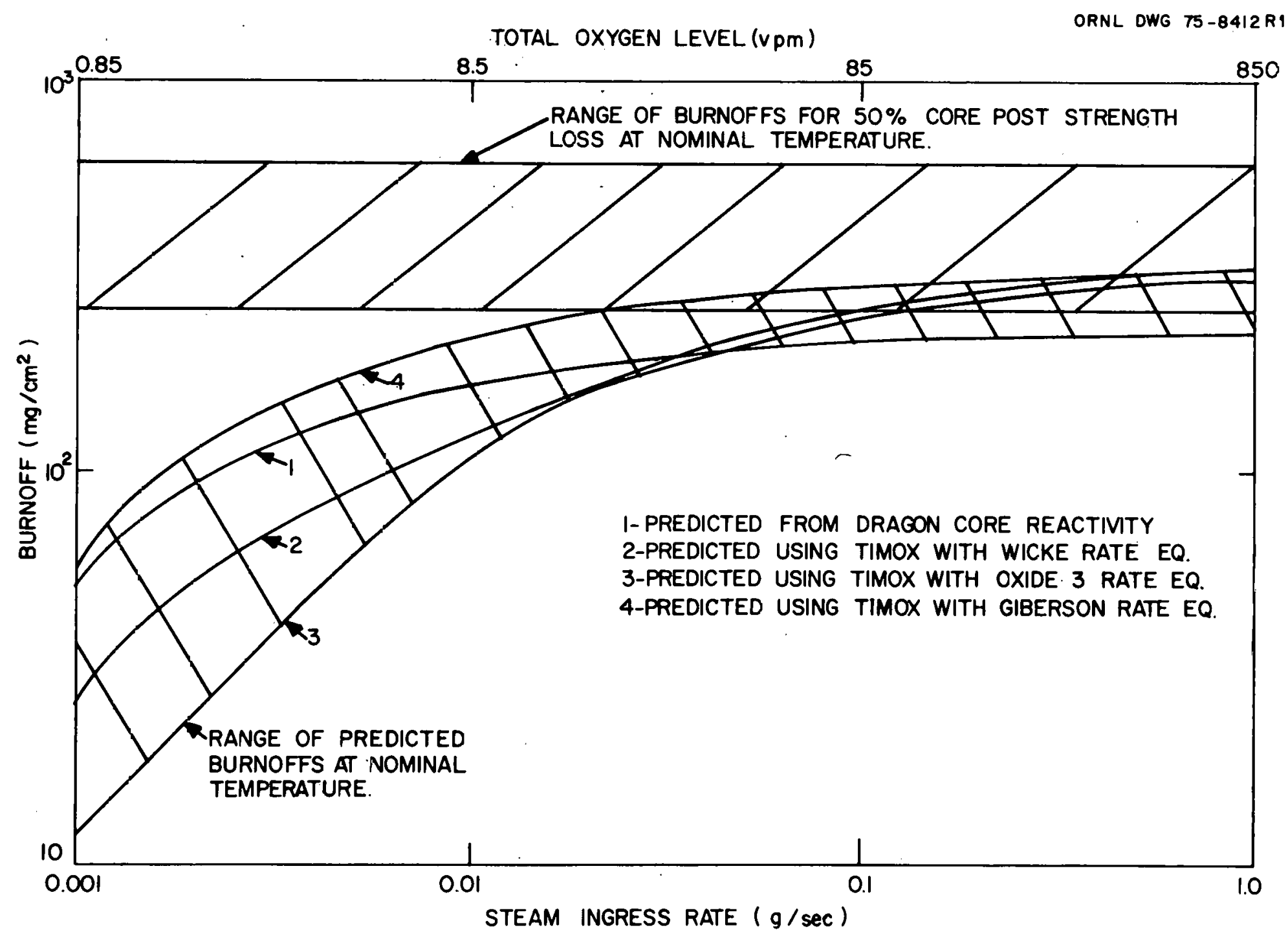

Fig. 6.5. Core post burnoffs at end of 40-year life - for nominal core post temperature and nominal purification flow. 
ATJ corrosion expression tends to become zero order (i.e., independent of $\mathrm{H}_{2} \mathrm{O}$ concentration) for the higher concentrations resulting from the higher ingress rates. Core reactivity thus is a less sensitive parameter at the higher values of steam ingress.

The degree of burnoff estimated to cause the maximum allowable strength loss of $50 \%$ is indicated by the horizontal band. This range was determined by setting the fractional strength loss (FSL) to a value of 0.5 in Eq. of sect. 6.2, and using the core post diometer, D, of $15.24 \mathrm{~cm}$ (6 in.). Solving Eq. (3) for the burnoff for 50\% strength loss yields:

$$
\mathrm{BO}_{50}\left(\frac{\mathrm{g}}{\mathrm{cm}^{2}}\right)=\frac{3.68}{\mathrm{P}(\mathrm{T})},
$$

where $P(T)$ are temperature-dependent factors given in Table 6.2. For the nominal core post temperature of $786^{\circ} \mathrm{C}, \mathrm{P}(\mathrm{T})$ is estimated to range between 5.95 and 14.0, which yields the indicated uncertainty band for $50 \%$ strength loss.

Figure 6.5 shows that for continuous ingress rated below $0.024 \mathrm{~g} / \mathrm{sec}$ there is a zero probability of $50 \%$ strength loss at the end of the 40-year life, for this case assuming nominal core post temperature. continuous ingress rates above $0.02 \% \mathrm{~g} / \mathrm{sec}$ begin to show some vverlap in the range of predicted burnoffs with the range willch could result in $50 \%$ strength 10 ss. Hence, ingress rates above $0.024 \mathrm{~g} / \mathrm{sec}$ yield some nonzero probability of $50 \%$ strength loss. A general methor for predicting lhe probability for this case of overlapping error bands is outlincd. in Appendix A. The results show that if the precise burnoff for 50\% core nost. strength loss Iles equal pro-' bability between the indicated limits $\left(620 \mathrm{mg} / \mathrm{cm}^{2}\right.$ to $260 \mathrm{mg} / \mathrm{cm}^{2}$ in Fig. 6.5$)$, and the predicted burnoff also can be with equal probahility within tlis iflalcated errur band at any given ingress rate, the probability for $50 \%$ core post strength loss is given by

$$
r_{1}(50)=\frac{\left(y_{2}-x_{1}\right)^{2}}{2\left(x_{2}-x_{1}\right)\left(y_{2}-y_{1}\right)} \text {, }
$$

where 
$p_{1}(50)=$ probability for $50 \%$ core post strength loss,

$\mathrm{y}_{2}, \mathrm{y}_{1}=$ upper and lower limit to predicted burnoff range,

$\mathrm{x}_{2}, \mathrm{x}_{1}=$ upper and lower limit to burnoff range for $50 \%$ strength Ioss.

Equation (6) applies to the case shown in Fig. 6.5 where the error band for predicted burnoffs intrudes partially into the lower portion of the error band for 50\% strength loss. The application of values from Fig. 6.5 to Eq. (6) indicates that the probability of $50 \%$ core post strength loss at $1.0 \mathrm{~g} / \mathrm{sec}$ continuous ingress rate is $8 \%$.

The situation with respect to the portions of the core posts at the maximum estimated sustained core post temperature of $876^{\circ} \mathrm{C}$ is illustrated in Fig. 6.6. The range of burnoffs is approximately a factor of 8 higher than-occurs at the nominal core post temperature. The estimated range of burnoffs that could cause 50\% strength loss is also somewhat higher since the values of the penetration factor, $P(T)$, decrease with increasing temperature, as shown in Table 6.2.

The estimates in Fig. $6: 6$ show that there begins to be some nonzero probability for $50 \%$ core post strength loss at ingress rates of 0.0014 $\mathrm{g} / \mathrm{sec}$ for the core post material at this higher temperature.

For the burnoff range predicted between ingress rates of 0.0014 and $0.0023 \mathrm{~g} / \mathrm{sec}$, Eq. (6) may be used to estimate the probability for $50 \%$ strength loss. Equation (7), derived in Appendix A, is appropriate for the situation between ingress rates of 0.0023 and $0.007 \mathrm{~g} / \mathrm{scc}$, where the estimated range of burnoffs straddles both ends of the range for $50 \%$ strength loss. For this case,

$$
\mathrm{P}_{4}(50)=\frac{2 \mathrm{y}_{2}-\left(\mathrm{x}_{1}+\mathrm{x}_{2}\right)}{2\left(\mathrm{y}_{2}-\mathrm{y}_{1}\right)} \text {, }
$$

where definitions are the same as those for Eq. (6). Equation (8) pertains to the region between ingress rates of 0.007 and $0.012 \mathrm{~g} / \mathrm{sec}$, where the estimated burnoffs Intrude into the upper portion of the $50 \%$ strength loss error band: 


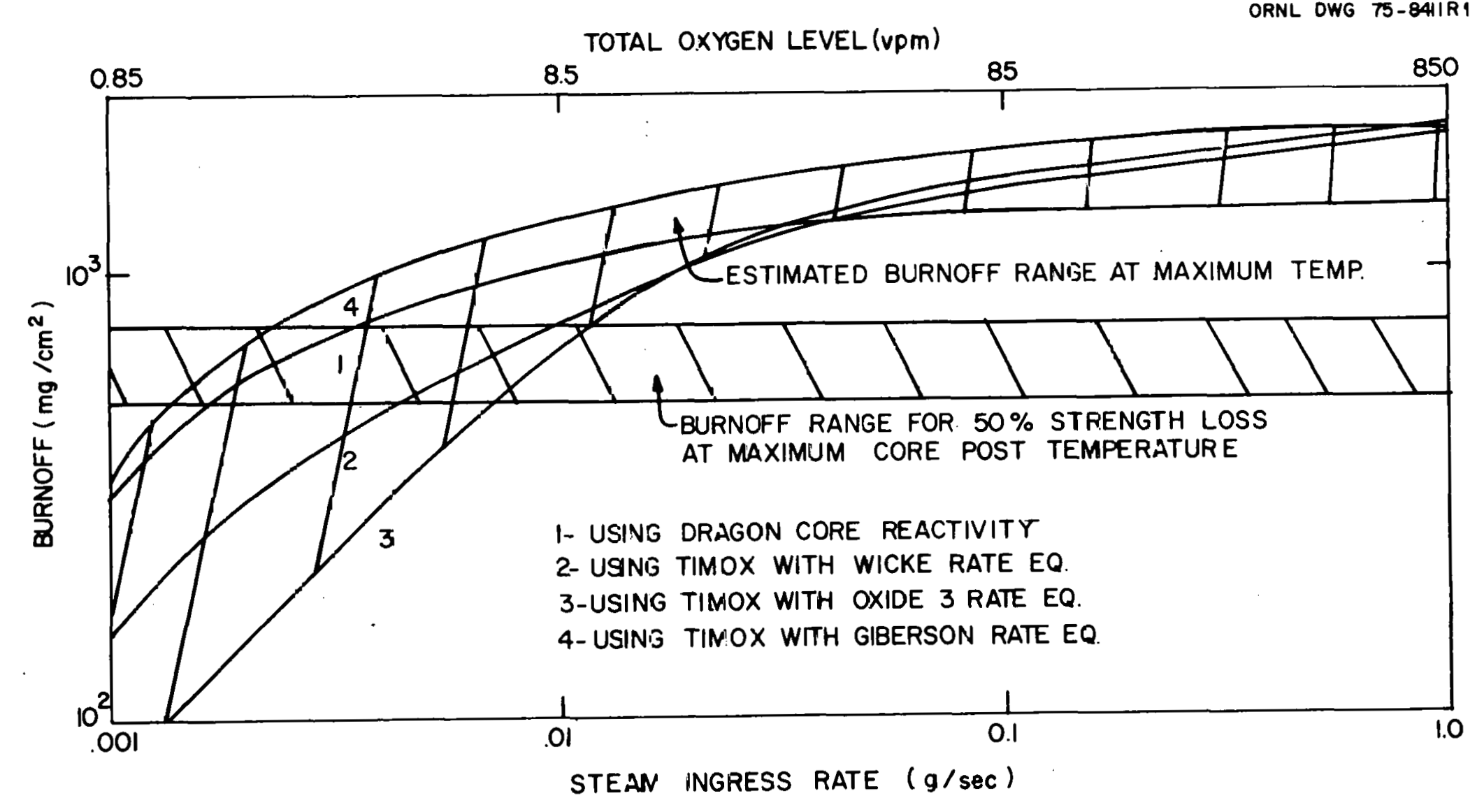

FiE. 6.6. Core post burnoffs at end of 4c-year life, for maximum ccre post temperajure and nominal purification flct. 


$$
\mathrm{P}_{3}(50)=\frac{\left(\mathrm{x}_{2}-\mathrm{y}_{1}\right)\left[0.5\left(\mathrm{y}_{2}+\mathrm{x}_{1}\right)-\mathrm{x}_{1}\right]}{\left(\mathrm{x}_{2}-\mathrm{x}_{1}\right)\left(\mathrm{y}_{2}-\mathrm{y}_{1}\right)}+\frac{\mathrm{y}_{2}-\mathrm{x}_{2}}{\mathrm{y}_{2}-\mathrm{y}_{1}}
$$

Ingress rates above $0.012 \mathrm{~g} / \mathrm{sec}$ yield a probability for $50 \%$ strength loss of $100 \%$, since the predicted burnoff band is totally above the $50 \%$ strength loss range.

The probabilities for sustaining 50\% core post strength loss as a function of continuous, 40-year steam ingress rates are summarized in Fig. 6.7. This figure shows that the probability for 50\% strength loss is quite low throughout the examined range of ingress rates for the core posts at the nominal temperature, but is significantly higher for the core post material at maximum sustained temperature. At the 10-vpm total oxygen level projected for ingress rates slightly above $0.01 \mathrm{~g} / \mathrm{sec}, 50 \%$ core post strength loss is virtually assured for the post material at the maximum estimated sustained temperature.

Additional details of the predicted range of core post strength loss at nominal purification flow as a function of assumed ingress rates from 0.001 to $1.0 \mathrm{~g} / \mathrm{sec}$ are given in Figs. B.1-B.4 in Appendix B. These four figures refer to strength losses which result from 40-year exposures to corrosive atmospheres projected from the four estimate methods employed for HTGR core reactivity to $\mathrm{H}_{2} \mathrm{O}$. These figures show that an ingress rate of $0.011 \mathrm{~g} / \mathrm{sec}$, which results in a total oxygen level of $10 \mathrm{vpm}$, would causc a etrength 1 oss ranging from 15 to $42 \%$ on 40-year exposure of the core posts at the nominal temperature level. The hotter core post material would, under these conditions, lose from 47 to $94 \%$ of its initial strength.

\section{4 .2 Effect of purification rate on core post burnoff and strength}

Figure 6.8 illustrates the effect of varying purification flow on burnoff for core posts at buth the nominal and highest sustained temperature for an assumed ingress rate of $0.011 \mathrm{~g} / \mathrm{sec}$. As in sect. 6.4.1, the estimated burnoffs are shown as a range covering the span predicted from the four methods employed for calculating the impurity compositions. The burnot' range eslimated to cause 50\% strength loss at each level of core post temperature is shown as the shaded area on the left of the figure. 


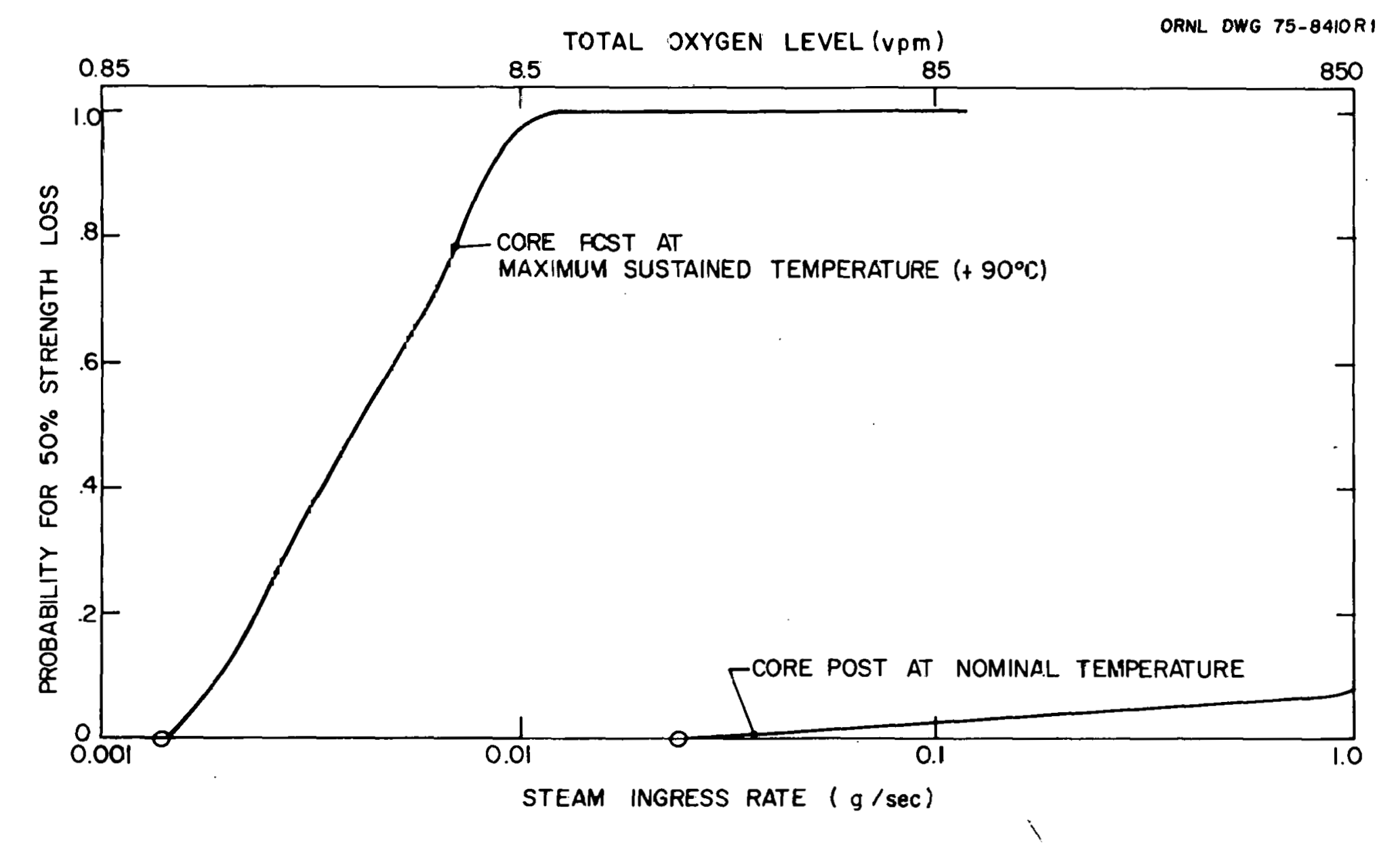

850

Fig. 6.T. Probability of $5 \%$ core post strength loss vs steam ingress rate. Nominal Furification rate. 
TOTAL OXYGEN LEVEL ( $v \mathrm{pm}$ )

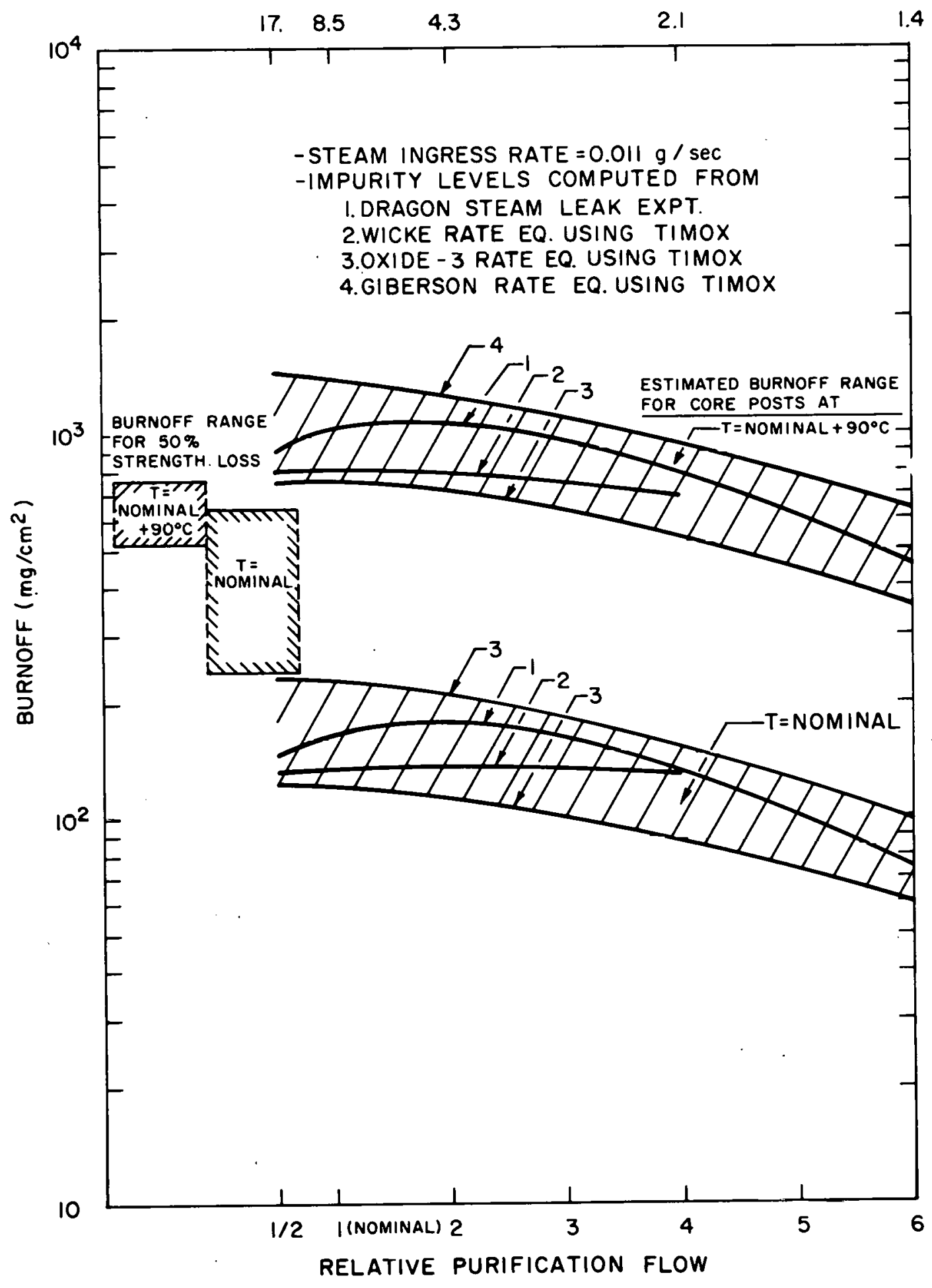

Fig. 6.0. Effect of purifination flow on core post burnoff. 
A small sensitivity of predicted burnoff to modest variations of the purification rate around the nominal value can be seen. As the purification flow is increased both the products of corrosion, which inhibit the corrosion rate, and the oxidant levels decrease. These concentration trends with purification flow tend to offset each other rendering burnoff insensitive to small changes in purification flow. The figure shows that the burnoff range causing 50\% strength loss at the nominal core post temperature lies entirely above these projected burnoffs for $0.011 \mathrm{~g} / \mathrm{sec}$ steam ingress rate. Thus, the probability for $50 \%$ strength loss ic zero for the entirc range of purlelcation fllows. The probability for $50 \%$ strength loss is seen to be quite high for the hotter core post material, from purification flows equal to one-half to about five times the nominal rate for this assumed ingress rate.

The probabilities for 50\% strength loss, listed in Table 6.4 for these cases, were estimated using the general method outlined in the previous section and in Appendix A.

Table 6.4. Probability for 50\% strength loss of core post at maximum sustained temperature as a function of purification rale; assumed steam ingross rate $=0.01 \mathrm{~g} / \mathrm{sec}$

\begin{tabular}{|c|c|c|c|}
\hline $\begin{array}{c}\text { Relative } \\
\text { purificallun } \\
\text { rale }\end{array}$ & $\begin{array}{c}\text { 'l'otal oxygen } \\
\text { (vpm) }\end{array}$ & $\begin{array}{l}\text { Burnoff range } \\
\text { at maximim } \\
\text { tempcre.tims } \\
\left(\mathrm{mg} / \mathrm{cm}^{2}\right)\end{array}$ & $\begin{array}{l}\text { Probability } \\
\text { Pur 5o\% Btrength } \\
\text { loss }\end{array}$ \\
\hline 0.5 & 17 & $750-1440$ & 0.999 \\
\hline 1. (nominal) & 8.5 & $750-1400$ & 0.999 \\
\hline 2 & 4.3 & $710-1250$ & 0.988 \\
\hline 4 & 2.1 & $520-940$ & 0.708 \\
\hline 6 & 1.4 & $370-640$ & 0.111 \\
\hline
\end{tabular}


The estimates in Table 6.4 show that increased purification flows could substantially reduce the probability for $50 \%$ strength loss of the hotter core post material, but that significant benefit results only for purification rates above about five times the nominal rate. The results shown in Table 6.4 pertain to an assumed ingress rate of $0.01 \mathrm{~g} / \mathrm{sec}$ $\left(\sim 0.091 \mathrm{~b}_{\mathrm{m}} / \mathrm{hr}\right)$.

Further details regarding the degree of core post strength loss as a function of purification flow are given in Figs. B.5 and B.6 of Appendix B.

\subsubsection{Effect of primary system temperature level on core post burnoff}

Since the nominal core post temperature in the reference design chosen for this study is about $30^{\circ} \mathrm{C}$ higher than selected for GASSAR, and since this temperature difference represents about a factor of 2 increase in intrinsic reactivity of the core post material, it is pertinent to investigate the effect of this difference on the conclusions regarding estimated loss of core post strength.

Several interrelated factors need to be considered for determining the way core post strength loss due to corrosion is affected by increased cuolant exit temperatures. As noted above, the intrinsic rate of corrosion increases rapidly with temperature - about a factor of 2 for each $30^{\circ} \mathrm{C}$ temperature rise for ATJ under these conditions; however, the corrosive environment also changes with increasing coolant temperature. Since the core graphite reactivity to steam determined the corrosive environment, and since an increase in coolant exit temperature must be affected by an increase in core graphite temperature, it is evident that the coolant becomes less oxiolzlry as the tcmperature is elevated for a given ingress rate, by virtue of the improved oxidant gettering ability of the core. Hence, the rise in intrinsic corrosion rate of post material with temperature tends to be offset by an accompanying drop in oxidant level. Finally, the burnoff profile in the post material changes with temperature in the manner discussed in Sect. 4.2, with the attendant result that a given amount of corrosion causes less strength loss at a higher temperulure. This is 
reflected in diminishing values of the penetration factor, $P(T)$, for increasing temperatures.

Figure 6.9 illustrates an estimate of the way core post burnoff varies with a general rise in the primary system temperature of $50^{\circ} \mathrm{C}$ and $100^{\circ} \mathrm{C}$, assuming a nominal purification flow and a steam ingress rate of $0.011 \mathrm{~g} / \mathrm{sec}$. The lower set of curves refers to core posts at the nominal temperature, and the upper set of curves refers to post material at the estimated maximum sustained temperature. The impurity levcls as a furktion of temperature were estimated using the TIMOX progrew in conjunction with the Wicke, oxIUt-3, and Gihersen corrogion rale expressions for determining the core reactivity.

The figure shows that when either the wicke or the OXIDE-3 expression is used to determine the impurity composition, the predicted burnoff is lower when the primary system temperature is elevated $100^{\circ} \mathrm{C}$, compared with the predicted burnoff at the nominal temperature level. This is true for both the average core post temperature and the maximum sustained core post temperature. However, when the Giberson rate expression is used for the core graphite, an opposite effect. is seen - the eslinated burnoff is higher at the elevated primary system temperature.

The way these burnofes affect core post strength is illustrated in Fig. 6.10. Improved retention of strength with primary system temperature rise is shown for cases where the Wicke and OXIDE-3 rate expressions are used for the core graphite reactivity. When the Giberson rate expression is used, evidently no major change of estimated strength loss with temperature occurs.

Figure 6.10 shows that more precise information on cure reactivity to steam corrosion is required before une can contidientiy predict the effect of primary system temperature changes on core post strength loss due to corrosion. Apparently, a reasonable chance exists that elevated. primary system temperatures may improve the core poot situation as a result of: (1) improved oxidant gettering by the core, and (2) smaller strength loss for a given degree of corrosion at the higher temperature. 


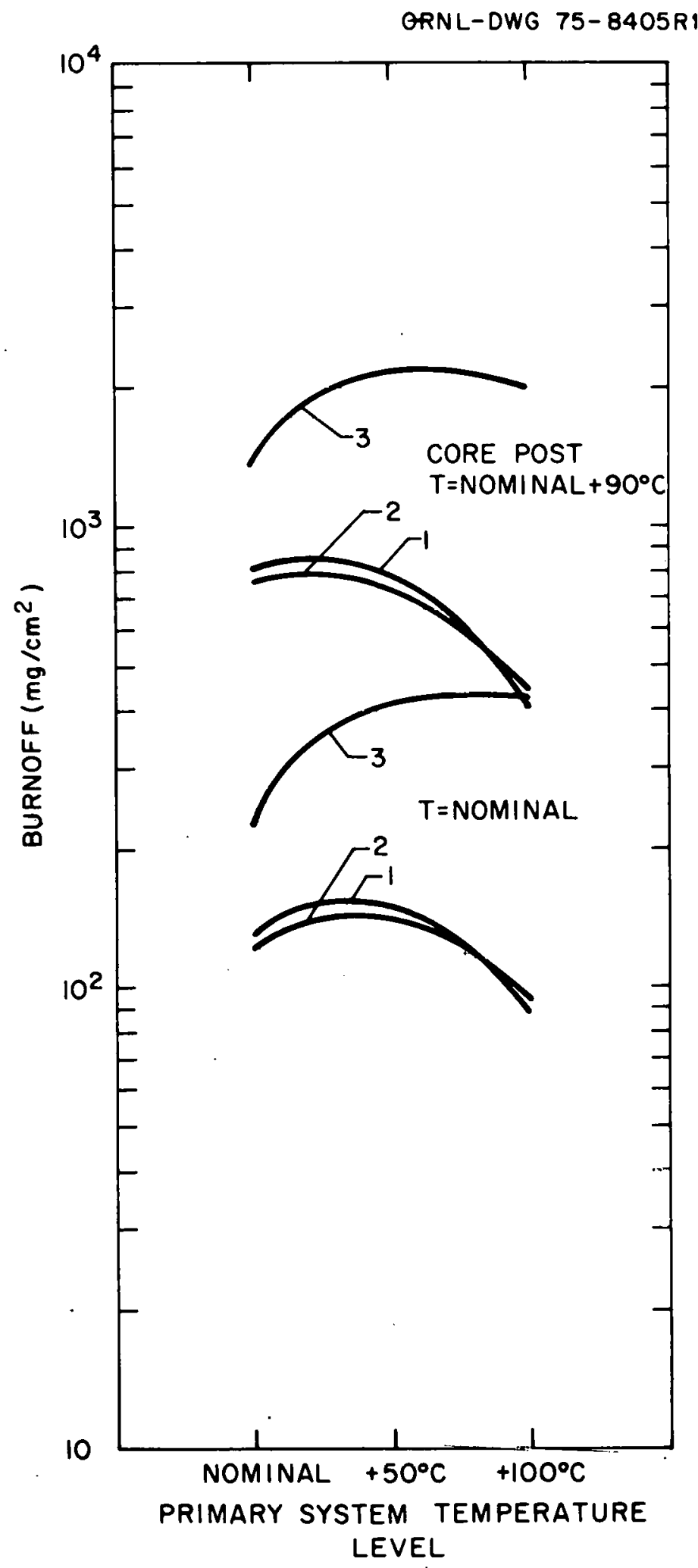

Fig. 6.9. Effect of general temperature level in the primary system on core post burnot't. Purlfication flow - nominal, steam ingress rate $=0.011 \mathrm{~g} / \mathrm{sec}$. Based on impurity levles using TIMOX; 1 . Wicke; 2. OXIDE-3; 3. Giberson rate equations. 


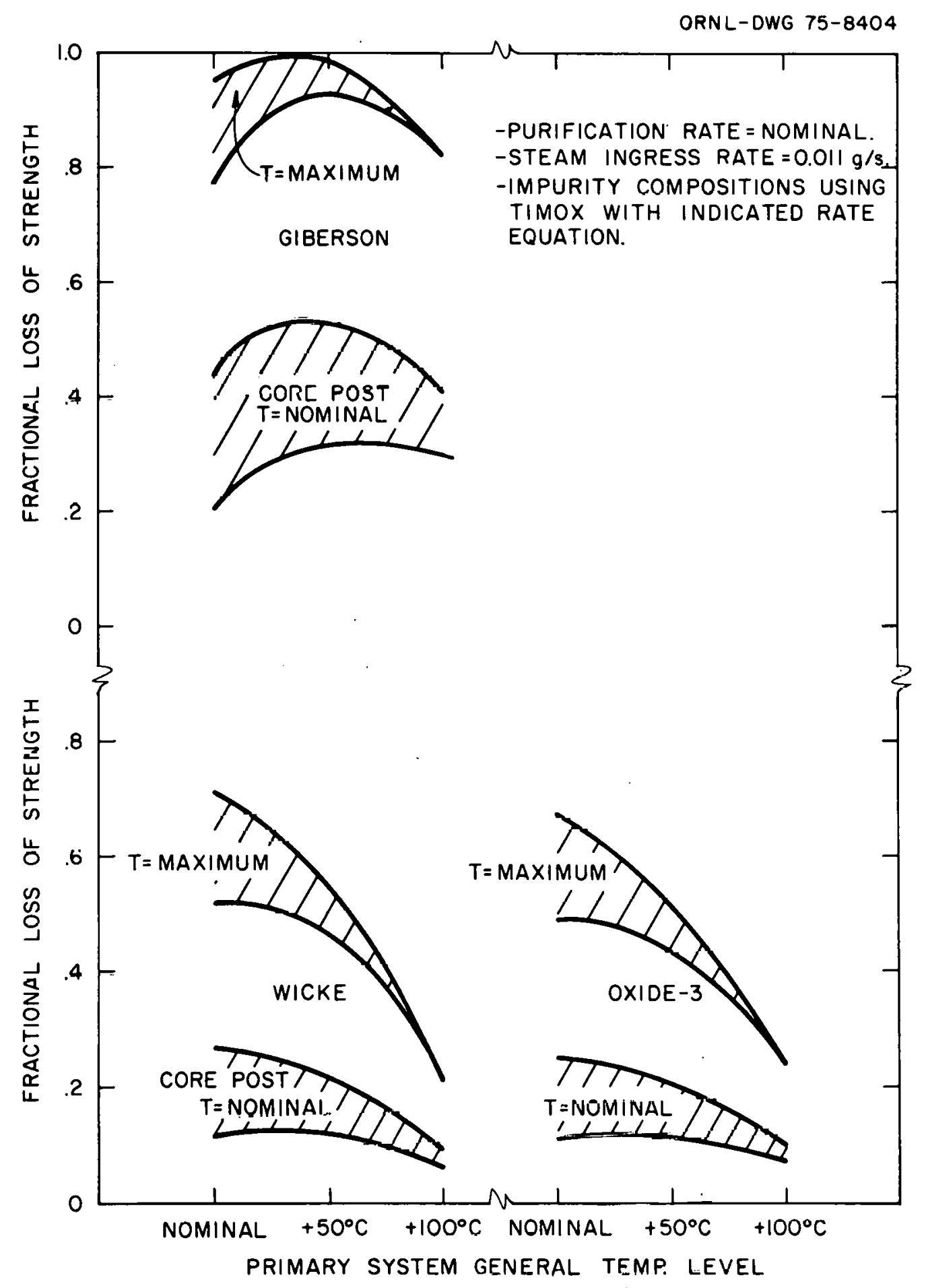

Fig. 6.10. Loss of core post strength vs a general temperature elevation in the primary system. 


\subsubsection{Maximum permissible oxygen and oxidant levels}

The total oxygen concentration (defined as the sum of oxygen in all oxygen-bearing species) in the primary circuit is a function solely of the relative steam ingress and purification rates, which allows the curves in Figs. 6.5-6.7 to be plotted against either the steam ingress rate or total oxygen concentration on the abscissa. Figure 6.7 indicates that the presently considered maximum allowable total oxygen level of $10 \mathrm{vpm}$ assures that the core posts at nominal temperature will not suffer $50 \%$ strength loss in 40 years of exposure. However, the core post material at the estimated maximum sustained temperature of $90^{\circ} \mathrm{C}$ above nominal will likely suffer $50 \%$ strength Ioss.

It is beyond the scope of this report to conment extensively on maximum permissible oxidant levels. Figure 6.7 shows that 10-vpm total oxygen may be too high a limit; however, more extensive studies are needed before any definite limit is set, or before it can be stated positively that 10 vpm is indeed too high. The following additional studies are required:

(1) More precise definition of the maximum sustained core post temperature is needed. This study would involve hot streaking analyses, analyses of flux or power distributions within a refueling zone, and operational characteristics of the coolant orificing system which regulates the coolant distribution radially diruss the core.

(2) The volume and location of the hot zones should be determined. If the core post material experiencing these higher temperatures is aufficiently small, perhaps the requirement for a safety factor of 5 for this portion of the core posts could be relaxed. For example, if a safety factor of 2 were permitted fur a sufficiently small region or set of regions, $80 \%$ strength loss would be permissible. The maximum allowable total oxygen level would then be set on the basis of $50 \%$ strength loss for the nominal posts and $80 \%$ luss for the hotter post.s, whichever is lower. 
Wince the burnoff rate depends far more directly on the oxidant concentration, $\mathrm{H}_{2} \mathrm{O}$ and $\mathrm{CO}_{2}$, than the total oxygen level, which includes $\mathrm{CO}$ that actually inhibits corrosion, it appears that an improved definition of maximum permissible impurity level could be stated in terms of total oxidant rather than total oxygen. The broad error band on predicted burnoffs shown in Figs. 6.5 and 6.6 is due to differences in the predicted distribution of a known amount of total oxygen between oxidant, $\mathrm{H}_{2} \mathrm{O}$, and product of corrosion, $\mathrm{CO}$. The four core reactivities employed predict varying distributions. If this information were plotted ugainst $\mathrm{H}_{2} \mathrm{O}$ concentration instead, the error band would be much narrower, as seen in Figs. 6.11 and 6.12.

Figure 6.11 indicates that the probability for $50 \%$ strength loss is zero for the riominal core posts if the steady $\mathrm{H}_{2} \mathrm{O}$ level is sustained below $20 \mathrm{vpm}$. Very high $\mathrm{H}_{2} \mathrm{O}$ levels do not greatly increase the probability for $50 \%$ strength loss; for example, $\mathrm{P}(50)=8.5 \%$ at $1000 \mathrm{vpm} \mathrm{H}_{2} \mathrm{O}$ for the nominal core posts. In an actual case where significant radiolytic $\mathrm{CO}_{2}$ levels exist, the total oxidant concentration would simply be stated as the sum of the $\mathrm{H}_{2} \mathrm{O}$ and $\mathrm{CO}_{2}$ concentrations.

Figure 6.12 shows that the core post material at the maximum sustaincd temperature has a zero probability of $50 \%$ strength loss at continuous oxidant levels below $.1 .0 \mathrm{vpm}$, and $100 \%$ probability for $50 \%$ strength loss above $5.3-v p m$ oxidant.

\subsection{References for section 6}

1. G. H. Helsby and M. R. Iverett, Some Graphite Corrosion Problems Related to HTGR's, D.P. Rept. 566 (August 1968).

2. R. P. Wiohns.r, persultil communicalion, August 1975.

3. HTGR Base Program Quart. Progr. Rept. for Period Ending Aug. 31, 1971, GGA-A10784 (September 1971); Fig. 4.1, p. 3 .

4. GASSAR-6 - Fig. 4.2-19.

5. Public Services Company of Colorado, Research and Development Program, Quart. Progr. Rept. for Period Ending Sept. 30, 1966, CA-7453 (Febmary 1967), Fig. 3.31, p. 130. 
ORN DWG 75-8436R1

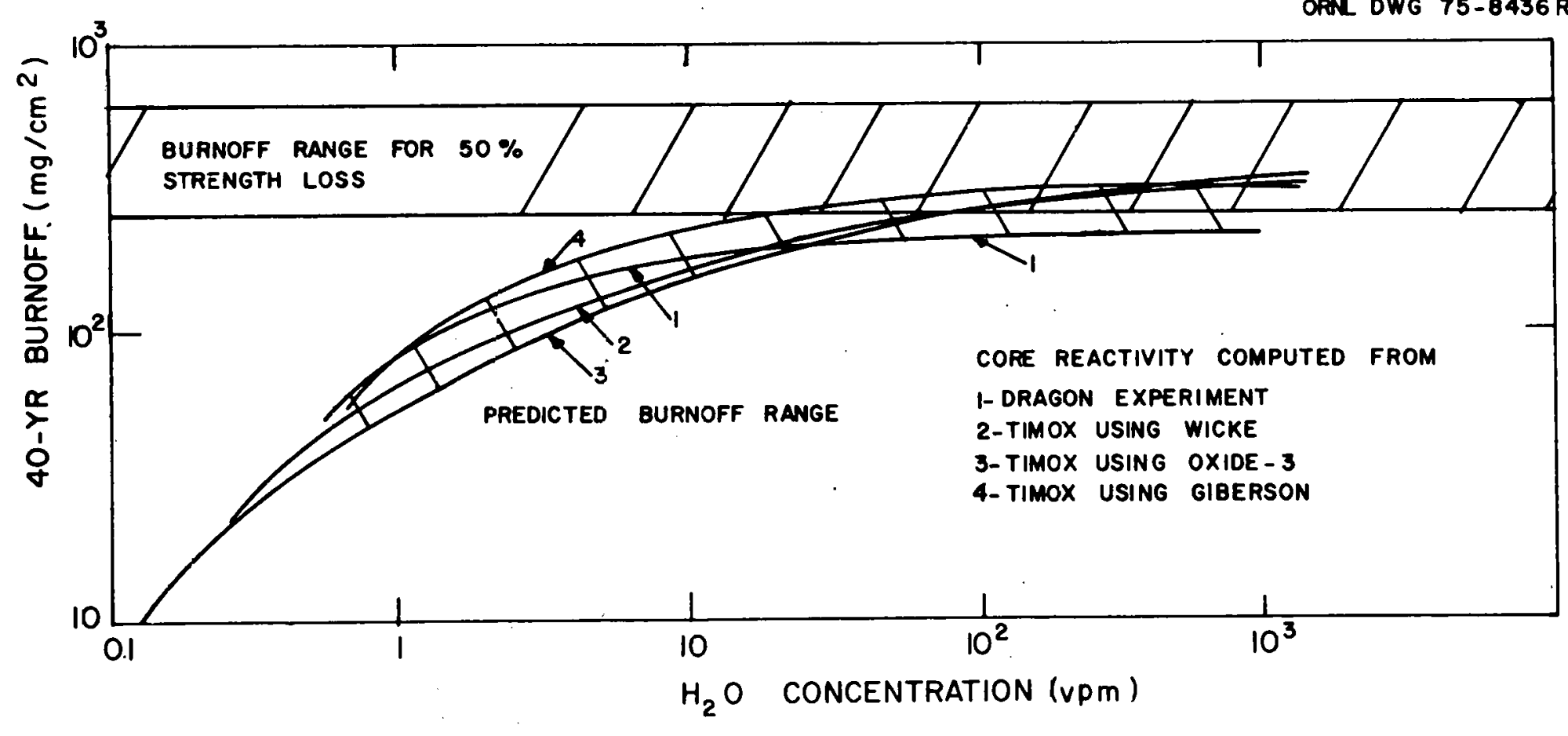

Fig. 6:11. Fortjr-year core post burnoffs vs vpm- $\mathrm{H}_{2} \mathrm{O}$. Nominal core post temperature. 


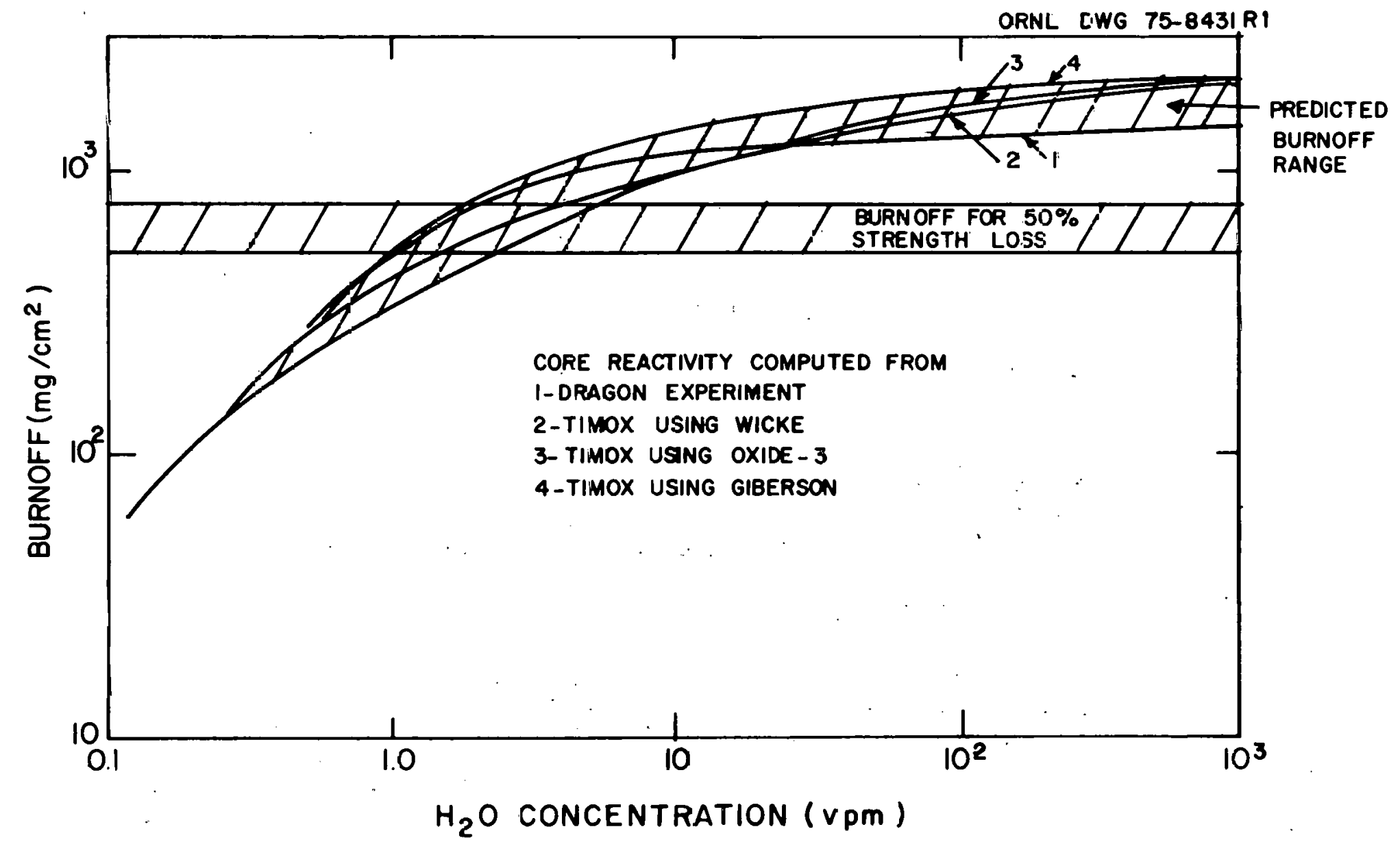

Fig. Б́.12. Forty-year core post burnoff vs $\mathrm{vpm}_{2} \mathrm{H}_{2} \mathrm{O}$. Maximum sustained core post temperature. 
6. GASSAR-6, Section 4.2, p. 57

7. GASSAR-6, Section 4.2, p. 76 .

8. Delmarva Power and Light Preliminary Safety Analysis Report, Section 4.2.2.1.2.

9. GASSAR-6, Table 4.2-13.

10. Delmarva Power and Light Preliminary Safety Analysis Report, Section 4.4.2.3.1.

11. GASSAR-6, Section 4.4.1.2.

12. GASSAR-6, Section 5.4.1.5, Table 5.3-1.

13. Delmarva Power and Light Preliminary Safety Analysis Report, Section 5.3.2.5, Table 5.3.1-1, and Appendix E.

\section{ACKNOWLEDGMENTS}

I am most grateful for the assitance provided by D. J. Strickler of the Computer Sciences Division in communicating with the computer and particularly for the development of the TIMOX program. C. W. Nestor, Jr., also of the Computer Sciences Division aided significantly in developing the probabilistic method of presenting the results which are derived in Appendix A. 
THIS PAGE

\section{WAS INTENTIONALLY LEFT BLANK}


APPENDIX A: METHOD FOR ESTTMATING PROBABILITY OF 50\% CORE POST STRENGTH LOSS FOR CASES WHERE THE ESTTMATED BURNOFF RANGE AND THE RANGE FOR 50\% STRENGTTH LOSS OVERLAP

Let $f(X)$ be the probability density function for bumoffs which cause $50 \%$ strength loss, where $\mathrm{X}$ is a random variable signifying value of burnoff. Thus,

$$
\left|\begin{array}{l}
\text { probability that the burnoff } \\
\text { which causes } 50 \% \text { strength loss } \\
\text { lies in } d X \text { about } X
\end{array}\right|=f(X) d X .
$$

The distribution function for burnoffs which cause $50 \%$ strength loss, $\mathrm{F}(\mathrm{X})$, defines the probability that $50 \%$ strength loss has occurred at $X$ value of burnoff or below.

$$
F(X)=\int_{0}^{X} f\left(X^{\prime}\right) d X^{\prime}
$$

A flat density function is assumed in this work; that is, the burnoff which causes $50 \%$ strength loss can with equal likelihood be a value between the upper and lower limits, $x_{2}$ and $x_{1}$. For this case, $f(x)$ is given by

$$
\begin{array}{cc}
0 & 0<x<x_{1} \\
\frac{1}{x_{2}-x_{1}} & x_{1}<x<x_{2} \\
0 & x>x_{2},
\end{array}
$$

hence, $F(X)$ is given by

$$
\begin{array}{cc}
0 & 0<x<x_{1}, \\
\frac{x-x_{1}}{x_{2}-x_{1}} & x_{1}<x<x_{2}, \\
I & x>x_{2} .
\end{array}
$$

Let $g(Y)$ be the probability density function for estimated burnoffs, that is, 


$$
\left\{\begin{array}{l}
\text { probability that estimated burnoff } \\
\text { lies within } d Y \text { about } Y
\end{array}\right\}=g(Y) d Y .
$$

For a flat distribution between upper and lower limits $\mathrm{y}_{2}$ and $\mathrm{y}_{1}, \mathrm{~g}(\mathrm{Y})$ is given by

$$
\begin{array}{cc}
0 & Y<y_{1}, \\
\frac{1}{y_{2}-y_{1}} & y_{1}<y<y_{2}, \\
U & Y>y_{2} .
\end{array}
$$

Theretiorc; the probability that burnoff $Y$ about dY occurs within the error band of estimated burnoffs, and that $50 \%$ strength Ioss is caused by this amount of burnoff or less, is given by,

$$
F(50)=\int_{0}^{\infty} g(Y) F(Y) d Y
$$

where $P(50)$ is the probability for 50\% strength loss.

Expressions for the probability of $50 \%$ strength loss will be obtained for four cases of hurnoff ranges, each assuming the flat distributions represented by Eqs. (A4) and (A6).

\section{Case I:}

The estimated burnoff range, $\mathrm{y}_{1}$ to $\mathrm{y}_{2}$, intrudes into the lower portion of the burnoff range for $50 \%$ strength loss, $x_{1}$ to $x_{2}$.

$$
\begin{aligned}
& \mathrm{y}_{1}\left(\begin{array}{c}
\text { estimated } \mathrm{BO}) \\
\text { range }
\end{array}\right) \\
& \mathrm{P}_{2}(50)=\frac{\left(\mathrm{y}_{2}-\mathrm{x}_{1}\right)^{2}}{2\left(\mathrm{x}_{2}-\mathrm{x}_{1}\right)\left(\mathrm{y}_{2}-\mathrm{y}_{1}\right)}
\end{aligned}
$$

\section{Case II:}

The estimated burnoff range is totally enclosed in the range which may cause $50 \%$ strength loss. 


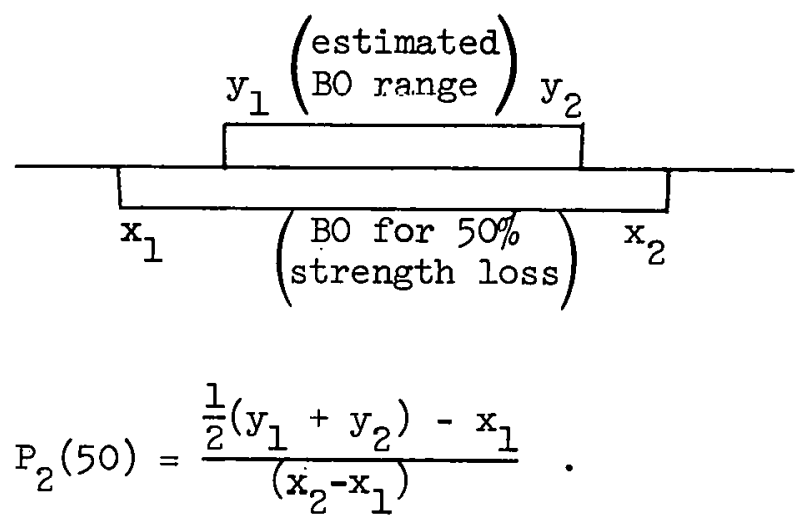

Case III:

The estimated burnoff range extends beyond the upper part of the range for $50 \%$ strength loss.

$$
\begin{gathered}
\frac{\mathrm{y}_{1}\left(\begin{array}{l}
\text { estimated } \\
\text { BO range }
\end{array}\right) \mathrm{y}_{2}}{\mathrm{x}_{1}\left(\begin{array}{c}
\text { B0 for 50\% } \\
\text { strength loss }
\end{array}\right) \mathrm{x}_{2}} \\
\mathrm{P}_{3}(50)=\frac{\left(\mathrm{x}_{2}-\mathrm{y}_{1}\right)\left[\frac{1}{2}\left(\mathrm{x}_{2}+\mathrm{y}_{1}\right)-\mathrm{x}_{1}\right]}{\left(\mathrm{x}_{2}-\mathrm{x}_{1}\right)\left(\mathrm{y}_{2}-\mathrm{y}_{1}\right)}+\frac{\mathrm{y}_{2}-\mathrm{x}_{2}}{\mathrm{y}_{2}-\mathrm{y}_{1}} .
\end{gathered}
$$

Case IV:

The estimated burnoff range straddles the range for $50 \%$ strength loss.

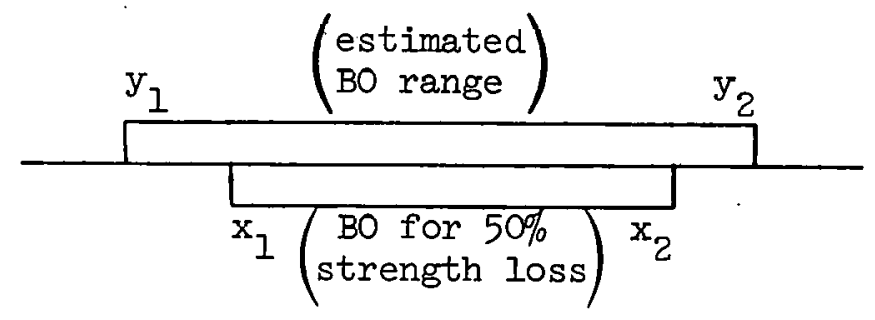

$$
P_{4}(50)=\frac{2 y_{2}-\left(x_{1}+x_{.2}\right)}{2\left(y_{2}-y_{1}\right)}
$$


THIS PAGE

\section{WAS INTENTIONALLY LEFT BLANK}


APPENDIX B: CORE POST STRENGTH LOSS VS STEAM INGRESS RATE AND PURIFICATION FLOW. SUPPIEMENTARY INFORMATION TO SECTION 6.4

Figures B.I-B. 4 depict the estimated range of core post strength loss for assumed steam ingress rates of from 0.001 to $1.0 \mathrm{~g} / \mathrm{sec}$. These estimates all pertain to the case of nominal purification flow.

The information shown in the figures was generated as follows:

(1) The impurity level and composition for an assumed ingress rate was determined from methods described in sect. 5 . Figure B.I is based on an atmosphere determined from Dragon inleakage data by methods described in Sect. 5.2. Figures B.2-B.4 are based on impurity compositions predicted by using TIMOX, described in sect. 5.3, and assuming the Wicke, OXIDE-3, and Giberson rate equations for the core reactivity, respectively.

(2) The burnoff was estimated by using Eq. (10) of sect. 4.1 for ATJ graphite.

(3) The fractional strength reduction was determined using Eq. (3) of sect. 6.4, with penetration factors for the two temperature levels given by Table 6.2. The depicted range of uncertainty is caused by the uncertainty in the value of the penetration factor.

Figures B.5 and B.6 show the predicted variation of sore post strength loss with changing purification flow for an assumed ingress rate of 0.01 $\mathrm{g} / \mathrm{sec}$. The calculational procedures correspond closely with those previously described for Figs. B.I-B.4.

The bottom of Fig. B.5 shows the case where the core reactivity was determined from the Dragon steam ingress experiment. The top of Fig. B.5 and the two cases shown in Fig. B.6 refer to estimates made using TIMOX to predict the composition of the impurities in the primary system.

As discussed in Sect. 6.4.2, the variation of strength loss with purification flow tends to be flatter than anticipated, because the 


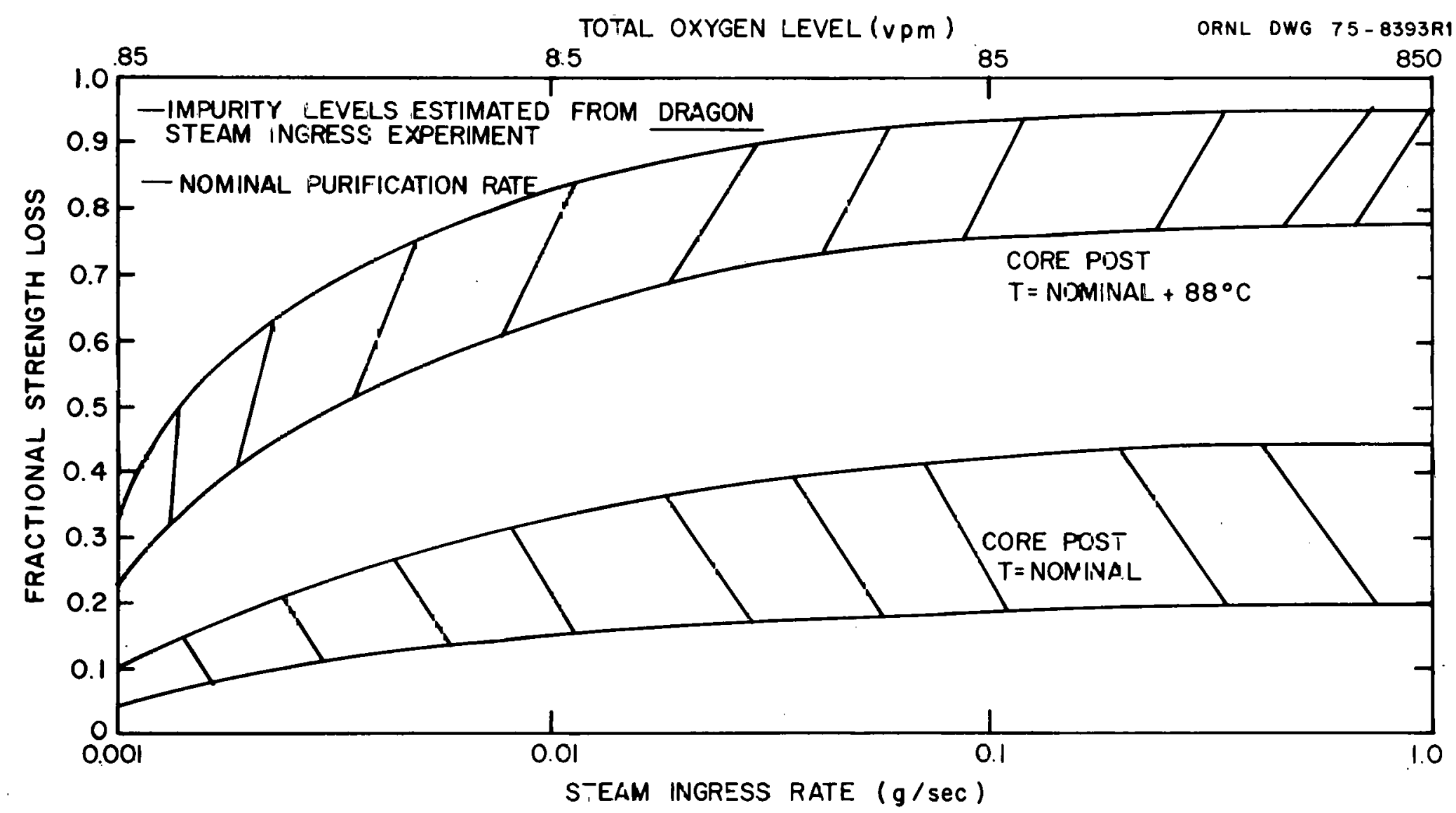

Fig. B.1. Forty-year core post strength loss vs sieam ingress rate. 


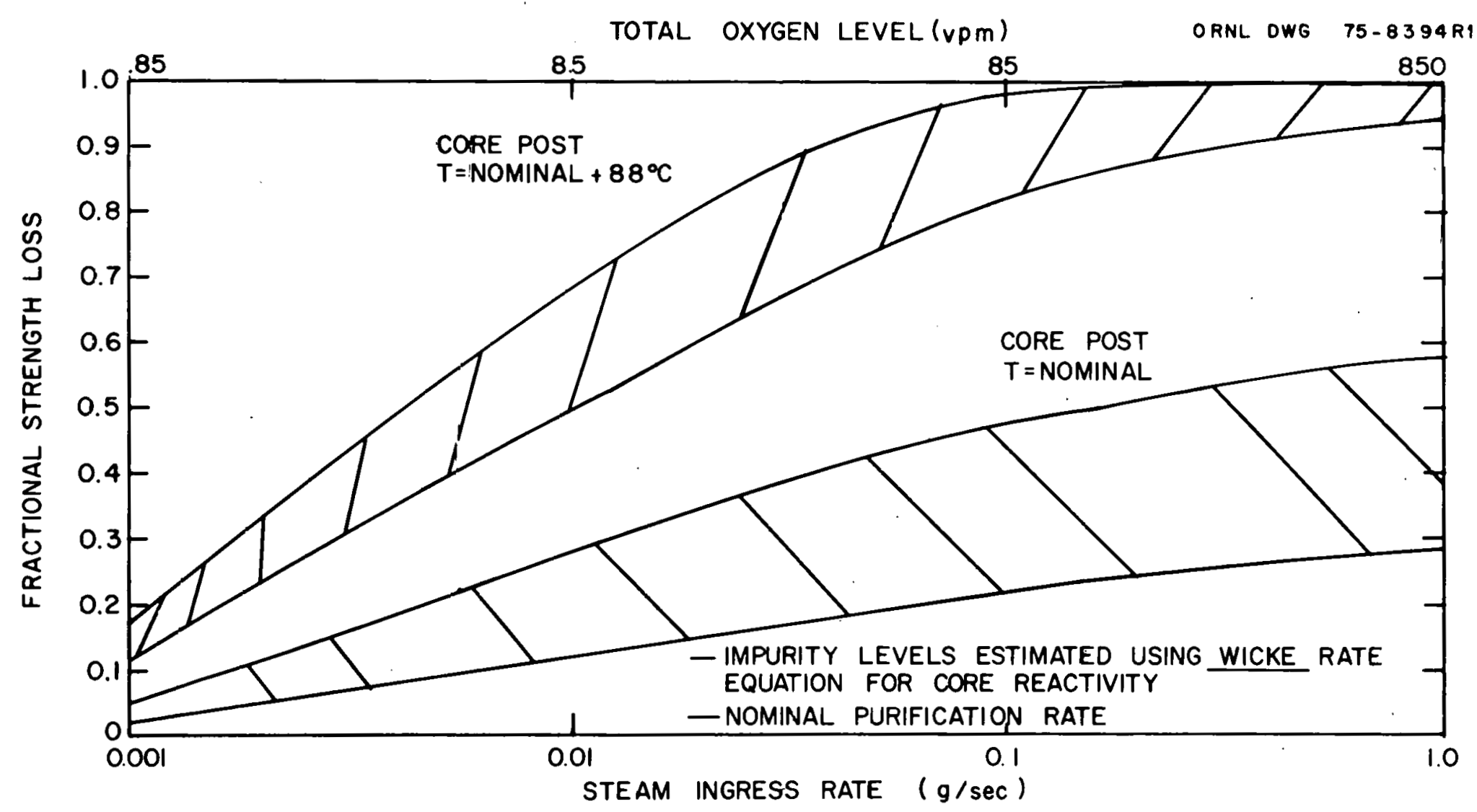

Fig. B.2. Forty-year core post strength Ioss vs steam ingress rate. 
TOTAL OXYGEN LEVEL, upm

ORNL DWG 75-8395

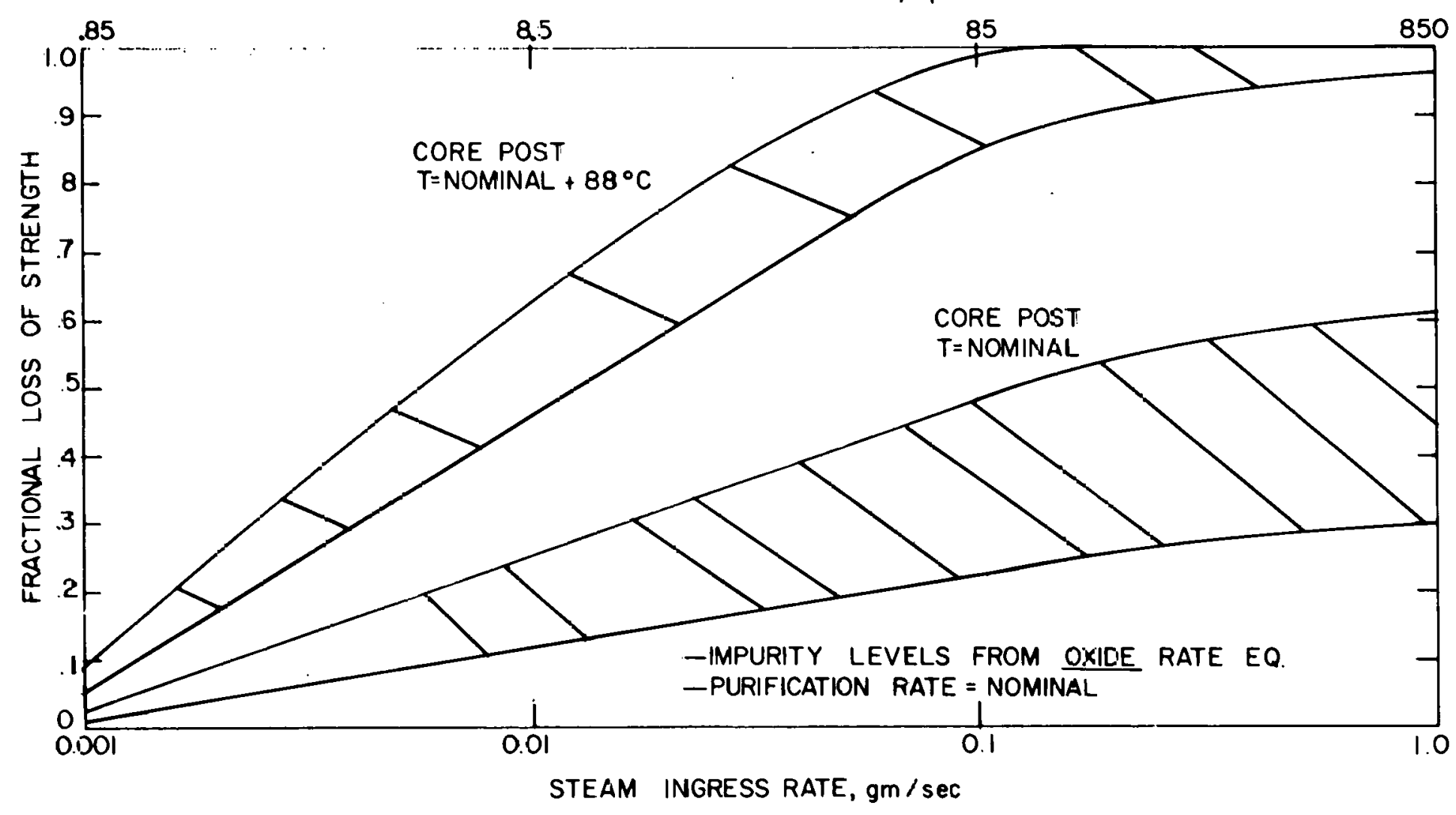

Fig. B.3. Forty-year ccre post strength loss vs steam ingress rate. 


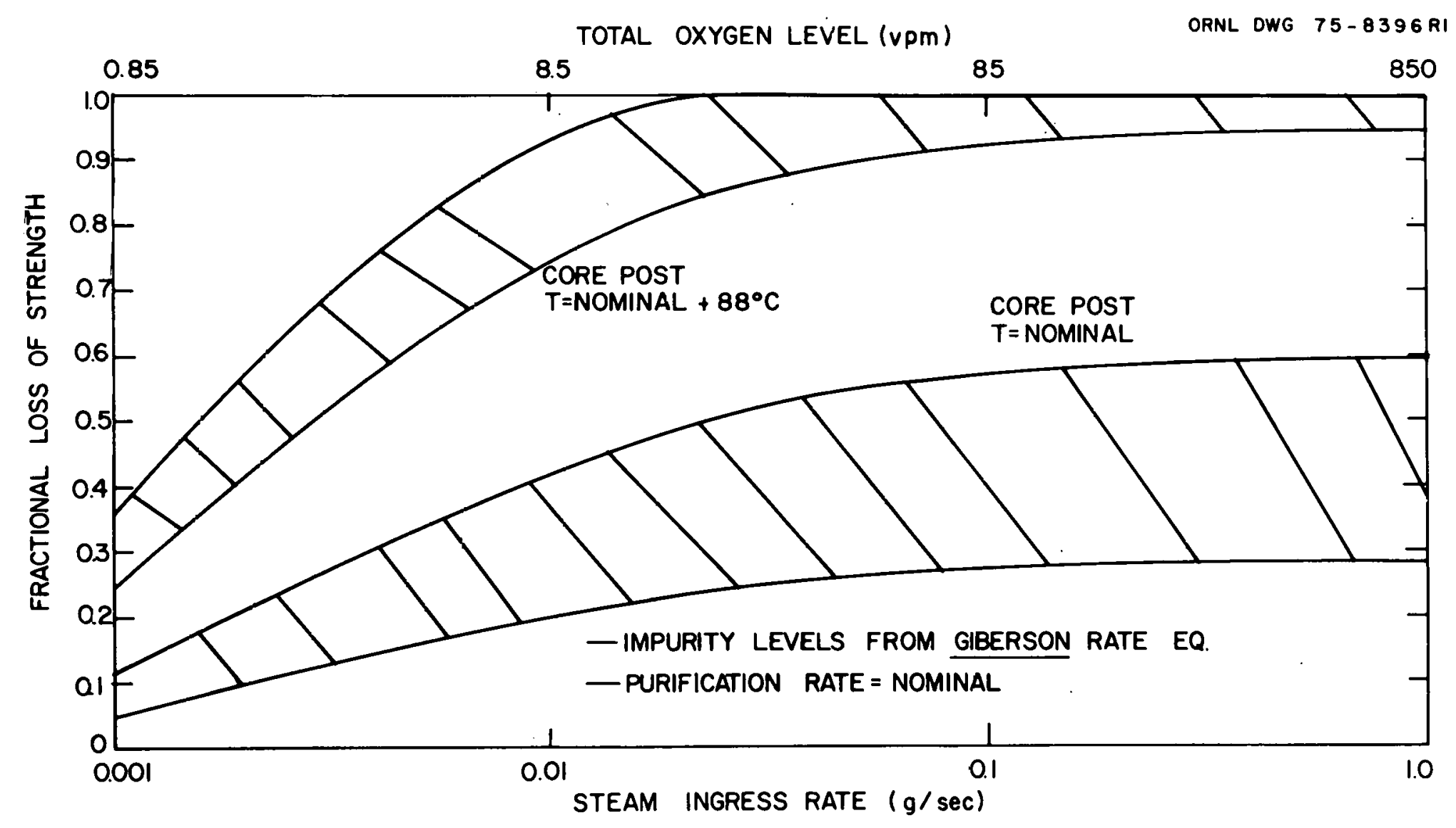

Fig. B.4. Forty-year core post strength loss vs steam ingress rate. 
ORNL-DWG 75-8402

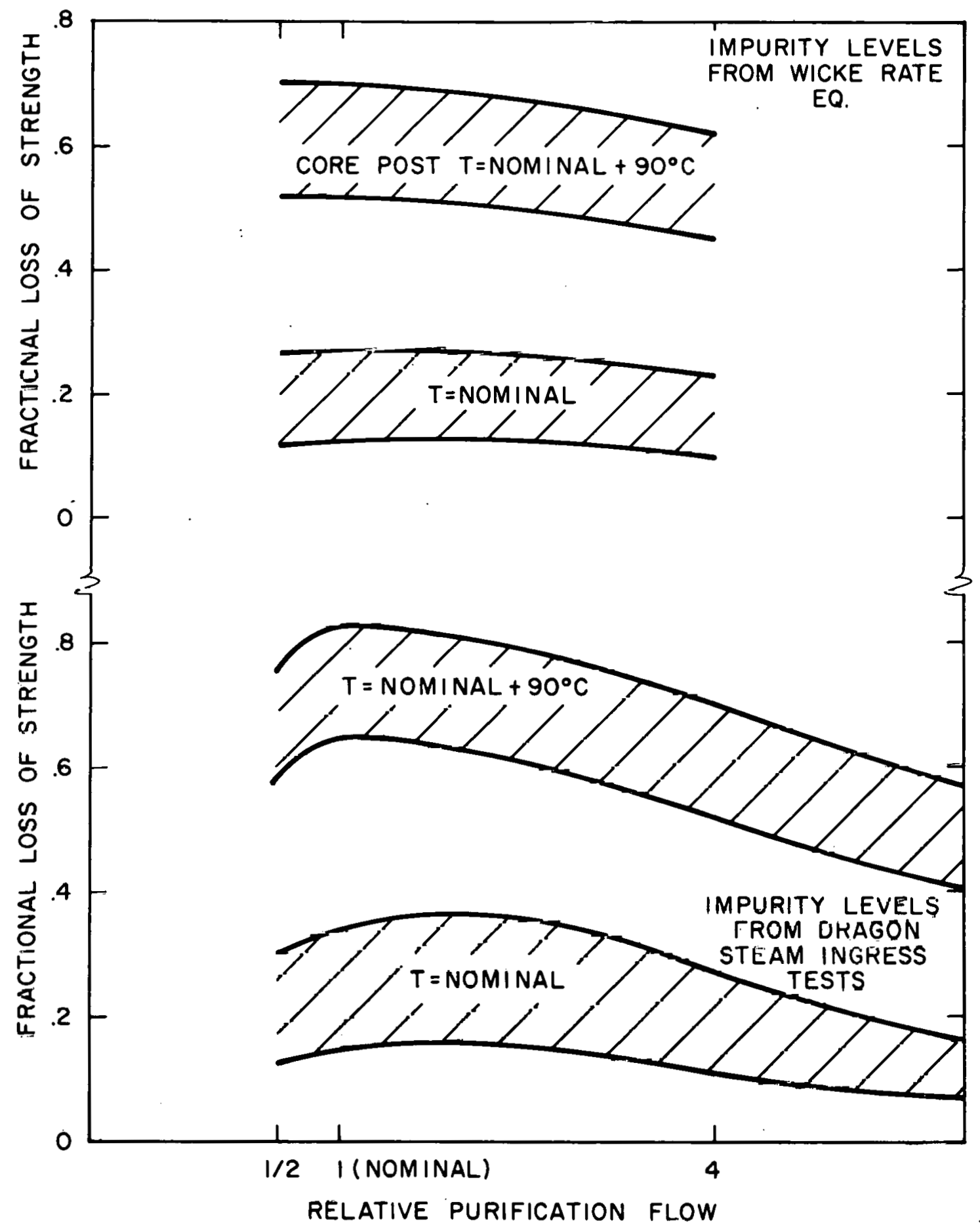

Fig. B.5. Loss of core post strength vs purification flow rate. Assumed ingress rate $=0.01 \mathrm{~g} / \mathrm{sec}$. 
ORNL-DWG 75-8403R1

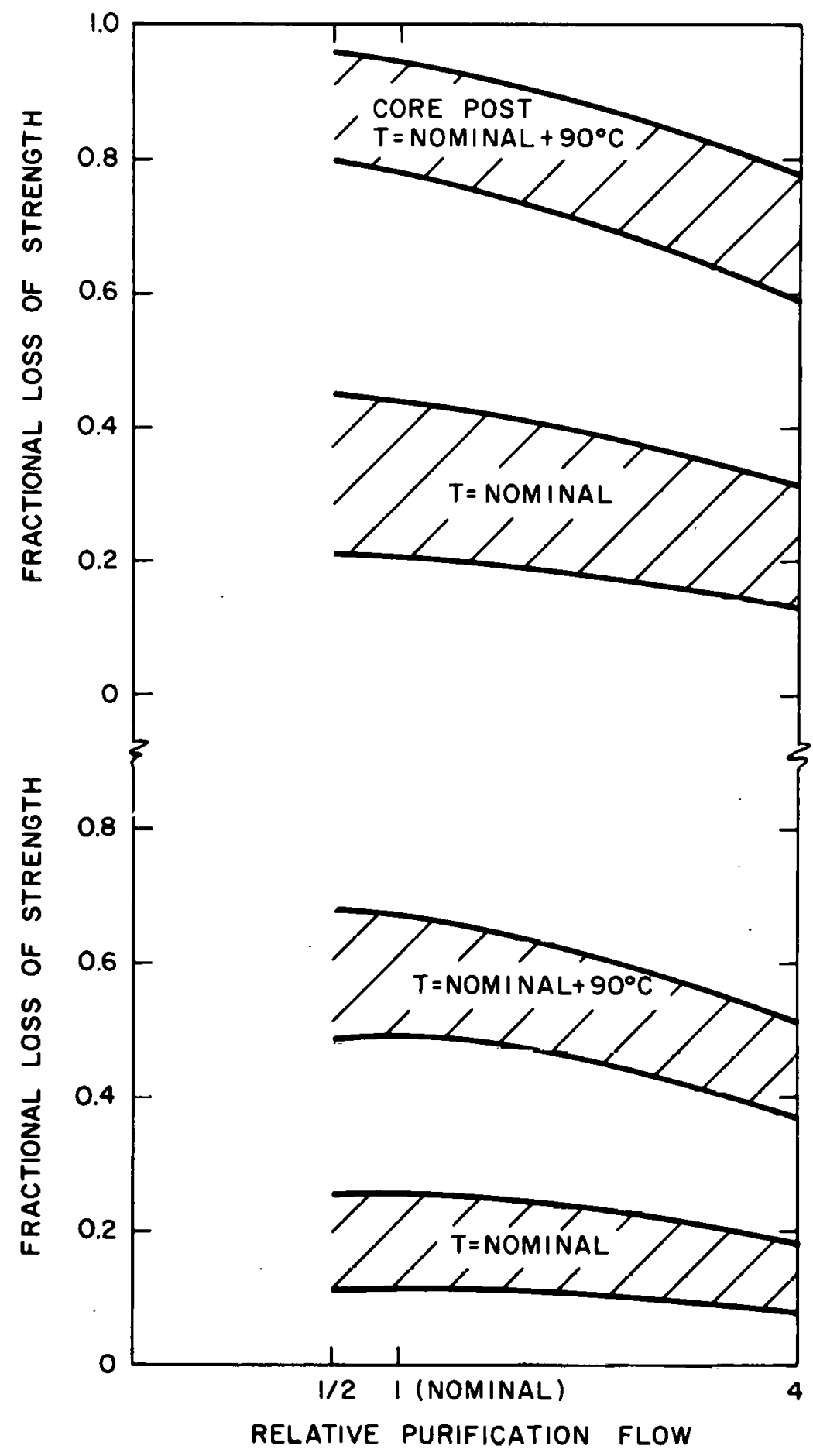

IMPURITY LEVELS

FROM GIBERSON

RATE EQUATION

IMPURITY LEVELS

FROM OXIDE - 3

RATE EQUATION

Fig. B.6. Loss of core post strength vs purification flow. Assumed irigress rate $=0.01 \mathrm{~g} / \mathrm{cec}$. 
purification flow removes materials which inhibit the corrosion reaction as well as augment it. Not until purification rates of about six times the nominal are reached is significant improvement of the behavior at the higher core post temperature achieved.

The above conclusion is reached in sect. 6.4 .2 by superimposing results from the four methods of calculating the impurity compositions. Since the reference core graphite, H-45I, could behave differently from the composite of these four cases, the calculations should be repeated when the reaction rate equation for $\mathrm{H}-45 \mathrm{l}$ becomes available. 
NOMENCLATURE

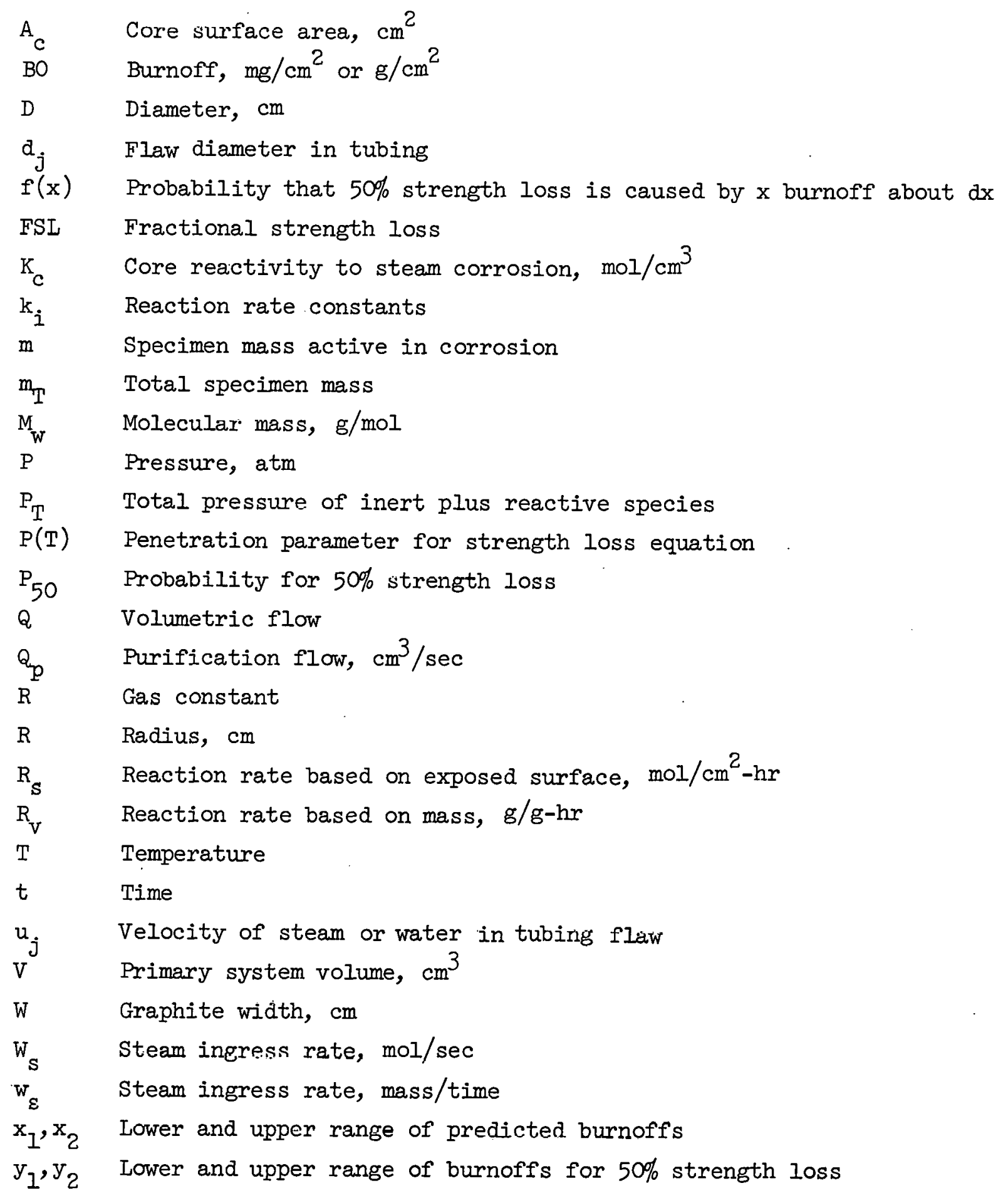




\begin{tabular}{|c|c|}
\hline$\Delta \mathrm{H}$ & Activation energy, cal/mol \\
\hline$\Delta \mathrm{h}$ & $\begin{array}{l}\text { Active corrosion depth, } \mathrm{cm} \\
\text { Density, } \mathrm{g} / \mathrm{cm}^{3}\end{array}$ \\
\hline$\mu$ & Partial pressure, $\mu a t m$ \\
\hline$\delta t$ & Time interval, sec \\
\hline ] & Concentration, $\mathrm{mol} / \mathrm{cm}^{3}$ \\
\hline
\end{tabular}


ORNL/TM-5534

Dist. Category UC-77

INTERNAL DISTRIBUTION

1. J. L. Anderson

2. S. J. Ball

3. D. E. Bartine

4. C. D. Baumann

5. R. L. Beatty

6. J. P. Callahan

7. D. A. Canonico

8. C. E. Clifford

9. J. A. Conlin

10. J. H. Coobs

11. D. A. Costanzo

12. F. C. Davis

13. J. R. Distefano

14. B. C. Duggins

15. W. P. Eatherly

16. D. E. Ferguson

17. Uri Gat

18. A. G. Grindell

19. W. S. Groenier

20. P. A. Hass

2l. W. R. Hamel

22. F. E. Harrington

23. C. C. Haws

24. L. C. Hensley

25. R. M. Hill, Jr.

26. F. J. Homan

27. J. R. Horton

28. Vivian Jacobs

29. J. D. Jenkins

30. D. R. Johnson

31-33. P. R. Kasten

34. W. J. Lackey

35. K. H. Lin

36. T. B. Lindemer
37. E. L. Long, Jr.

38. A. L. Lotts

39. R. E. MacPherson

40. A. P. Malinauskas

41. W. R. Martin

42. K. J. Notz

43. L. C. Oakes

44. A. R. Olsen

45. W. H. Pechin

46. H. Postma

47. R. H. Rainey

48. D. P. Reid

49. A. D. Ryon

50. J. P. Sanders

51. Dunlap Scott

52. J. D. Sease

53. J. H. Shaffer

54. R. L. Shepard

55. J. W. Snider

56. P. R. Stein

57. R. S. Stone

58. M. L. Tobias

59. J. E. Van Cleve

60. V. C. A. Vaughen

61-70. R. P. Wichner

71. R. G. Wymer

72-73. Central Research Library

74. Document Reference Section

75. Laboratory Records, ORNL-RC

76-85. Laboratory Records

36. Ken Davie (consultant)

87. E. L. Gaden, Jr. (consultant)

88. C. H. Ice (consultant)

89. R. B. Richards (consultant)

\section{EXTERNAL DISTRIBUTION}

90. Research and Technical Support Division, ERDA-ORO, P. O. BOX E, Oak Rj.dge, Tn. 3,830

91. Director, Reactor Division, ERDA-ORO, P. O. BOX E, Oak Ridge, Tn. 37830

92-93. Director, Division of Nuclear Fuel Cycle and Production, ERDA, Washington, D.C. 20545

94-95. Director, Division of Reactor Research and Development, ERDA, Washington, D.C. 20545

96-266. Given distribution as shown in TID-4500 under category UC-77Gas-Cooled Reactor Technology 